\title{
USING CHEMICALS TO OPTIMIZE CONFORMANCE CONTROL IN FRACTURED RESERVOIRS
}

\author{
Final Report \\ October 1, 1998-September 30, 2001 \\ By: \\ Randall S. Seright \\ Jenn-Tai Liang \\ Richard Schrader \\ John Hagstrom II \\ Ying Wang \\ Anand Kumar \\ Kathryn Wavrik \\ Date Published: October 2001
}

Work Performed Under Contract No. DE-AC26-98BC15110

New Mexico Petroleum Recovery Research Center

New Mexico Institute of Mining and Technology

Socorro, New Mexico

\section{National Energy Technology Laboratory National Petroleum Technology Office U.S. DEPARTMENT OF ENERGY Tulsa, Oklahoma}




\section{DISCLAIMER}

This report was prepared as an account of work sponsored by an agency of the United States Government. Neither the United States Government nor any agency thereof, nor any of their employees, makes any warranty, expressed or implied, or assumes any legal liability or responsibility for the accuracy, completeness, or usefulness of any information, apparatus, product, or process disclosed, or represents that its use would not infringe privately owned rights. Reference herein to any specific commercial product, process, or service by trade name, trademark, manufacturer, or otherwise does not necessarily constitute or imply its endorsement, recommendation, or favoring by the United States Government or any agency thereof. The views and opinions of authors expressed herein do not necessarily state or reflect those of the United States Government.

This report has been reproduced directly from the best available copy. 
$\mathrm{DOE} / \mathrm{BC} / 15110-7$

Distribution Category UC-122

Using Chemicals to Optimize Conformance Control in Fractured Reservoirs

\author{
By \\ Randall S. Seright \\ Jenn-Tai Liang \\ Richard Schrader \\ John Hagstrom II \\ Ying Wang \\ Anand Kumar \\ Kathryn Wavrik
}

October 2001

Work Performed Under DE-AC26-98BC15110

Prepared for

U.S. Department of Energy

Assistant Secretary for Fossil Energy

Tom Reid, Project Manager

National Petroleum Technology Office

P.O. Box 3628

Tulsa, OK 74101

Prepared by

New Mexico Petroleum Recovery Research Center

New Mexico Institute of Mining and Technology

801 Leroy Place

Socorro, NM 87801-4796 


\section{TABLE OF CONTENTS}

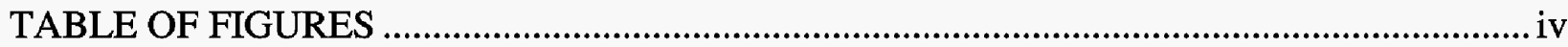

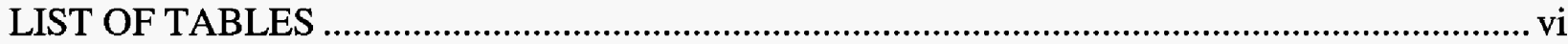

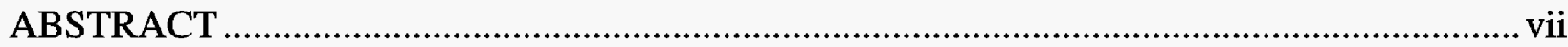

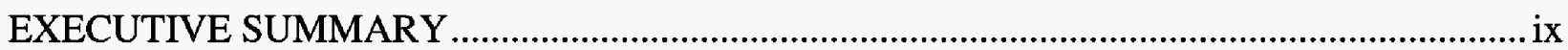

Disproportionate Permeability Reduction ................................................................................ ix

Gel Properties in Fractures ........................................................................................................ ix

Gelant Treatments in Hydraulically Fractured Production Wells ................................................. $\mathrm{x}$

Future Work and Technology Transfer ....................................................................................

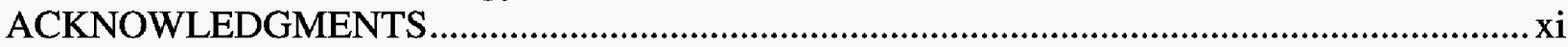

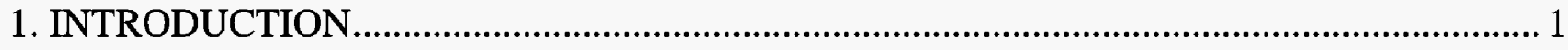

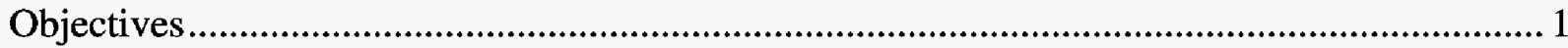

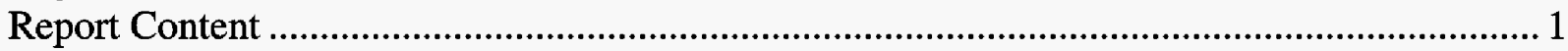

2. DISPROPORTIONATE PERMEABILITY REDUCTION ……............................................. 3

Experimental Materials ........................................................................................................... 4

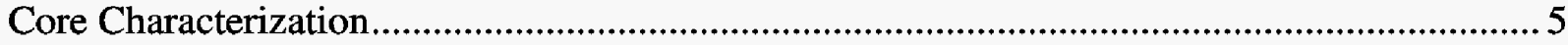

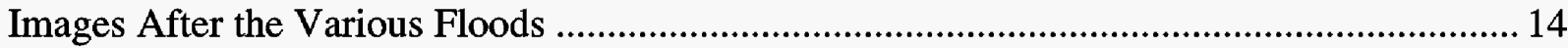

Berea Sandstone Image Analyses ..................................................................................... 17

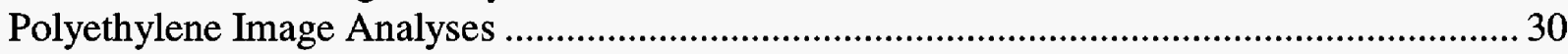

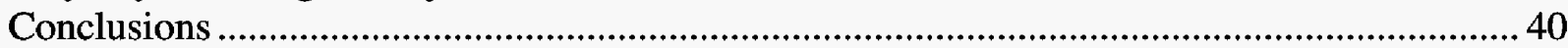

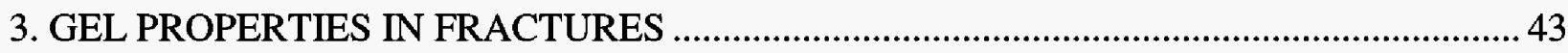

Previous Experimental Work ............................................................................................ 43

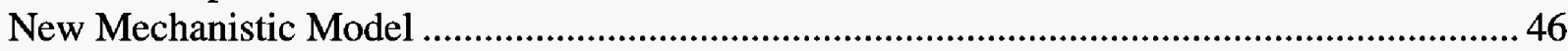

Effect of Temperature …………………................................................................................ 48

Effect of Gel Composition ............................................................................................ 52

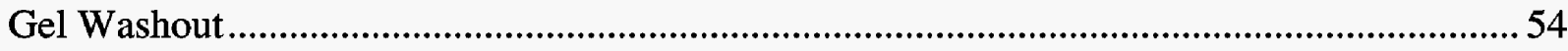

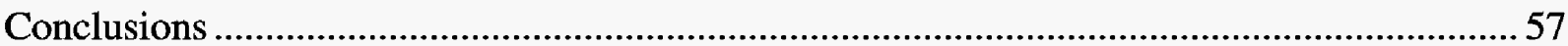

4. GELANT TREATMENTS IN FRACTURED PRODUCTION WELLS ...............................59

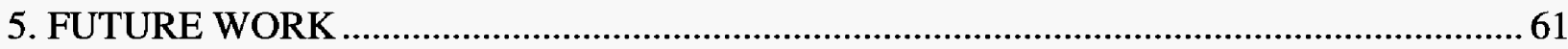

Disproportionate Permeability Reduction .......................................................................................... 61

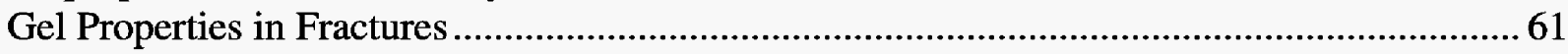

NOMENCLATURE

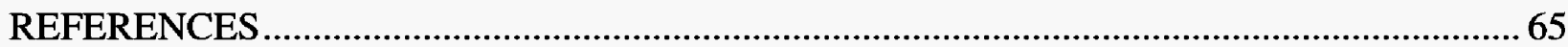

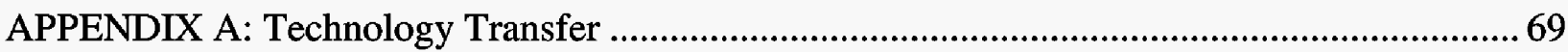

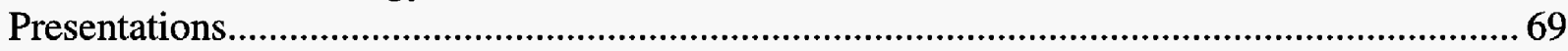

Internet Postings on the Project and Software to Download........................................................... 71

Papers and Publications............................................................................................................ 71 


\section{TABLE OF FIGURES}

Fig. 1-XMT image cross-section of Berea. $1.15 \mathrm{~mm}$ x $1.15 \mathrm{~mm}$............................................. 7

Fig. 2-XMT image cross-section of polyethylene. $1.15 \mathrm{~mm} \times 1.15 \mathrm{~mm}$.................................... 7

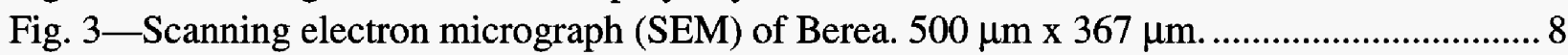

Fig. 4-SEM of polyethylene. $500 \mu \mathrm{m}$ x $367 \mu \mathrm{m}$. ...................................................................... 8

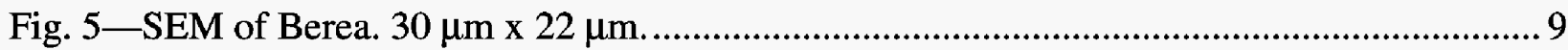

Fig. 6-SEM of an unsaturated polyethylene core. $30 \mu \mathrm{m}$ x $22 \mu \mathrm{m}$. .......................................... 9

Fig. 7-SEM of a polyethylene core after exposure to hexadecane. $30 \mu \mathrm{m} \times 22 \mu \mathrm{m}$. ................... 10

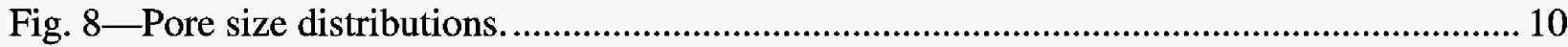

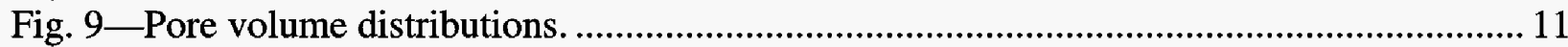

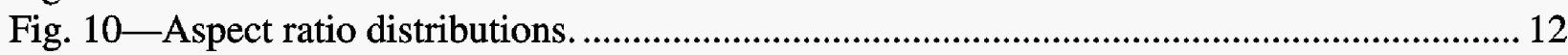

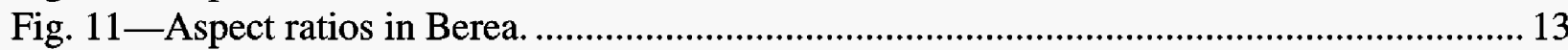

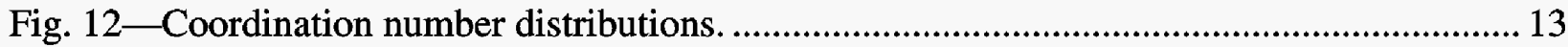

Fig. 25-Water saturations at $S_{w r}$ and $S_{o r}$ before gel placement in Berea sandstone cores. .......... 18

Fig. 26-Water saturation distributions at $S_{w r}$ before gel. $1^{\text {st }}$ Berea core. ................................... 19

Fig. 27-Water saturation distributions at $S_{o r}$ before gel. $1^{\text {st }}$ Berea core..................................... 19

Fig. 28-Water saturation distributions at $1^{\text {st }} S_{w r}$ before gel. $2^{\text {nd }}$ Berea core............................... 20

Fig. 29-Water saturation distributions at $S_{o r}$ before gel. $2^{\text {nd }}$ Berea core................................. 20

Fig. 30-Water saturation distributions at $2^{\text {nd }} S_{w r}$ before gel. $2^{\text {nd }}$ Berea core................................2 20

Fig. $31-S_{w}$ changes from $S_{w r}$ to $S_{o r}$ for individual pores in the first Berea core.........................22

Fig. 32- $S_{w}$ changes from $1^{\text {st }} S_{w r}$ to $S_{o r}$ for individual pores in the $2^{\text {nd }}$ Berea core........................23

Fig. 33- $S_{w}$ changes from $S_{o r}$ to $2^{\text {nd }} S_{w r}$ for individual pores in the $2^{\text {nd }}$ Berea core......................23

Fig. 34- $S_{w}$ changes from $1^{\text {st }} S_{w r}$ to $2^{\text {nd }} S_{w r}$ for individual pores in the $2^{\text {nd }}$ Berea core. ...............2 24

Fig. 35-Water saturations at $S_{\text {or }}$ immediately before versus immediately after gel placement. . 25

Fig. $36-S_{w}$ changes during gelant injection for individual pores in the $1^{\text {st }}$ Berea core. ...............25

Fig. 37-Effect of gel on $S_{w r}$ and $S_{o r}$ in Berea sandstone. ........................................................ 26

Fig. $38-S_{w}$ changes for individual pores in Berea during oil injection after gelation.................. 28

Fig. $39-S_{w}$ changes for individual pores in Berea during water injection after gelation. ........... 28

Fig. $40-S_{w}$ differences for individual pores in Berea at $S_{w r}$ before versus after gel placement. . 29

Fig. $41-S_{w}$ differences for individual pores in Berea at $S_{o r}$ before versus after gel placement... 29

Fig. 42-Water saturations at $S_{w r}$ and $S_{\text {or }}$ before gel placement in the polyethylene core..............30

Fig. 43-Water saturation distributions at first $S_{\text {or }}$ before gel. Polyethylene core. ....................... 32

Fig. 44-Water saturation distributions at $S_{w r}$ before gel. Polyethylene core. ……………............32

Fig. 45-Water saturation distributions at second $S_{o r}$ before gel. Polyethylene core.................... 33

Fig. $46-S_{w}$ changes from the $1^{\text {st }} S_{o r}$ to $S_{w r}$ for individual pores in the polyethylene core.............33

Fig. 47- $S_{w}$ changes from $S_{w r}$ to the $2^{\text {nd }} S_{o r}$ for individual pores in the polyethylene core...........34

Fig. 48- $S_{w}$ changes from the $1^{\text {st }} S_{o r}$ to the $2^{\text {nd }} S_{o r}$ for individual pores in the polyethylene core. 34

Fig. $49-S_{w}$ changes during gelant injection for individual pores in the polyethylene core.......... 35

Fig. 50-Effect of gel on $S_{w r}$ and $S_{o r}$ in polyethylene.............................................................. 36

Fig. $51-S_{w}$ changes for individual pores in polyethylene during oil injection after gelation....... 38

Fig. $52-S_{w}$ changes for individual pores in polyethylene during water injection after gelation. 38

Fig. 53- $S_{w}$ differences in polyethylene pores at $S_{w r}$ before versus after gel placement................ 39

Fig. 54- $S_{w}$ differences in polyethylene pores at $S_{o r}$ before versus after gel placement. .............. 40

Fig. 55-Pressure gradients required for gel extrusion through open fractures. .............................44

Fig. 56-Degree of gel dehydration versus fracture width (from Ref. 41)....................................45 


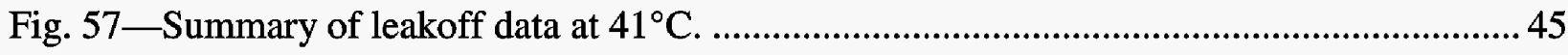

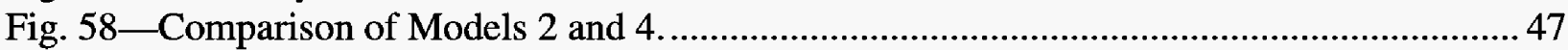

Fig. 59-Effect of temperature on leakoff when long heat exchanger was used......................... 49

Fig. 60-Leakoff in 4-ft-long fractures without using the long heat exchanger.........................50

Fig. 61-Leakoff in 6-inch-long fractures without using the long heat exchanger. .................... 50

Fig. 62-Leakoff in 4-ft-long fractures: $4^{\text {th }}$ set versus $2^{\text {nd }}$ set...............................................52

Fig. 63-Effect of gel composition during extrusion. .....................................................5 53

Fig. 64-Pressure gradient and elastic modulus versus HPAM concentration........................... 54

Fig. $65-$ Gel washout during brine injection after gel placement. ...................................... 55

Fig. 66-Effect of $0.1 \%-0.2 \%$ fiberglass on gel washout......................................................5 56 


\section{LIST OF TABLES}

Table 1-Proposed Mechanisms for Disproportionate Permeability Reduction ........................ 3

Table 2-Fluid Saturations .......................................................................................... 14

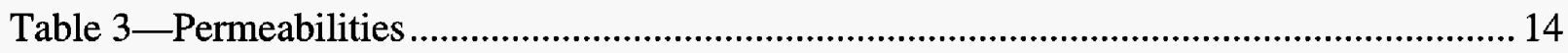

Table 4-Properties for Various Pore Size Ranges for the $1^{\text {st }}$ Berea Core ................................ 21

Table 5-Properties for Various Pore Size Ranges for the $2^{\text {nd }}$ Berea Core ..............................21

Table 6-Properties for Various Pore Size Ranges for the Polyethylene Core ....................... 31 


\section{ABSTRACT}

This report describes work performed during the third and final year of the project, "Using Chemicals to Optimize Conformance Control in Fractured Reservoirs." This research project had three objectives. The first objective was to develop a capability to predict and optimize the ability of gels to reduce permeability to water more than that to oil or gas. The second objective was to develop procedures for optimizing blocking agent placement in wells where hydraulic fractures cause channeling problems. The third objective was to develop procedures to optimize blocking agent placement in naturally fractured reservoirs.

X-ray computed microtomography was used to investigate why gels reduce permeability to water more than that to oil in strongly water-wet Berea sandstone and in an oil-wet porous polyethylene core. Although the two porous media had very different porosities (22\% versus $40 \%$ ), the distributions of pore sizes and aspect ratios were similar. A Cr(III)-acetate-HPAM gel caused comparable oil and water permeability reductions in both porous media. In both cores, the gel reduced permeability to water by a factor 80 to 90 times more than that to oil. However, the distributions of water and oil saturations (versus pore size) were substantially different before, during, and after gel placement.

The disproportionate permeability reduction appeared to occur by different mechanisms in the two porous media. In Berea, gel caused disproportionate permeability reduction by trapping substantial volumes of oil that remained immobile during water flooding. With this high trapped oil saturation, water was forced to flow through narrow films, through the smallest pores, and through the gel itself. In contrast, during oil flooding, oil pathways remained relatively free from constriction by the gel. In the polyethylene core, oil trapping did not contribute significantly to the disproportionate permeability reduction. Instead, oil films and a relatively small number of pore pathways provided conduits for the oil. For reasons yet to be understood, the small pore pathways appeared largely unavailable for water flow.

A new model was developed that accounts for the most important elements of gel propagation and dehydration in fractures. Predictions from this model matched experimental data quite well. This model was derived strictly from mechanistic considerations, whereas our previous models were based on an empirical two-parameter fit. We extended our studies of gel extrusion through fractures to different temperatures. For a $\mathrm{Cr}(\mathrm{III})$-acetate-HPAM gel, pressure gradients and gel dehydration during extrusion were similar at $20^{\circ} \mathrm{C}, 40^{\circ} \mathrm{C}, 60^{\circ} \mathrm{C}$, and $80^{\circ} \mathrm{C}$. We also extended our studies of gel extrusion to include different gel compositions. Similar gel dehydration behavior was observed over a three-fold range of concentration for $\mathrm{Cr}$ (III)-acetate-HPAM gels. During extrusion, measurements of pressure gradient versus HPAM concentration paralleled those of elastic modulus versus HPAM concentration. We began an investigation of why gels mechanically fail in fractures during water flow after gel placement. With an understanding of the mechanism for gel extrusion and dehydration in fractures, we ultimately hope to predict conditions, compositions, and volumes that provide the optimum gel placement in fractured reservoirs.

Finally, we incorporated several improvements into our software for designing gelant treatments to reduce water production from hydraulically fractured production wells. 


\section{EXECUTIVE SUMMARY}

This report describes work performed during the third and final year of the project, "Using Chemicals to Optimize Conformance Control In Fractured Reservoirs." This research project had three objectives. The first objective was to develop a capability to predict and optimize the ability of gels to reduce permeability to water more than that to oil or gas. The second objective was to develop procedures for optimizing blocking agent placement in wells where hydraulic fractures cause channeling problems. The third objective was to develop procedures to optimize blocking agent placement in naturally fractured reservoirs. This research project consisted of three tasks, each of which addressed one of the above objectives. Our work was directed at both injection wells and production wells and at vertical, horizontal, and highly deviated wells.

\section{Disproportionate Permeability Reduction}

Many polymers and gels can reduce the permeability to water more than that to oil or gas. This property is critical to the success of water-shutoff treatments in production wells if hydrocarbonproductive zones cannot be protected during polymer or gelant placement. However, the magnitude of the effect has been unpredictable from one application to the next. Presumably, the effect would be more predictable and controllable if we understood why the phenomenon occurs. This topic is the focus of Chapter 2 of this report.

$\mathrm{X}$-ray computed microtomography was used to investigate why gels reduce permeability to water more than that to oil in strongly water-wet Berea sandstone and in an oil-wet porous polyethylene core. Although the two porous media had very different porosities (22\% versus $40 \%$ ), the distributions of pore sizes and aspect ratios were similar. A Cr(III)-acetate-HPAM gel caused comparable oil and water permeability reductions in both porous media. In both cores, the gel reduced permeability to water by a factor 80 to 90 times more than that to oil. However, the distributions of water and oil saturations (versus pore size) were substantially different before, during, and after gel placement.

The disproportionate permeability reduction appeared to occur by different mechanisms in the two porous media. In Berea, gel caused disproportionate permeability reduction by trapping substantial volumes of oil that remained immobile during water flooding. With this high trapped oil saturation, water was forced to flow through narrow films, through the smallest pores, and through the gel itself. In contrast, during oil flooding, oil pathways remained relatively free from constriction by the gel.

In the polyethylene core, oil trapping did not contribute significantly to the disproportionate permeability reduction. Instead, oil films and a relatively small number of pore pathways provided conduits for the oil. For reasons yet to be understood, the small pore pathways appeared largely unavailable for water flow.

\section{Gel Properties in Fractures}

Many conformance control treatments rely on the ability of gels to extrude through fractures during the placement process. Chapter 3 describes an experimental investigation of the 
mechanism for propagation of a $\mathrm{Cr}(\mathrm{III})$-acetate-HPAM gel through fractures. A new model (Model 4) was developed that accounts for the most important elements of gel propagation and dehydration in fractures. Predictions from this model matched experimental data quite well. This model was derived strictly from mechanistic considerations, whereas our previous models were based on an empirical two-parameter fit.

We extended our studies of gel extrusion through fractures to different temperatures. For a $\mathrm{Cr}$ (III)-acetate-HPAM gel, pressure gradients and gel dehydration during extrusion were similar at $20^{\circ} \mathrm{C}, 40^{\circ} \mathrm{C}, 60^{\circ} \mathrm{C}$, and $80^{\circ} \mathrm{C}$. We also extended our studies of gel extrusion to include different gel compositions. Similar gel dehydration behavior was observed over a three-fold range of concentration for $\mathrm{Cr}$ (III)-acetate-HPAM gels. During extrusion, measurements of pressure gradient versus HPAM concentration paralleled those of elastic modulus versus HPAM concentration.

We began an investigation of why gels mechanically fail in fractures during water flow after gel placement. Our first studies indicate that in a 0.04-in.-wide fracture, gel mobilization during brine injection occurs at pressure gradients similar to those during gel injection. In wider fractures (0.08- and 0.16-in.), our standard $1 \mathrm{X} \mathrm{Cr}(\mathrm{III})$-acetate-HPAM gel experienced mobilization at lower than expected pressure gradients. We are exploring how incorporation of particulate matter into the gel affects washout. Preliminary studies were performed in beakers using gels that incorporated one of six particulates, including fine mica, fine nut plug, diatomaceous earth, celloflakes, shredded ski rope, and fiberglass insulation. The shredded ski rope and fiberglass insulation formed fairly homogeneous suspensions in the $1 \mathrm{X} \mathrm{Cr}$ (III)-acetateHPAM gelant and gel. The other materials experienced severe gravity segregation. During gel extrusion through fractures, incorporation of $0.1 \%-0.2 \%$ fiberglass insulation into the $1 \mathrm{X} \mathrm{Cr}(\mathrm{III})$ acetate-HPAM gel reduced gel washout during subsequent brine injection. However, improved formulations are needed to prevent washout for fractures that are wider than 0.08 inches.

\section{Gelant Treatments in Hydraulically Fractured Production Wells}

Often, when hydraulic fracturing stimulates production wells, the fracture unintentionally extends through shale or calcite barriers into water zones, causing substantially increased water production. Previously, we developed software (Gel Design) for sizing gelant treatments in hydraulically fractured production wells. As described in Chapter 4, we updated this software to Version 2.0 to incorporate several improvements. First, the units on input parameters may now be either SI or English (oilfield). Second, the program can now handle low water-cut cases much better. Finally, in addition to oil wells, the program can now handle gas wells with water production problems. The software can be downloaded from our web site at http://baervan.nmt.edu/randy.

\section{Future Work and Technology Transfer}

Future work that will be addressed in a new research project (supported by DOE Contract DEFC-01BC15316) is described in Chapter 5. Technology transfer efforts for the current project are listed in Appendix A. 


\section{ACKNOWLEDGMENTS}

Financial support for this work is gratefully acknowledged from the United States Department of Energy (National Petroleum Technology Office), BP-Amoco, Chevron, Chinese Petroleum Corporation, Chinese National Petroleum Corporation, Marathon, Shell, and Texaco. I greatly appreciate the efforts of those individuals who contributed to this project. Dr. Jenn-Tai Liang and John Hagstom played major roles in conducting the work described in Chapter 2. Image analyses for Chapter 2 were performed by Dr. Brent Lindquist (Department of Applied Mathematics and Statistics of State University of New York at Stony Brook). I also thank Dr. John Dunsmuir of ExxonMobil Research and Engineering Company for his aid during the X-ray microtomography studies and for allowing us to use the X2-B X-ray beamline. The research in Chapter 2 was carried out (in part) at the National Synchrotron Light Source, Brookhaven National Laboratory, which is supported by the U.S. Department of Energy, Division of Materials Sciences and Division of Chemical Sciences. Also regarding Chapter 2, I thank Dr. Jill S. Buckley (New Mexico PRRC) for helpful discussions and suggestions and Nelia Dunbar (New Mexico BMMR) for obtaining the electron micrographs. Richard Schrader performed most of the experimental work described in Chapter 3, with help from Ying (Annie) Wang and Kathryn Wavrik. Dr. JennTai Liang wrote the software described in Chapter 4. I especially appreciate the thorough review of this manuscript by Julie Ruff. 


\section{INTRODUCTION}

In the United States, more than 18 billion barrels of water are produced each year during oilfield operations. ${ }^{1}$ Today, the cost of water disposal is typically between $\$ 0.25$ and $\$ 0.50$ per bbl for pipeline transport and $\$ 1.50$ per bbl for trucked water. Therefore, a tremendous economic incentive exists to reduce water production if that can be accomplished without significantly sacrificing hydrocarbon production. For each $1 \%$ reduction in water production, the cost savings to the oil industry could be between $\$ 50,000,000$ and $\$ 100,000,000$ per year. Reduced water production would result directly in improved oil recovery (IOR) efficiency in addition to reduced oil production costs. A substantial positive environmental impact could also be realized if significant reductions are achieved in the amount of water produced during oilfield operations.

In an earlier project, we identified fractures (either naturally or artificially induced) as a major factor that causes excess water production and reduced oil recovery efficiency, especially during waterfloods and IOR projects. We found fractures to be a channeling and water production problem that has a high potential for successful treatment by gels and certain other chemical blocking agents. We also determined that the ability of blocking agents to reduce permeability to water much more than that to oil is critical to the success of these blocking treatments in production wells if zones are not isolated during placement of the blocking agent.

This report describes work performed during the third and final year of the project, "Using Chemicals to Optimize Conformance Control in Fractured Reservoirs." Results from the first two years were documented in Refs. 2 and 3.

\section{Objectives}

This research project had three objectives. The first objective was to develop a capability to predict and optimize the ability of gels to reduce permeability to water more than that to oil or gas. The second objective was to develop procedures for optimizing blocking agent placement in wells where hydraulic fractures cause channeling problems. The third objective was to develop procedures to optimize blocking agent placement in naturally fractured reservoirs. This research project consisted of three tasks, each of which addressed one of the above objectives. Our work was directed at both injection wells and production wells and at vertical, horizontal, and highly deviated wells.

\section{Report Content}

This report describes work performed during the third and final year of the project. In Chapter 2, we investigate the mechanism responsible for gels reducing the permeability to water more than that to oil. In Chapter 3, we report experimental results from studies of gel properties in fractures. In Chapter 4, we describe improvements in our software (Gel Design, Version 2.0) for designing gelant treatments to reduce water production from hydraulically fractured production wells. Finally, Chapter 5 briefly discusses future work. Technology transfer activities for the project are described in Appendix A. 



\section{DISPROPORTIONATE PERMEABILITY REDUCTION}

Many polymers and gels can reduce the permeability to water more than that to oil or gas. ${ }^{4-18}$ This property is critical to the success of water-shutoff treatments in production wells if hydrocarbon-productive zones cannot be protected during polymer or gelant placement. ${ }^{5,6}$ However, the magnitude of the effect has been unpredictable from one application to the next. Presumably, the effect would be more predictable and controllable if we understood why the phenomenon occurs. Although many mechanisms have been considered (see Table 1), the underlying cause of the disproportionate permeability reduction remains elusive.

\section{Table 1-Proposed Mechanisms for Disproportionate Permeability Reduction}

1. Gels shrink in oil but swell in water. ${ }^{7-9}$

2. Gravity affects gel locations in pores. ${ }^{10}$

3. Lubrication effects. ${ }^{11}$

4. During brine injection, polymer leaches from the gel and significantly decreases the brine mobility. ${ }^{12}$

5. Balance between capillary forces and gel elasticity affects oil and water flow differently. ${ }^{12,13}$

6. Gelants or gels alter rock wettability. ${ }^{14,15}$

7. In a given pore, gels constrict water pathways more than oil pathways. (Wall effects.) ${ }^{14}$

8. Pore blocking by gel droplets. ${ }^{15,16}$

9. Combined wall-effect and gel-droplet model. ${ }^{16}$

10. On a microscopic scale, water and oil follow different pathways. ${ }^{10,12,15,17}$

11. Gels dehydrate when oil is injected. ${ }^{18}$

Previously, we used NMR imaging to observe disproportionate permeability reduction on a microscopic scale. ${ }^{19}$ Results from these experiments revealed that the imaging technique had many limitations that prevented us from obtaining reliable pore-level images. Most importantly, the spatial resolution was on the order of hundreds of micrometers, which was too low to clearly distinguish fluid pathways on the pore level.

In this chapter, we describe imaging experiments using high-resolution computed X-ray microtomography (XMT) to compare the oil and water pathways and fluid distributions before and after gel treatment. The current generation of synchrotron based XMT scanners provide the ability to obtain three-dimensional pore-level images of rock samples with a spatial resolution on the order of micrometers. ${ }^{20-26}$ For this study, we used the ExxonMobil beamline X2-B at the National Synchrotron Light Source. ${ }^{21} \mathrm{X} 2-\mathrm{B}$ is a dedicated XMT imaging facility capable of producing continuous registered stacks of 2048 x 2048 x 1024 14-bit three-dimensional images of X-ray linear attenuation coefficients at energies tunable from 8 to $40 \mathrm{keV}$. The highly collimated synchrotron $\mathrm{X}$-rays permit the reconstruction of a three dimensional image from twodimensional projections taken at uniformly spaced angles between 0 and 180 degrees. X2-B converts the pattern X-rays transmitted by the specimen (projections) to a visible light image using a thin single crystal of $\operatorname{CsI}(\mathrm{Na})$. This image was magnified by an optical microscope objective onto a $1024 \times 1024$ charge coupled device (CCD). Using Fourier methods, the set of 
angular projections at each row of pixels in the $\mathrm{CCD}$ was used to reconstruct the cross-sectional slice at that row. These slices were stacked to form the three-dimensional image. In this work, a $5 \mathrm{X}$ microscope objective was used to provide a pixel size of $4.1 \mu \mathrm{m}$ and a $4.1-\mathrm{mm}$ field of view. Since part of the core was outside the imaged area, a profile extension method was used to suppress edge artifacts.

Several authors used XMT to characterize the microscopic structure of porous media. ${ }^{20,22,26}$ For a 15-darcy sandstone, Coles $e t a l .^{22}$ found a mean tortuosity of 2.7, with a range from 1.5 to 4.5 . Along a 2.2-mm-long section of this core, porosity varied only a few percent around the average value $(26.4 \%)$. After oil flooding, this core was water flooded to a water saturation of $25.1 \%$. Interestingly, large variations in water saturation were observed along the 2.2-mm-long section-ranging from $12 \%$ to $39 \%$. A three-dimensional view showed the non-wetting phase (water in this case) to exist as large ganglia (blobs of non-wetting phase that extend over multiple pores—often exhibiting a branched structure). ${ }^{22}$

Chatzis et al. ${ }^{27,28}$ suggested that rock heterogeneity can be responsible for saturation variations within a porous medium. Non-wetting phase saturations that are lower than expected can occur when clusters of small pores are dispersed in a matrix dominated by large pores. In contrast, nonwetting phase saturations that are higher than expected can occur when clusters of large pores are dispersed in a matrix dominated by small pores. ${ }^{27}$ However, significant saturation variations can occur even in homogeneous porous media, depending on the pore body/pore throat aspect ratio. For homogeneous 2-dimensional micromodels, Chatzis et al. ${ }^{27}$ reported piston-like displacements with very little trapping of the non-wetting phase when the aspect ratio was two or less. However, for aspect ratios around 3, large non-wetting phase clusters formed as the wetting phase formed fingers while displacing the non-wetting phase. At higher aspect ratios, the nonwetting phase tended to be trapped in individual pores rather than in large clusters of pores. The pore coordination number had a minor effect on non-wetting phase residual saturations. ${ }^{27}$

Using XMT data, Lindquist $e t$ al. ${ }^{26}$ extensively characterized pore and throat size distributions for Fontainebleau sandstones. As core porosity increased from $7.5 \%$ to $22 \%$, they found that the average pore coordination number increased from 3.4 to 3.8 , the average channel length decreased from 200 to $130 \mu \mathrm{m}$, the average throat area increased from 1,600 to $2,200 \mu \mathrm{m}^{2}$, and the average pore volume remained fairly constant at around $0.0004 \mathrm{~mm}^{3}$. The average aspect ratio (effective average pore radius/effective average throat radius) was around 2.

\section{Experimental Materials}

We performed two sets of imaging experiments using strongly water-wet Berea sandstone cores and one set using a polyethylene core, which was strongly oil-wet. (The water-advancing contact angle was measured at 165 degrees for the brine/oil/polyethylene system used in this work.) The Berea cores had permeabilities of $\sim 0.47$ darcys and porosities of $22 \%$. The polyethylene core had a permeability of 8.8 darcys and a porosity of $40 \%$. (Consistent porosity values were determined from both image analyses and conventional mass balance measurements.) The cores were 6.5 $\mathrm{mm}$ in diameter and $30 \mathrm{~mm}$ in length, with an intermediate pressure tap $6 \mathrm{~mm}$ from the inlet face. Our scans focused on a segment of the core that was $6.5 \mathrm{~mm}$ in diameter and $3.25 \mathrm{~mm}$ in length. To avoid end effects, the scanned segment was located about half way between the inlet and outlet faces. The brine used during the water floods contained $1 \% \mathrm{NaCl}$ and $0.1 \% \mathrm{CaCl}_{2} . \mathrm{A}$ 
hexadecane mixture was used during the oil floods. To increase the image contrast between the brine and oil phases, hexadecane was doped with $10 \% \mathrm{w} / \mathrm{w}$ iodohexadecane in our first set of experiments in Berea and with $15 \% \mathrm{w} / \mathrm{w}$ bromohexadecane in the second set. For the polyethylene core, the hexadecane was doped with $15 \% \mathrm{w} / \mathrm{w}$ bromohexadecane. All experiments occurred at room temperature. The gelant used in these experiments contained $0.5 \%$ Alcoflood 935 HPAM (molecular weight $\approx 5 \times 10^{6}$ daltons; degree of hydrolysis $5 \%$ to $10 \%$ ), $0.0417 \%$ $\mathrm{Cr}$ (III) acetate, $1 \% \mathrm{NaCl}$, and $0.1 \% \mathrm{CaCl}_{2}$. The gelant viscosity at room temperature was $20 \mathrm{cp}$. The viscosities were $1.0 \mathrm{cp}$ for brine (without polymer), $3.3 \mathrm{cp}$ for the hexadecane/iodohexadecane mixture, and $3.6 \mathrm{cp}$ for the hexadecane/bromohexadecane mixture.

\section{Core Characterization}

Three-dimensional scans were performed after a gelant flood and after oil and water floods both before and after gel placement. (Images were acquired at saturation endpoints.) All floods in a given set of experiments were conducted without removing the core from the sample stand so that the images could be compared directly. For each scan the image was cropped into a $2.97 \mathrm{~mm}$ $\times 2.97 \mathrm{~mm} \times 2.1 \mathrm{~mm}$ rectangular block (the images were $725 \times 725 \times 512$ voxels at $4.1 \mu \mathrm{m} /$ voxel) to remove artifacts caused by those parts of the core that did not remain within the field of view through all 180 degrees of sample rotation. Image analyses were performed using a software package called 3DMA - a statistical analysis tool that correlates saturations with geometry. This software is capable of measuring distributions of pore size, pore-body/pore-throat aspect ratio, and coordination number of a porous rock using our three-dimensional images. The methods used to make these characterizations are described in Ref. 26. To visualize the pore structure and fluid locations, we first focused on thin cross-sections with dimensions of $1.15 \mathrm{~mm} \times 1.15 \mathrm{~mm}$ in the $x$-y directions (i.e., perpendicular to the flow direction). Figs. 1 and 2 compare the image cross-sections for the first Berea core when first saturated with brine and for the polyethylene core when first saturated with oil. The black areas show rock grains or polyethylene. The white areas show brine-saturated voids in the Berea and oil-saturated voids in the polyethylene. These figures highlight the irregular sizes and shapes of the voids. Although, the porosity difference is noticeable ( $22 \%$ for Berea and $40 \%$ for polyethylene), the pore body and throat sizes were comparable. For comparison with the XMT images, Figs. 3 and 4 show electron micrographs. Additional electron micrographs (Figs. 5-7) were obtained at high magnification for Berea and polyethylene to illustrate the character of the pore walls. (These images were obtained using a Cameca SX100 electron microprobe at the New Mexico Bureau of Mines.) Due to a coating of kaolinite, a significantly greater surface roughness and angularity existed in Berea (Fig. 5) than in the polyethylene core (Figs. 6 and 7$)$. Interestingly, thin filaments $(\sim 0.1-\mu \mathrm{m}$ diameter) bridged many of the small pores in new unsaturated polyethylene cores (Fig. 6). Although not shown, these filaments were not seen in the larger pores. Also, these filaments apparently dissolved after contacting hexadecane (Fig. 7), so we do not believe that they were present during our floods.

Size distributions. The pore size distributions for two Berea cores and the polyethylene core are shown in Fig. 8. The $y$-axis plots the percent of the total number of pores that had a given pore volume (indicated on the $x$-axis). The distributions (based on pore numbers) were similar for the three cores. For pores with volumes below $0.0003 \mathrm{~mm}^{3}$, the fraction of pores of a given size was fairly insensitive to the pore volume. Above $0.0003 \mathrm{~mm}^{3}$, the concentration of pores decreased significantly with increased pore volume. 


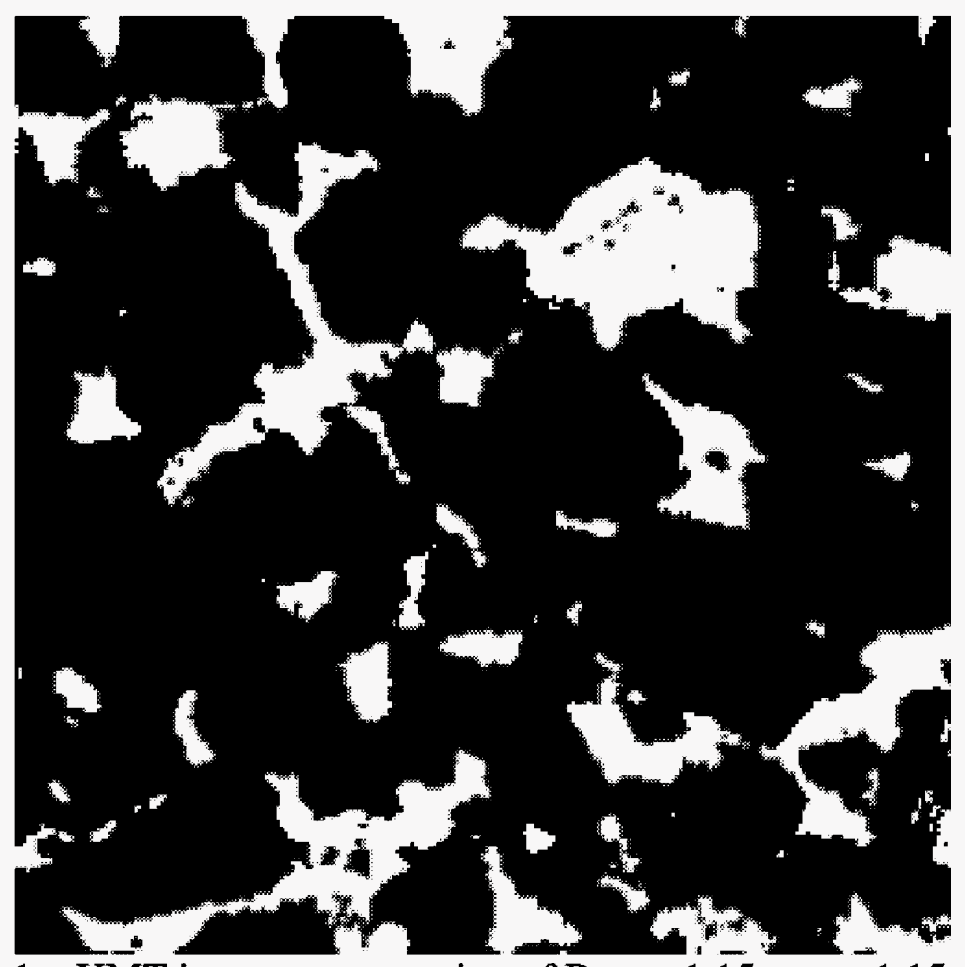

Fig. $1-\mathrm{XMT}$ image cross-section of Berea. $1 . \overline{15} \mathrm{~mm} \times 1.15 \mathrm{~mm}$.

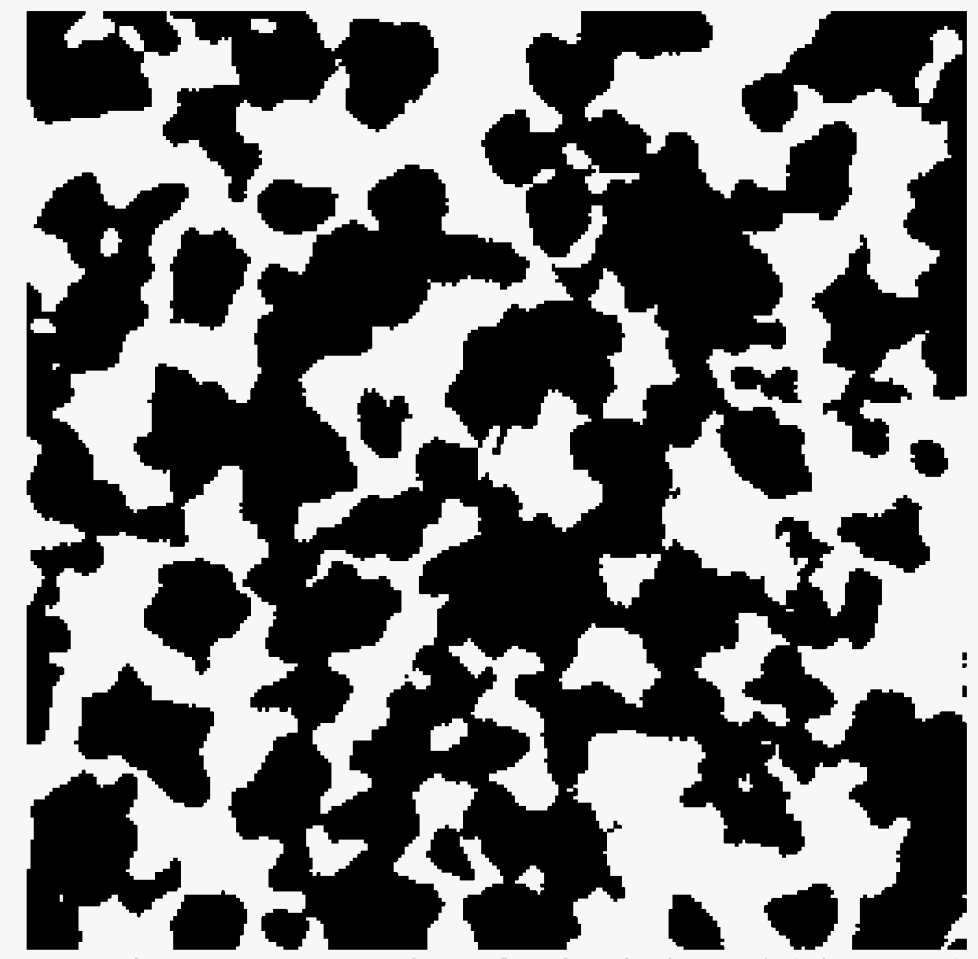

Fig. 2-XMT image cross-section of polyethylene. $1.15 \mathrm{~mm} \times 1.15 \mathrm{~mm}$. 


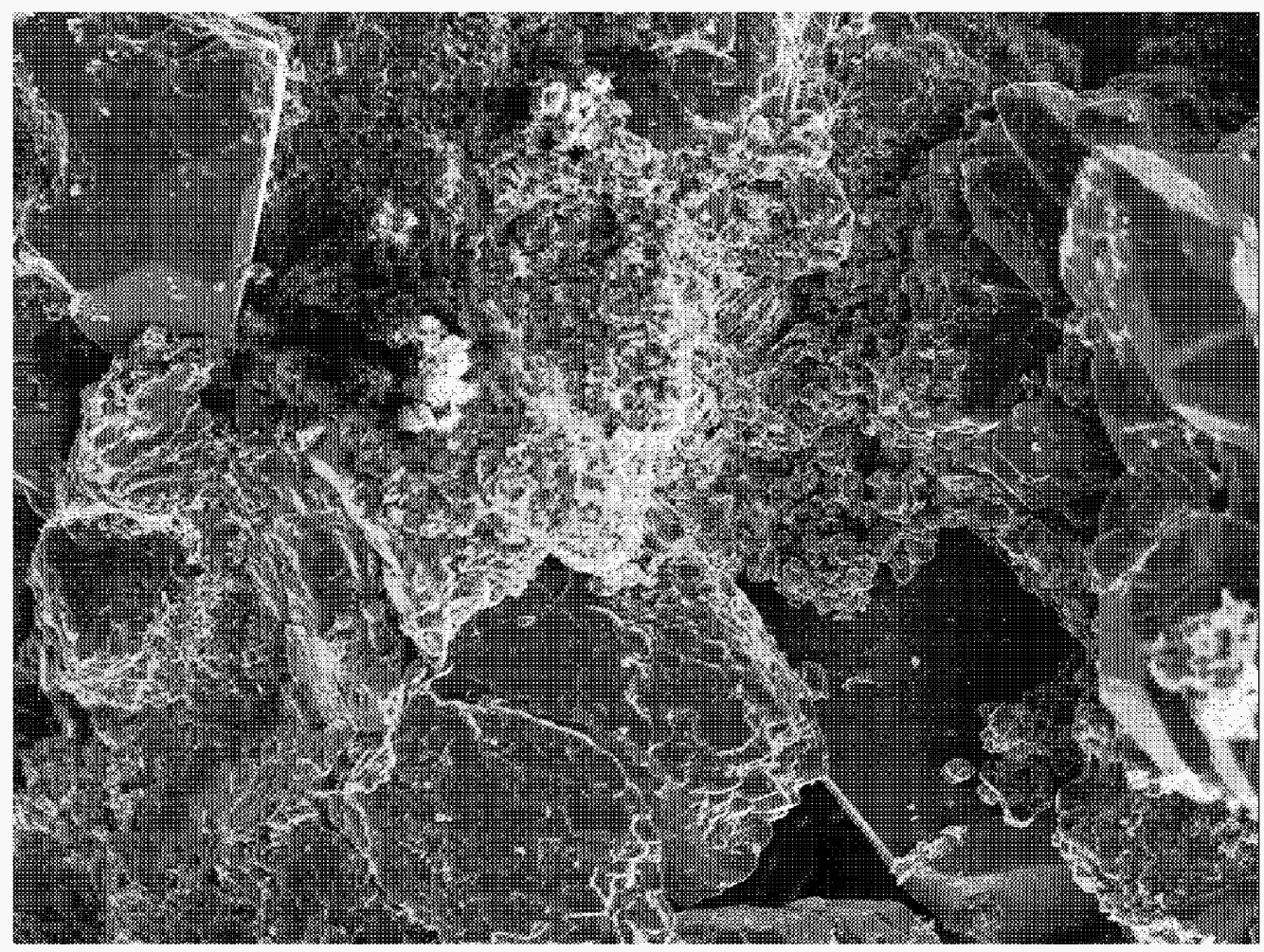

Fig. 3-Scanning electron micrograph (SEM) of Berea. $500 \mu \mathrm{m} \times 367 \mu \mathrm{m}$.

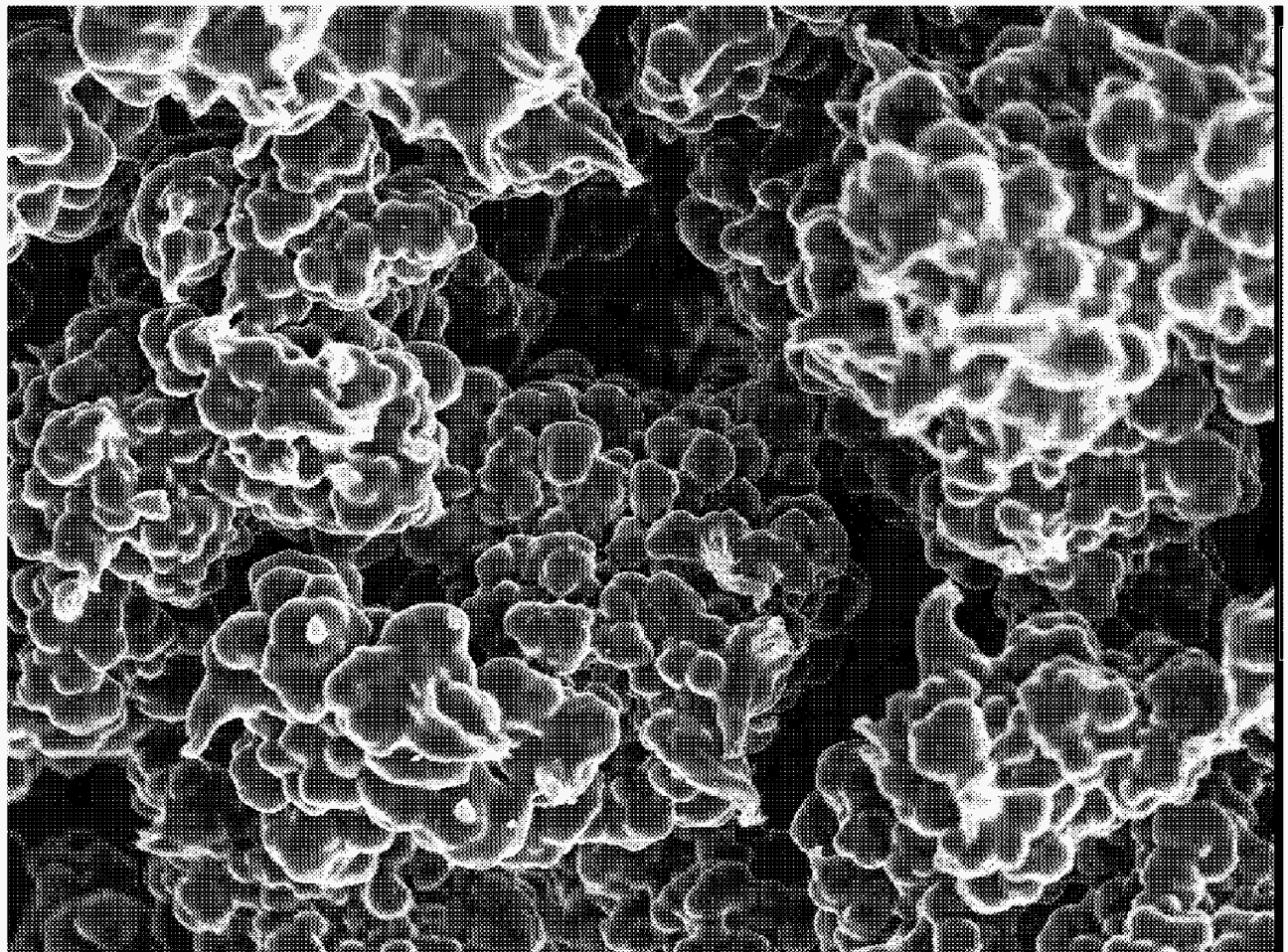

Fig. 4-SEM of polyethylene. $500 \mu \mathrm{m} \times 367 \mu \mathrm{m}$. 


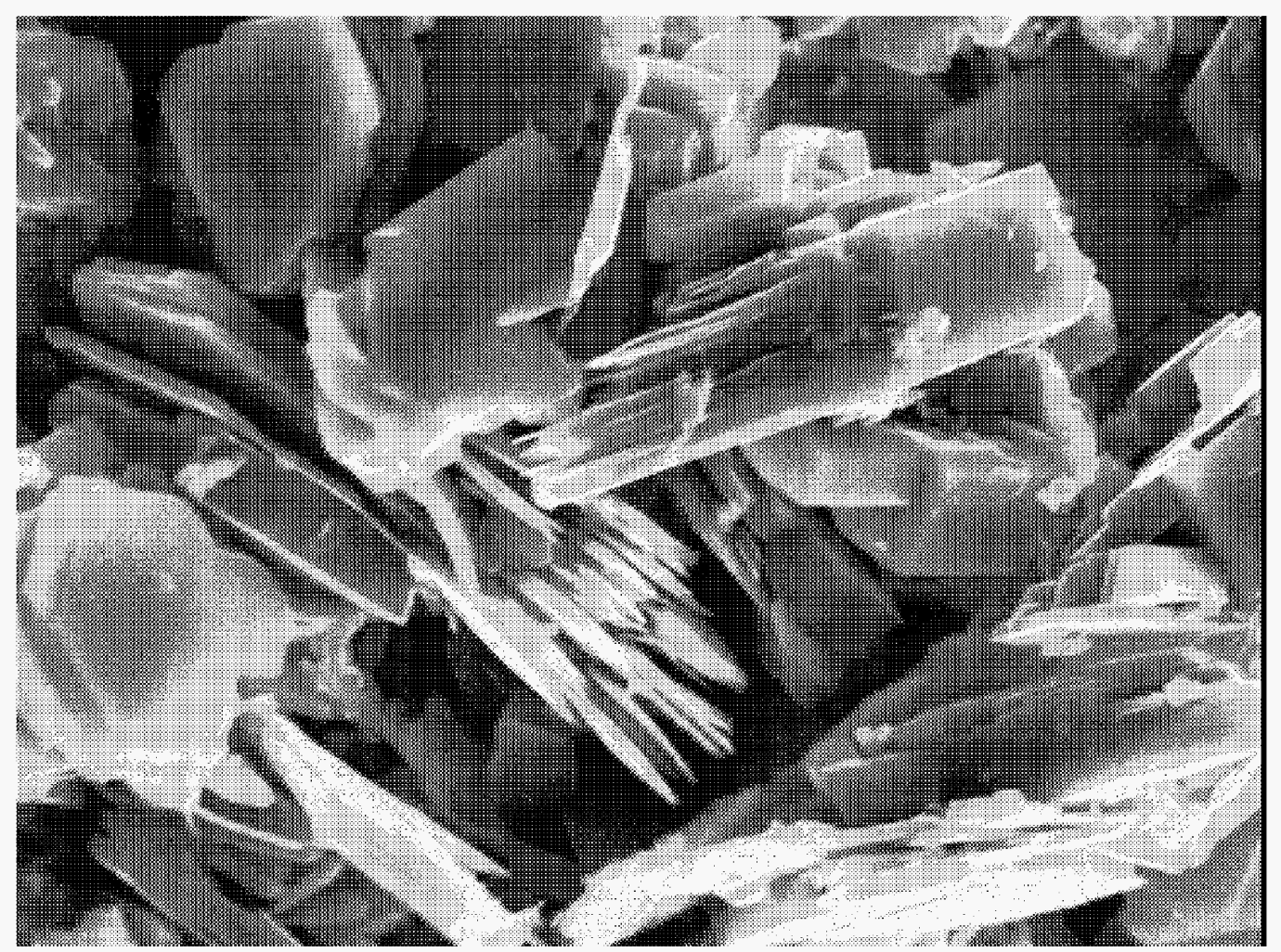

Fig. 5-SEM of Berea. $30 \mu \mathrm{m} \times 22 \mu \mathrm{m}$.

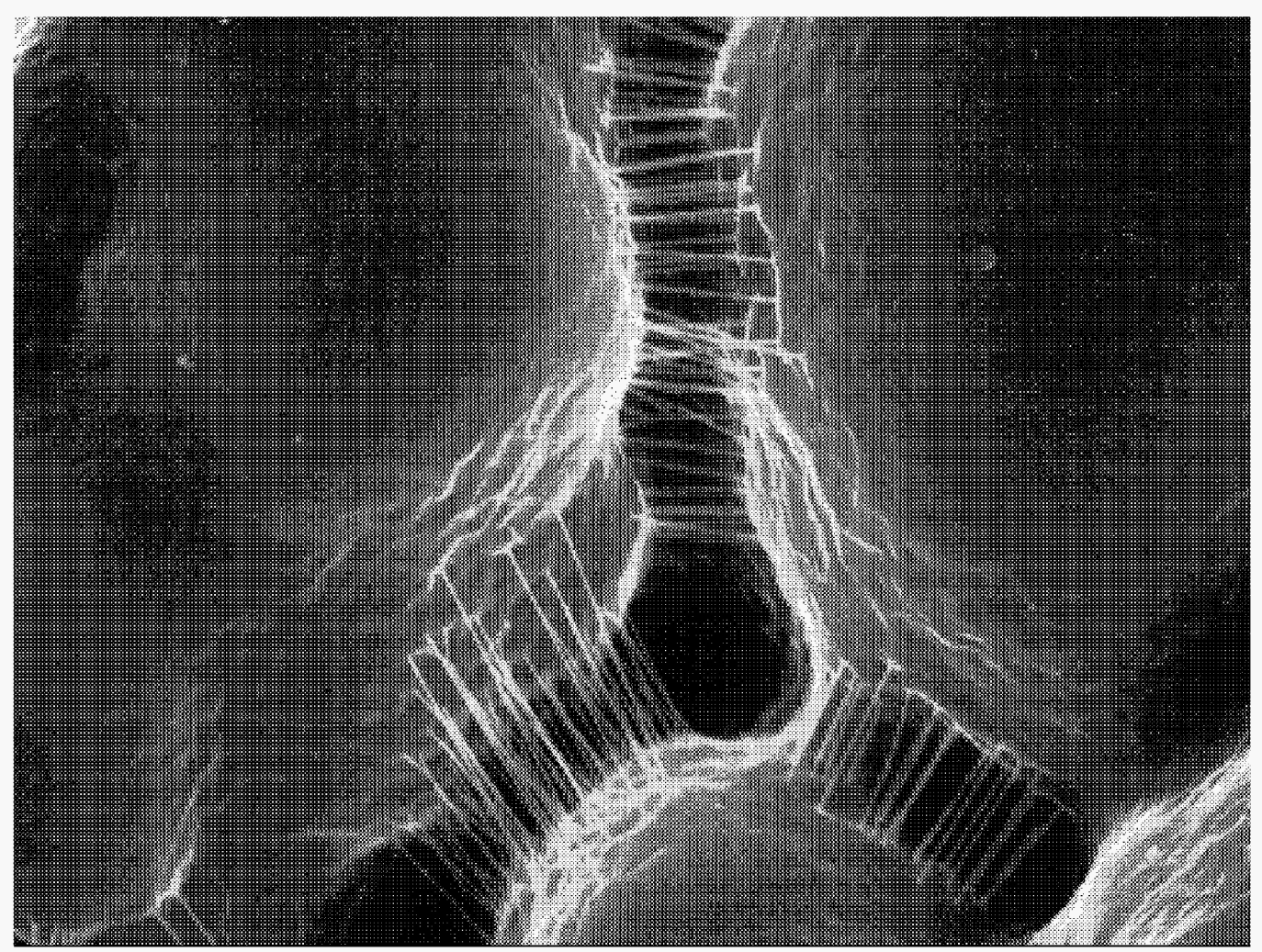

Fig. 6-SEM of an unsaturated polyethylene core. $30 \mu \mathrm{m} \times 22 \mu \mathrm{m}$. 


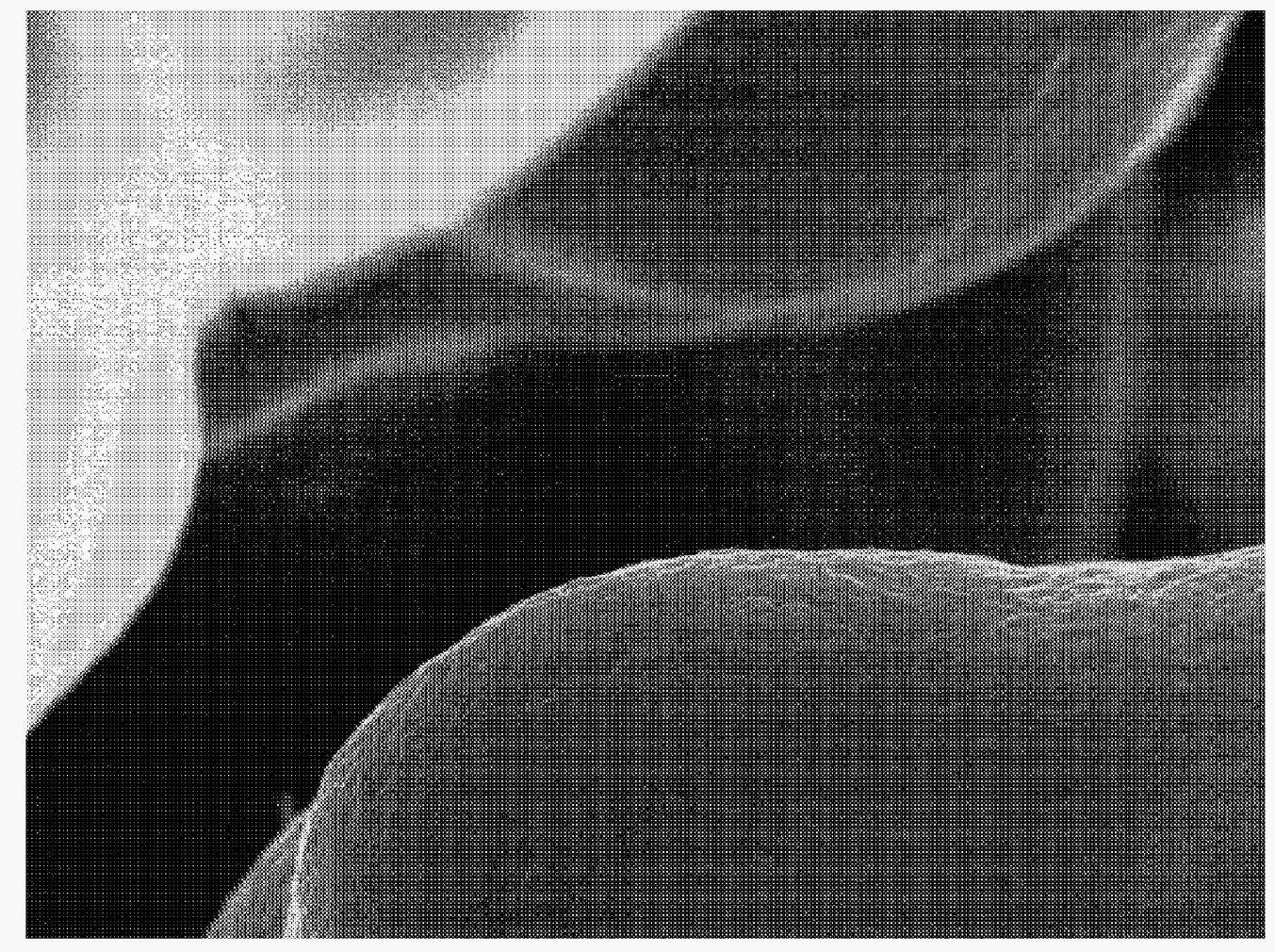

Fig. 7-SEM of a polyethylene core after exposure to hexadecane. $30 \mu \mathrm{m}$ x $22 \mu \mathrm{m}$.

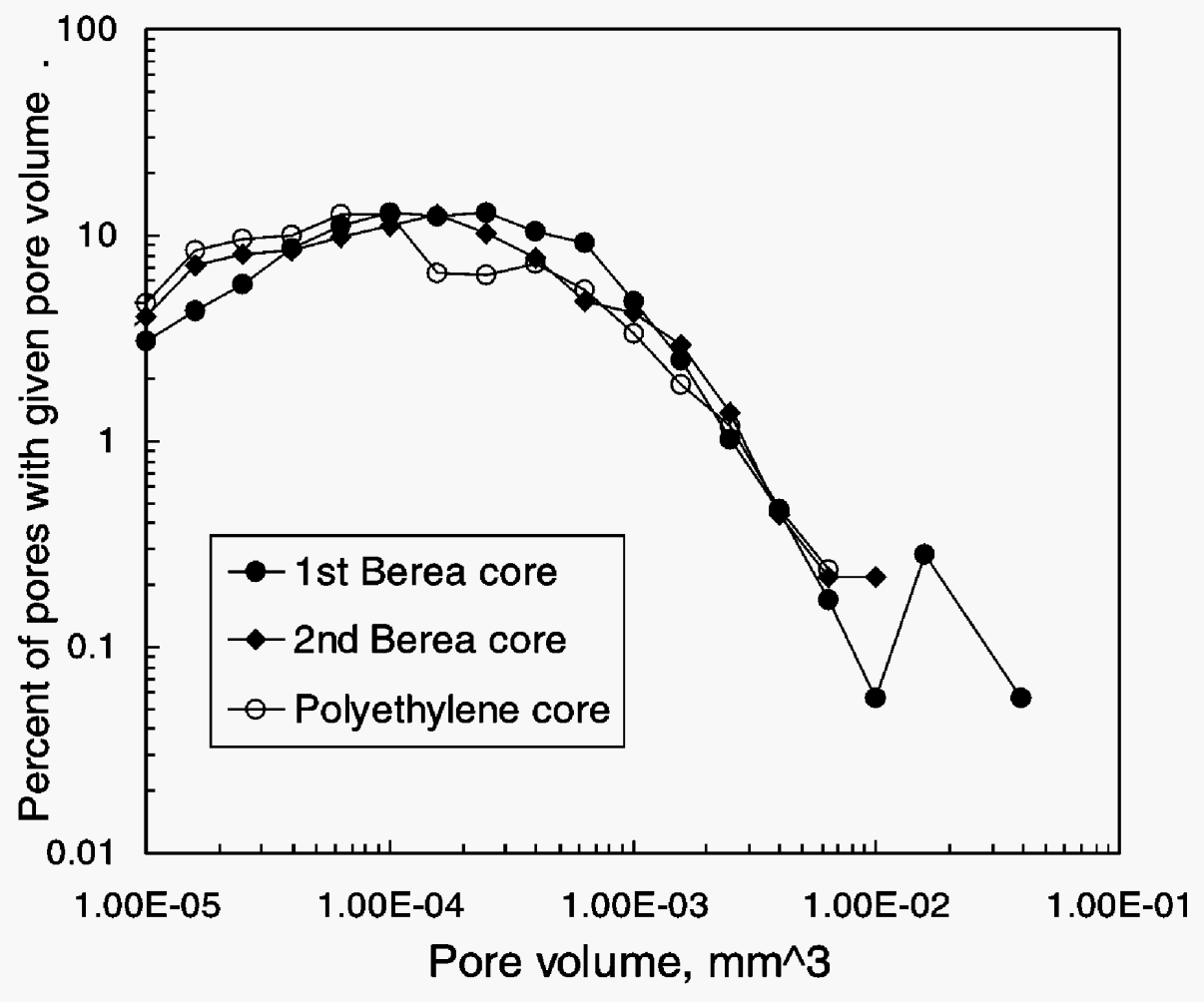

Fig. 8-Pore size distributions. 
Pore volume distributions for the three cores are shown in Fig. 9. The $y$-axis plots the percent of the total void volume that existed in pores with a given size (indicated on the $x$-axis). Again, the distributions were quite similar, considering the material differences. The peak in the pore volume occurred at an effective pore radius (assuming spherical pores) about $50 \mu \mathrm{m}$ for the first Berea core, $70 \mu \mathrm{m}$ for the second Berea core, and $70 \mu \mathrm{m}$ for the polyethylene core. The average nodal pore volumes for the three cores were very similar to those found by Lindquist $e t a l .^{26}$ for Fontainebleau sandstones $\left(\sim 0.0004 \mathrm{~mm}^{3}\right)$. A comparison of Figs. 8 and 9 reveals that although many pores existed with volumes less than $0.0001 \mathrm{~mm}^{3}$, their contribution to the total void volume was small.

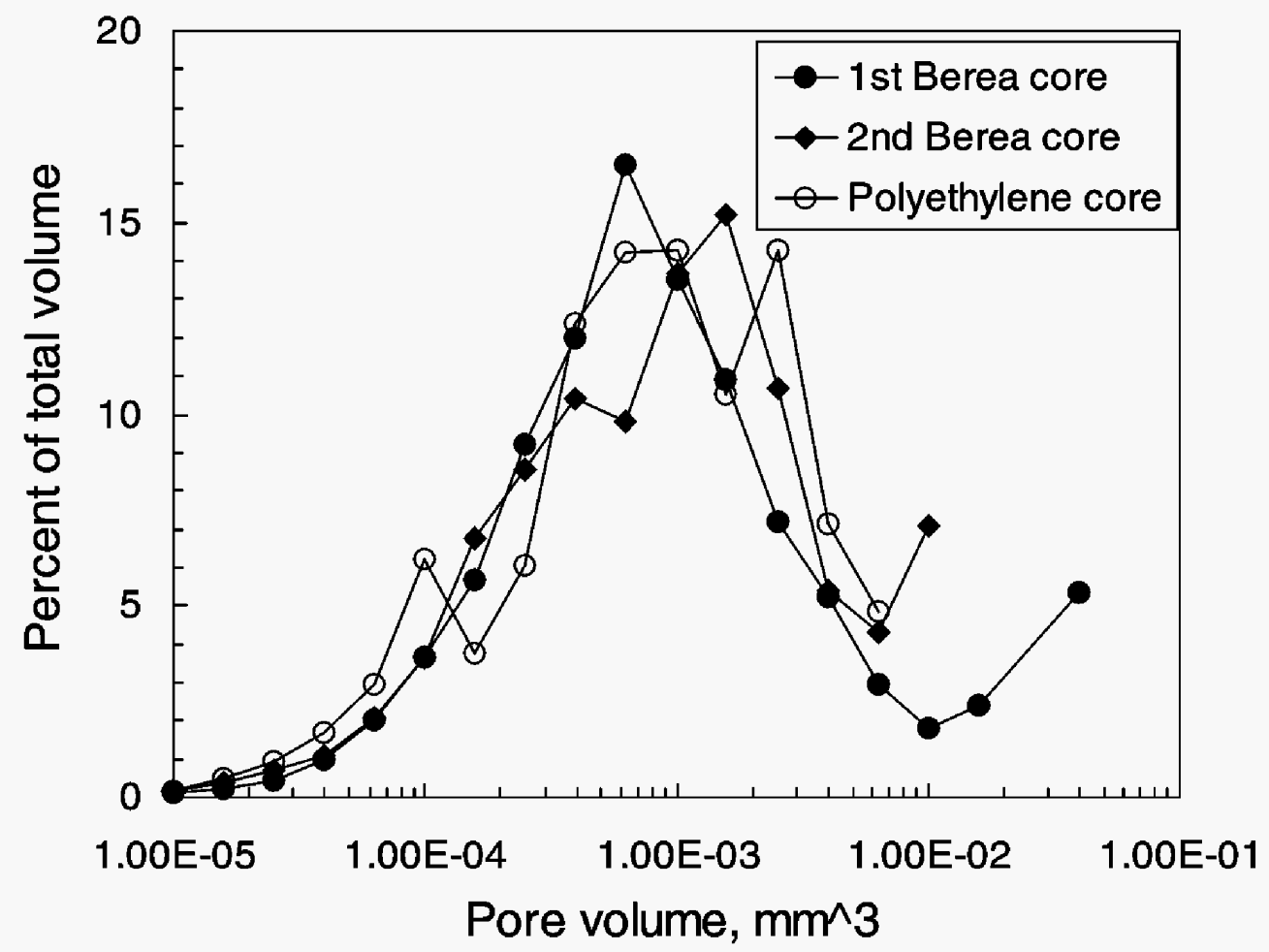

Fig. 9-Pore volume distributions.

Aspect Ratios. The distribution of aspect ratios (effective pore radius/effective throat radius) for the Berea and polyethylene cores are shown in Fig. 10. (The effective pore radius assumed that the pore was spherical. The effective throat radius assumed that the throat area was circular.) The $y$-axis plots the average aspect ratio in pores with a given size (indicated on the $x$-axis). Again, the distributions were surprisingly similar for the cores. The average aspect ratio was $4.0 / 1$ for the first Berea core, 4.2/1 for the second Berea core, and 4.4/1 for the polyethylene core. As pore volume increased from $10^{-5} \mathrm{~mm}^{3}$ (effective pore radius $\sim 13 \mu \mathrm{m}$ ) to $0.002 \mathrm{~mm}^{3}$ (effective pore radius $\sim 78 \mu \mathrm{m}$ ), the average aspect ratio increased steadily from 2 to 6 . Aspect ratios jumped sharply for the few largest pores. For a given pore size, a wide range of aspect ratios were noted. For all cores at a given pore size, the standard deviation (of aspect ratios) was typically $65 \%$ of the mean value. 


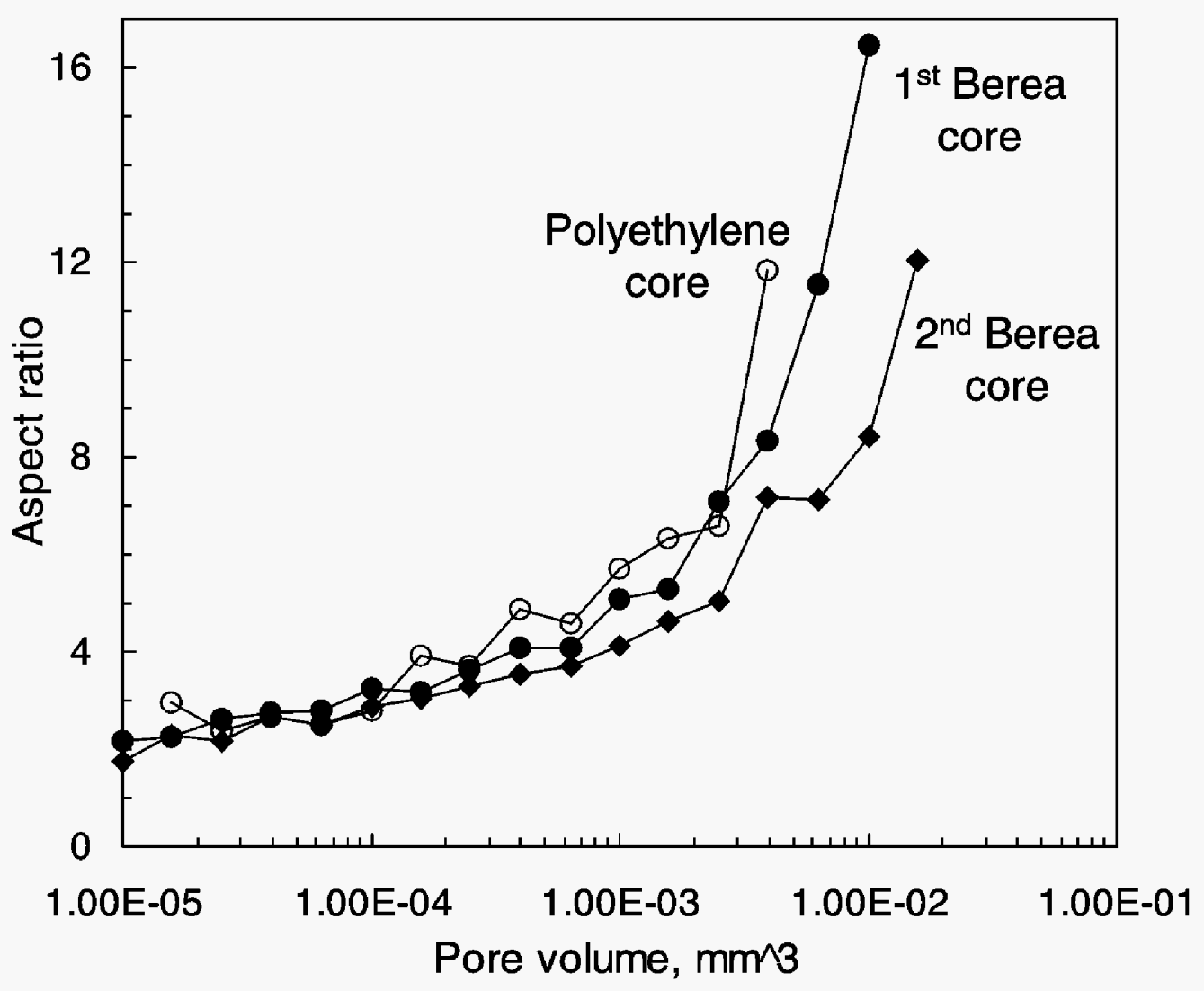

Fig. 10-Aspect ratio distributions.

For Berea sandstone, Fig. 11 plots the distributions of aspect ratios for each of four ranges of pore volume (PV): (1) PV $>0.01 \mathrm{~mm}^{3}$, (2) $0.001<P V<0.01 \mathrm{~mm}^{3}$, (3) $0.0001<P V<0.001 \mathrm{~mm}^{3}$, and (4) $\mathrm{PV}<0.0001 \mathrm{~mm}^{3}$. The $x$-axis plots various ranges of aspect ratio, $R$, from $R<2$ up to $R>30$. The $y$-axis plots the percent of the total aspect ratios (for a given PV range) that falls within a given range of aspect ratios. The solid and open triangles in Fig. 11 show that about $35 \%$ of the smallest pores were associated with aspect ratios that were less than 2 . Interestingly for all four pore-size ranges, $25-35 \%$ of the aspect ratios fell between 3 and 5 , and a significant percentage of aspect ratios fell between 5 and 10 . Aspect ratios above 10 were common for the larger pores but were rare for the smaller pores. In contrast, aspect ratios below 3 were very common for the smaller pores but were much less frequent for the larger pores.

The average throat area was $1,330 \mu \mathrm{m}^{2}$ for the first Berea core, $1,460 \mu \mathrm{m}^{2}$ for the second Berea core, and $1,630 \mu \mathrm{m}^{2}$ for the polyethylene core. These values were generally lower than the average throat areas reported for Fontainebleau sandstones $\left(1,600\right.$ to $\left.2,200 \mu \mathrm{m}^{2}\right){ }^{26}$ 


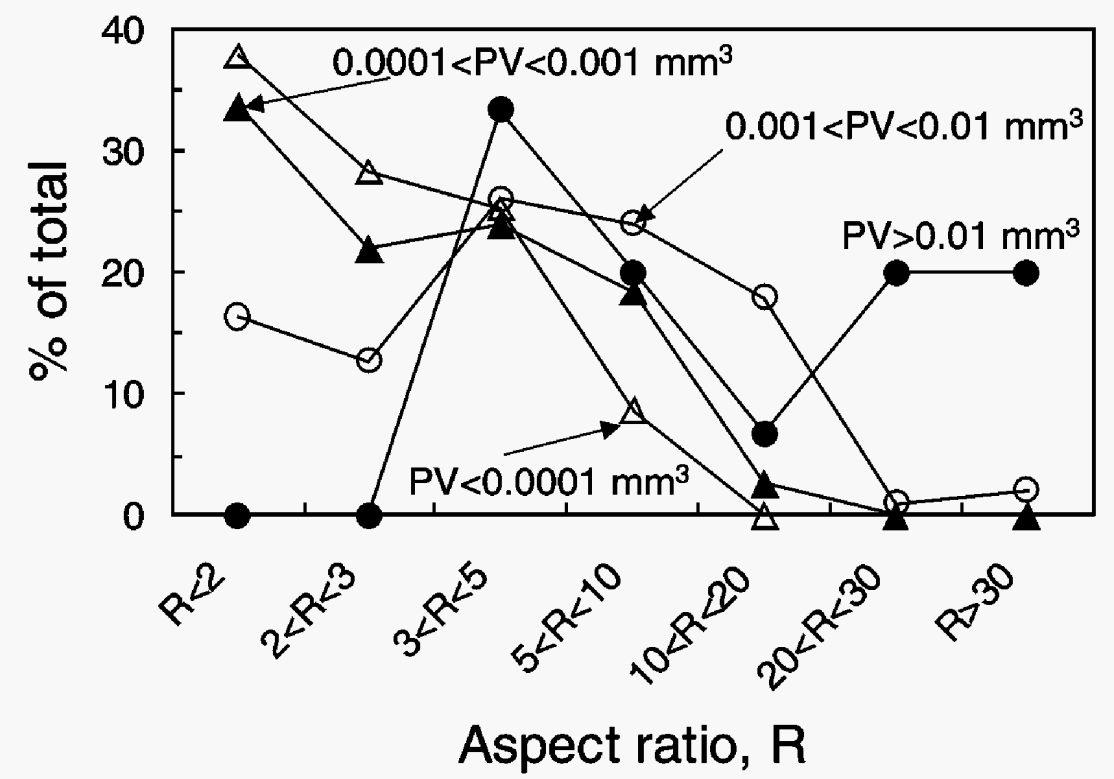

Fig. 11-Aspect ratios in Berea.

Coordination Numbers. The distributions of pore coordination numbers are shown in Fig. 12. (The coordination number is the number of exits from a pore.) The $y$-axis plots the average coordination number in pores with a given size (indicated on the $x$-axis). The average coordination number was 3.9 for the first Berea core, 4.7 for the second Berea core, and 6.2 for the polyethylene core. For the smallest pores, the coordination number was around three for all three cores. As the pore size increased, the coordination numbers increased-with the polyethylene core experiencing a slightly more rapid increase than the Berea cores. Coordination numbers up to 70 were noted for the largest pores. For a given pore size, standard deviations were typically $20 \%$ to $40 \%$ of the mean values.

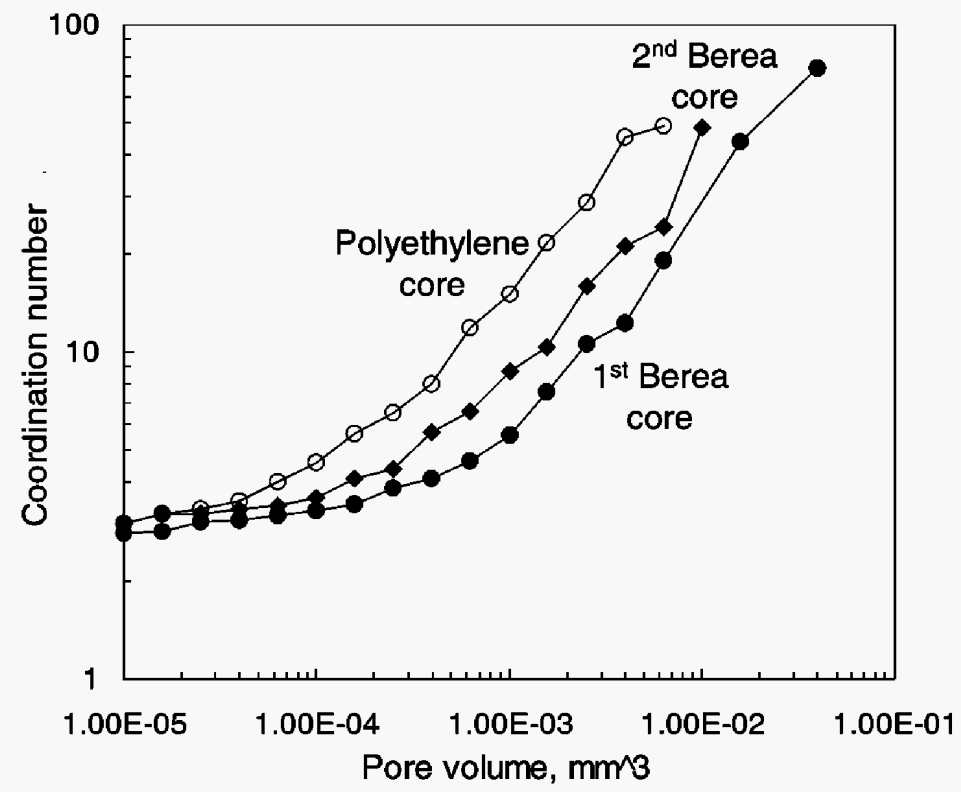

Fig. 12-Coordination number distributions. 


\section{Images After the Various Floods}

XMT scans were performed after each flood. Fig. 1 and Figs. 13-18 show image slices for the first Berea core for each of the flooding stages. Fig. 2 and Figs. 19-24 show images slices for the various flooding stages in the polyethylene core. In Figs. 13-24, oil is red, water is green, and the rock grains (or polyethylene) are black. To magnify the pore structure, these cross-sections are $1.15 \mathrm{~mm} \times 1.15 \mathrm{~mm}$. Corresponding fluid saturations and permeabilities associated with the floods are listed in Tables 2 and 3.

Table 2-Fluid Saturations

\begin{tabular}{|l|c|c|c|}
\hline & $1^{\text {st }}$ Berea core & $2^{\text {nd }}$ Berea core & Polyethylene core \\
\hline Permeability, darcys & 0.47 & 0.48 & 8.8 \\
\hline Porosity, \% & 22 & 22 & 40 \\
\hline First saturated with: & water & water & oil \\
\hline$S_{w}$ at $1^{\text {st }} S_{w r}, \%$ & 24.7 & 37.3 & 0.0 \\
\hline$S_{w}$ at $1^{\text {st }} S_{o r} \%$ & 56.5 & 56.8 & 77.7 \\
\hline$S_{w}$ at $2^{\text {nd }} S_{w r}, \%$ & & 34.3 & 15.2 \\
\hline$S_{w}$ at $2^{\text {nd }} S_{o r}, \%$ & & & 75.0 \\
\hline$S_{w}$ at $1^{\text {st }} S_{o r}$ after gel, $\%$ & 47.7 & & 94.4 \\
\hline$S_{w}$ at $S_{w r}$ after gel, $\%$ & 29.0 & & 75.7 \\
\hline$S_{w}$ at $2^{\text {nd }} S_{o r}$ after gel, $\%$ & 21.3 & & 92.4 \\
\hline
\end{tabular}

Table 3-Permeabilities

\begin{tabular}{|l|c|c|c|}
\hline & $1^{\text {st }}$ Berea core & $2^{\text {nd }}$ Berea core & Polyethylene core \\
\hline Permeability, darcys & 0.47 & 0.48 & 8.8 \\
\hline Porosity, \% & 22 & 22 & 40 \\
\hline First saturated with: & water & water & oil \\
\hline$k_{r o}$ at $1^{\text {st }} S_{w r}$ & 0.82 & 0.79 & 1.0 \\
\hline$k_{r w}$ at $1^{\text {st }} S_{o r}$ & 0.16 & 0.18 & 0.50 \\
\hline$k_{r o}$ at $2^{\text {nd }} S_{w r}$ & & 0.78 & 0.45 \\
\hline$k_{r w}$ at $2^{\text {nd }} S_{o r}$ & & & 0.49 \\
\hline$F_{r r o}$ & 15 & & 24 \\
\hline$F_{r r w}$ & 1,220 & & 2,130 \\
\hline$F_{r r w} / F_{r r o}$ & 81 & & 89 \\
\hline
\end{tabular}




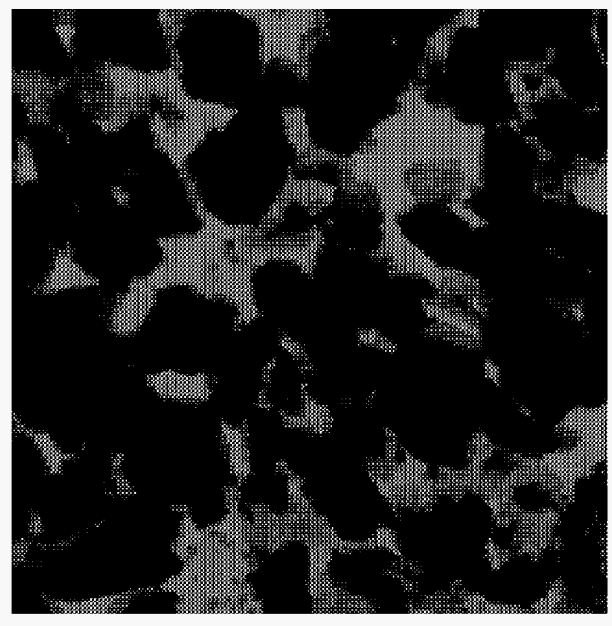

Fig. 13-Rock saturated with brine only.

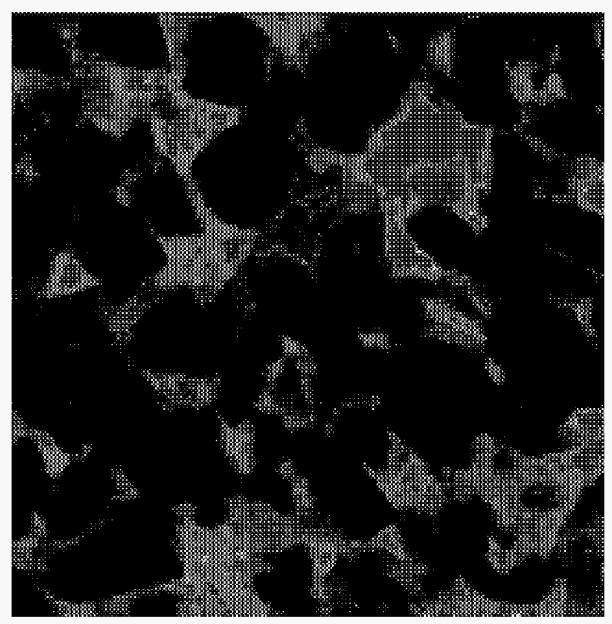

Fig. 15-At $S_{\text {or }}$ before gel.

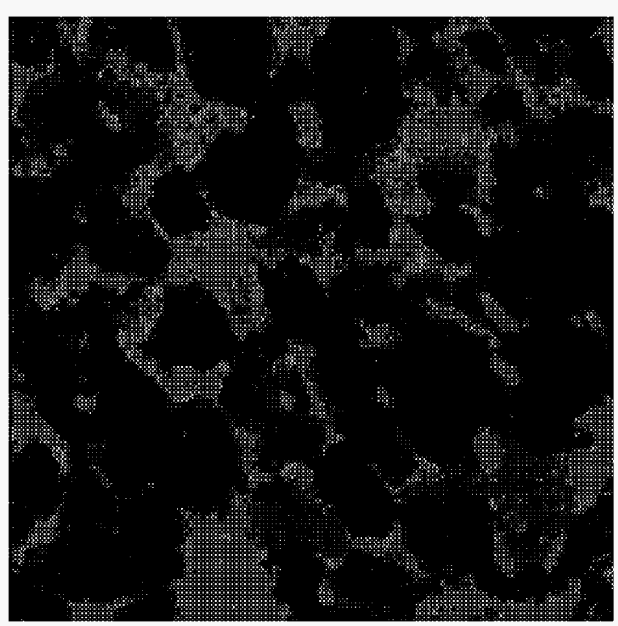

Fig. 17-At $S_{w r}$ after gel.

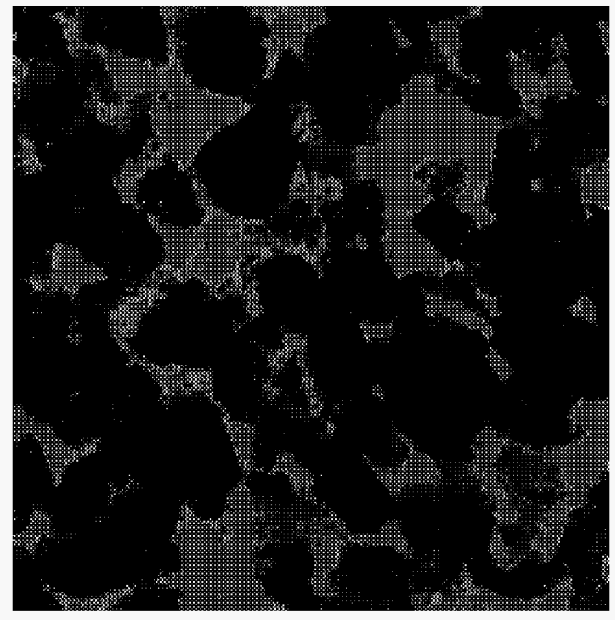

Fig. 14-At $S_{w r}$ before gel.

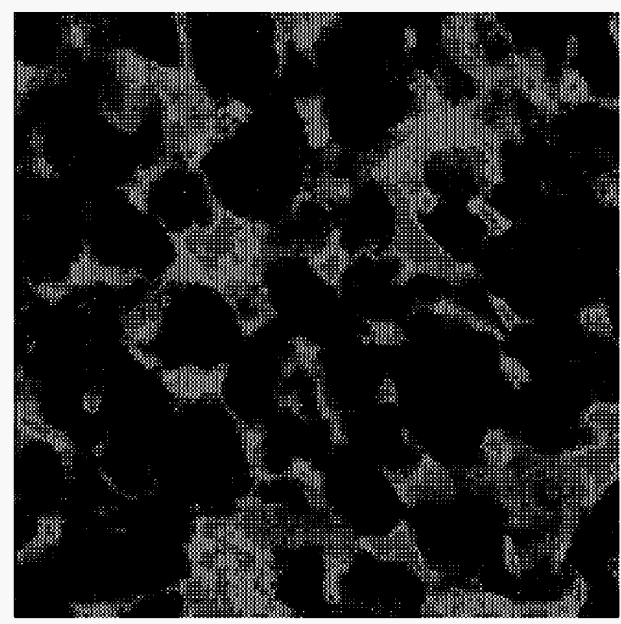

Fig. 16-After gel placement.

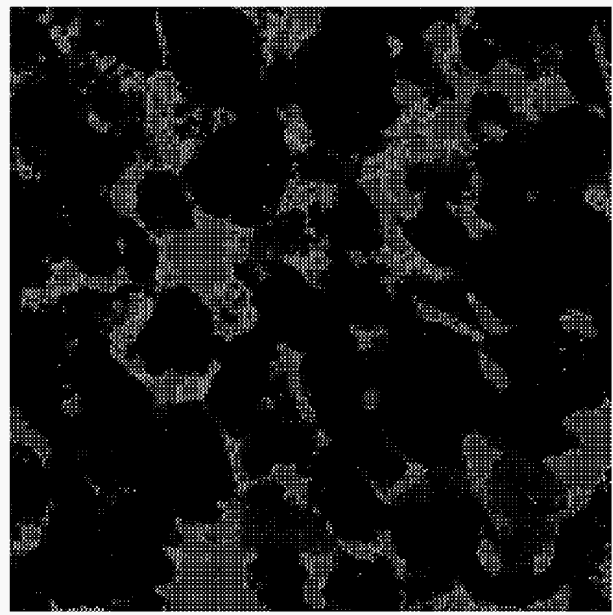

Fig. 18-At $S_{\text {or }}$ after gel.

Berea sandstone cross-sectional image slices (1.15 $\mathrm{mm} \times 1.15 \mathrm{~mm}$ each). Green is water. Red is oil. Black is rock. 


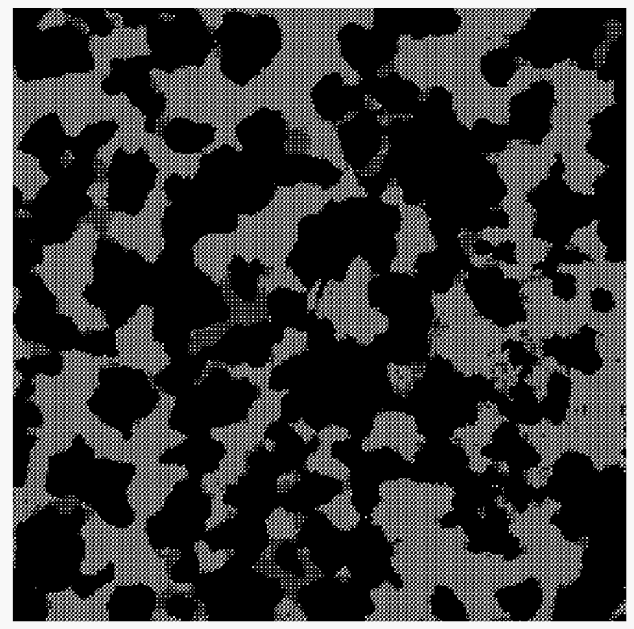

Fig. 19-At first $S_{\text {or }}$ before gel.

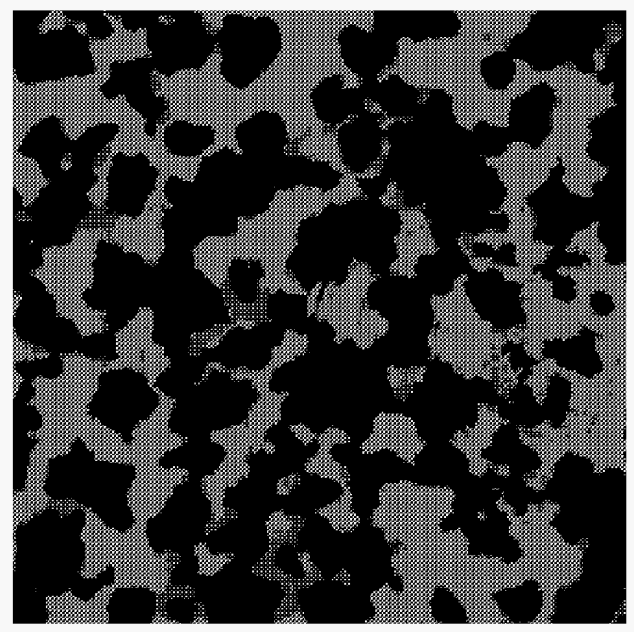

Fig. 21-At second $S_{\text {or }}$ before gel.

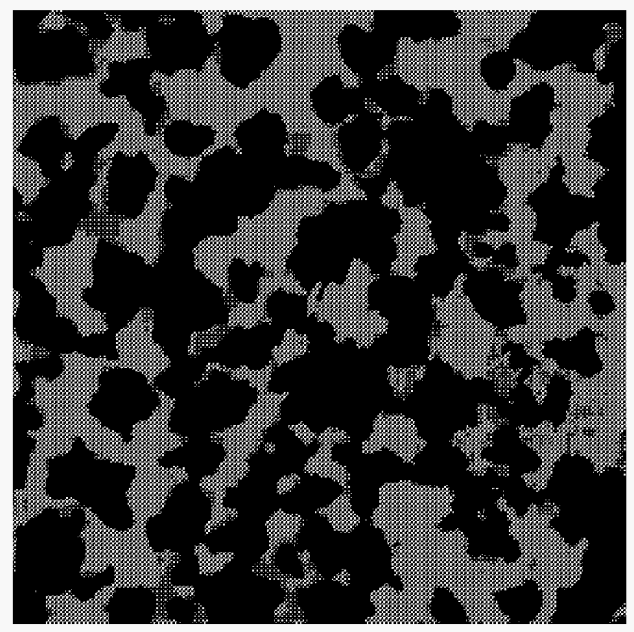

Fig. 23-At $\mathbf{S}_{w r}$ after gel.

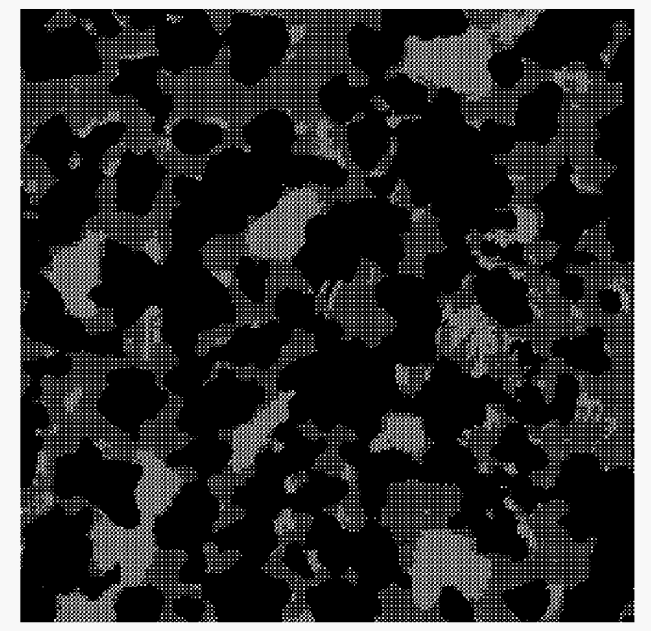

Fig. 20-At $\mathbf{S}_{w r}$ before gel.

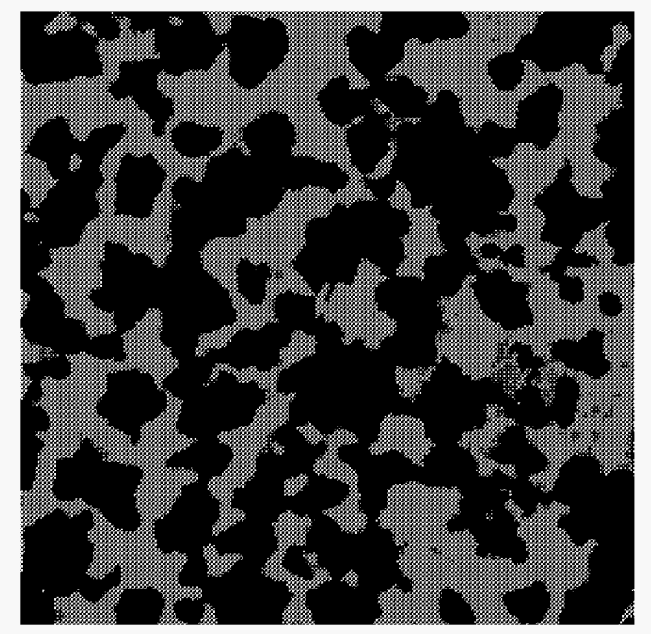

Fig. 22-After gel placement.

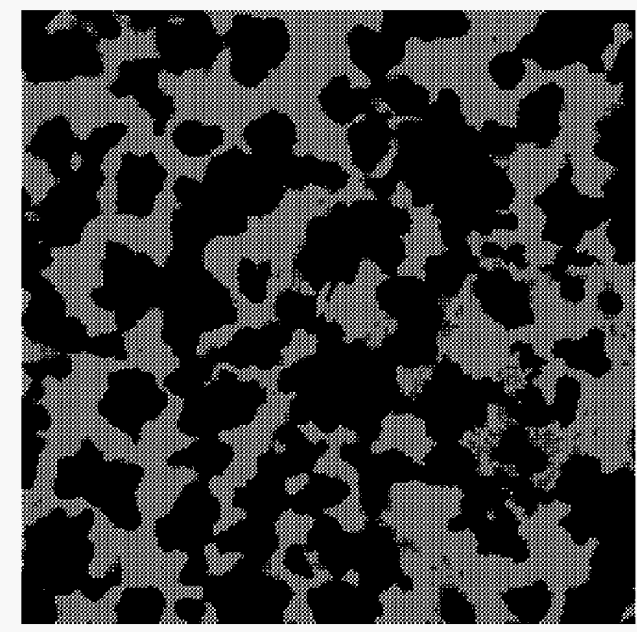

Fig. 24-At $\boldsymbol{S}_{\text {or }}$ after gel.

Polyethylene cross-sectional image slices (1.15 $\mathrm{mm} \times 1.15 \mathrm{~mm}$ each). Green is water. Red is oil. Black is polyethylene. 


\section{Berea Sandstone Image Analyses}

Before Gelant Injection. In the first Berea core, the first scan viewed the core with $100 \%$ brine saturation (Fig. 13). Second, the core was flooded with $\sim 35$ core pore volumes of oil and scanned at residual water saturation (Fig. 14). Oil invaded most pores while the residual water appeared dominantly in crevices and films between oil and the rock. The residual water saturation, $S_{w r}$, was $24.7 \%$ (Table 2), and the endpoint relative permeability to oil (relative to the absolute permeability), $k_{r o}$, was 0.82 (Table 3 ). Third, the core was flooded with water ( 70 core pore volumes) and scanned at residual oil saturation (Fig. 15). The residual oil occupied the centers of the pores while water formed a film around the residual oil. The residual oil saturation, $S_{o r}$, was $43.5 \%$ (i.e., $100 \%-56.5 \%$, from Table 2), and the endpoint relative permeability to water, $k_{r w}$, was 0.16 . These findings are qualitatively consistent with expectations in a strongly water-wet rock.

Using the 3DMA software, detailed analyses were performed using the complete threedimensional images (not just the two-dimensional slices shown in Figs. 13-24). The distributions of water and oil saturations were determined as a function of pore size. In Fig. 25, the solid symbols show the distribution of water saturations $\left(S_{w}\right)$ at $S_{w r}$ before gel placement. (In this figure and subsequent figures, average saturations for a given pore size are reported.) The open symbols show the distribution of water saturations at $S_{o r}$ before gel placement. (Of course, at any condition, the oil saturation is equal to $100 \%$ minus the water saturation.) As mentioned, the overall average $S_{w r}$ was $24.7 \%$ for the first Berea core. This number was consistent with $S_{w r}$ values measured using mass balances in this strongly water-wet Berea sandstone. As expected at $S_{w r}$, the water saturation generally increased with decreased pore size (solid circles in Fig. 25). A broad minimum in water saturation was noted around $0.002 \mathrm{~mm}^{3}$, and a local maximum was observed around $0.01 \mathrm{~mm}^{3}$. For a strongly water-wet porous medium, one might have expected the water saturation to approach $100 \%$ for the smallest pores. Instead, the water saturation in the smallest pores averaged $60 \%$. A calculation using the Laplace equation confirmed that oil should be able to enter the smallest pores in our Berea cores. Specifically, to enter the smallest pore throats $(\sim 7 \mu \mathrm{m}$ radius), a capillary pressure around $1 \mathrm{psi}$ was needed. This value was much lower than the $17 \mathrm{psi}$ (pressure drop across the core) that was applied during our flooding experiments. The behavior of $S_{w}$ versus pore size was confirmed during an imaging experiment in a second Berea core (solid squares in Fig. 25). This experiment included a second oil flood (following an intervening water flood). Results from this part of the experiment (solid triangles in Fig. 25) further confirmed the above behavior and indicated minimum hysteresis during cycles of water and oil flooding before gel placement. The fluid saturations and relative permeabilities from this second Berea core (Tables 2 and 3 ) also suggest that little hysteresis occurred during multiple flooding cycles.

As mentioned, the overall average $S_{o r}$ was $43.5 \%$ for the first Berea core. This number was significantly higher than the $S_{\text {or }}$ values measured using mass balances in this strongly water-wet Berea sandstone $(\sim 22 \%)$. At $S_{o r}$, the average water saturation was surprisingly insensitive to pore size (open circles in Fig. 25). The above results were confirmed during imaging studies of our second core (open squares in Fig. 25). 


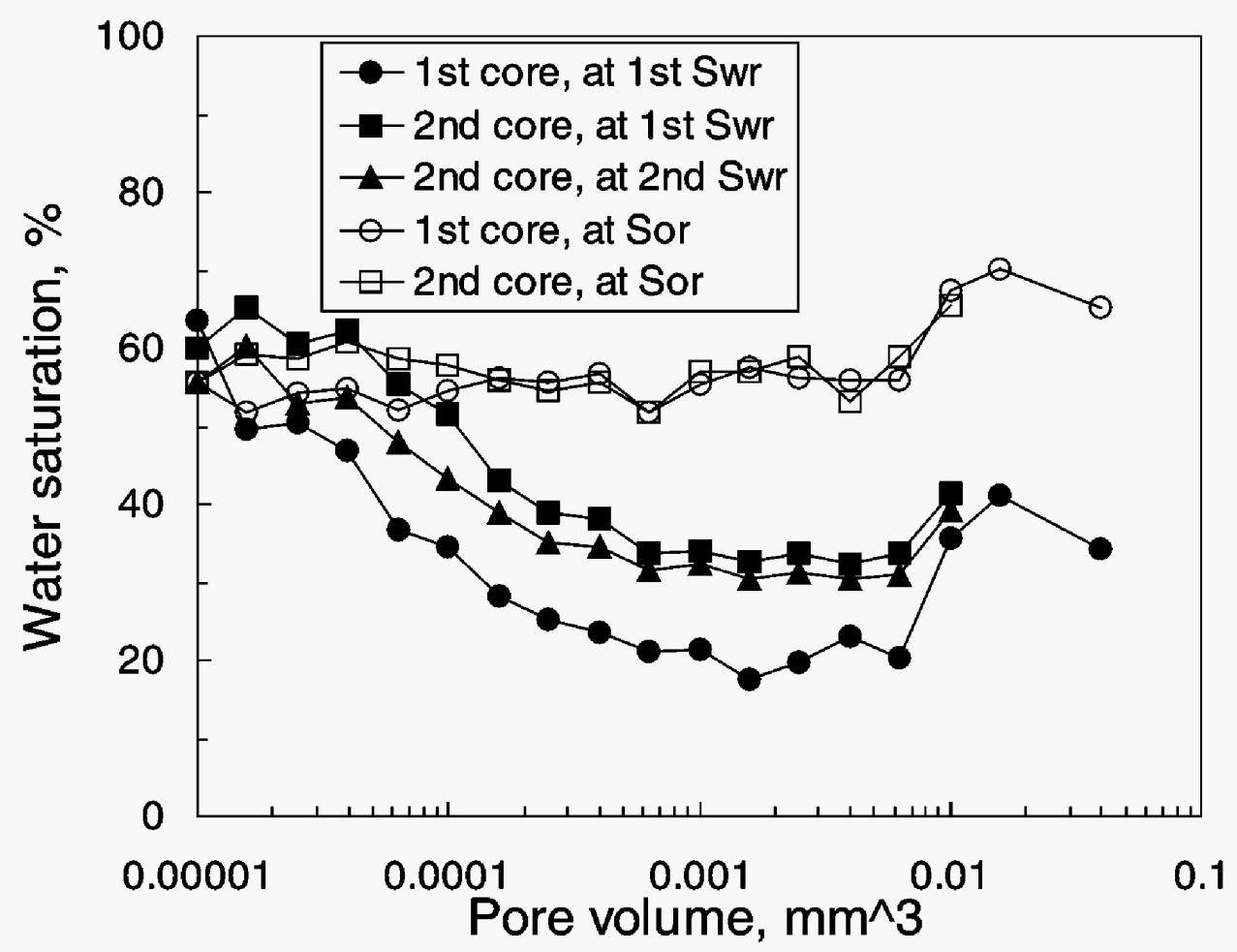

Fig. 25-Water saturations at $S_{w r}$ and $S_{o r}$ before gel placement in Berea sandstone cores.

For a given pore size, Fig. 25 shows the average water saturation from a given experiment. Of course, since many pores were present for any given pore size, a range of saturations was found. A detailed examination of the data revealed that for a given pore size, the range or distribution of water saturations was quite broad, both at $S_{o r}$ and at $S_{w r}$. This fact is illustrated by comparing Figs. 26 and 27 for the first Berea sandstone core and by comparing Figs. 28-30 for the second Berea core. In each figure, four ranges of pore size were considered: (1) 0.00001 to $0.0001 \mathrm{~mm}^{3}$, (2) 0.0001 to $0.001 \mathrm{~mm}^{3}$, (3) 0.001 to $0.01 \mathrm{~mm}^{3}$, and (4) $>0.01 \mathrm{~mm}^{3}$. For each range of pore size, the $y$-axis plots the cumulative fraction of the pore space that had a water saturation less than or equal to the value indicated on the $x$-axis. Tables 4 and 5 summarize averages and standard deviations of the water saturation distributions for the first and second Berea cores.

For the first Berea core, Fig. 26 shows the distributions of water saturations at $S_{w r}$ before gelant placement. There were 1,736 pores in the total population, and the overall average water saturation was $24.7 \%$. For the smallest pores considered $\left(0.00001\right.$ to $\left.0.0001 \mathrm{~mm}^{3}\right), 608$ pores were present, representing $35 \%$ of the pores but only $4 \%$ of the total pore volume. For these pores, the average water saturation was $42.3 \% \pm 27.2 \%$. In strongly water-wet Berea sandstone, higher water saturations were expected in the smallest pores. One might have expected the water saturations for these smallest pores to be even higher than the observed values. 


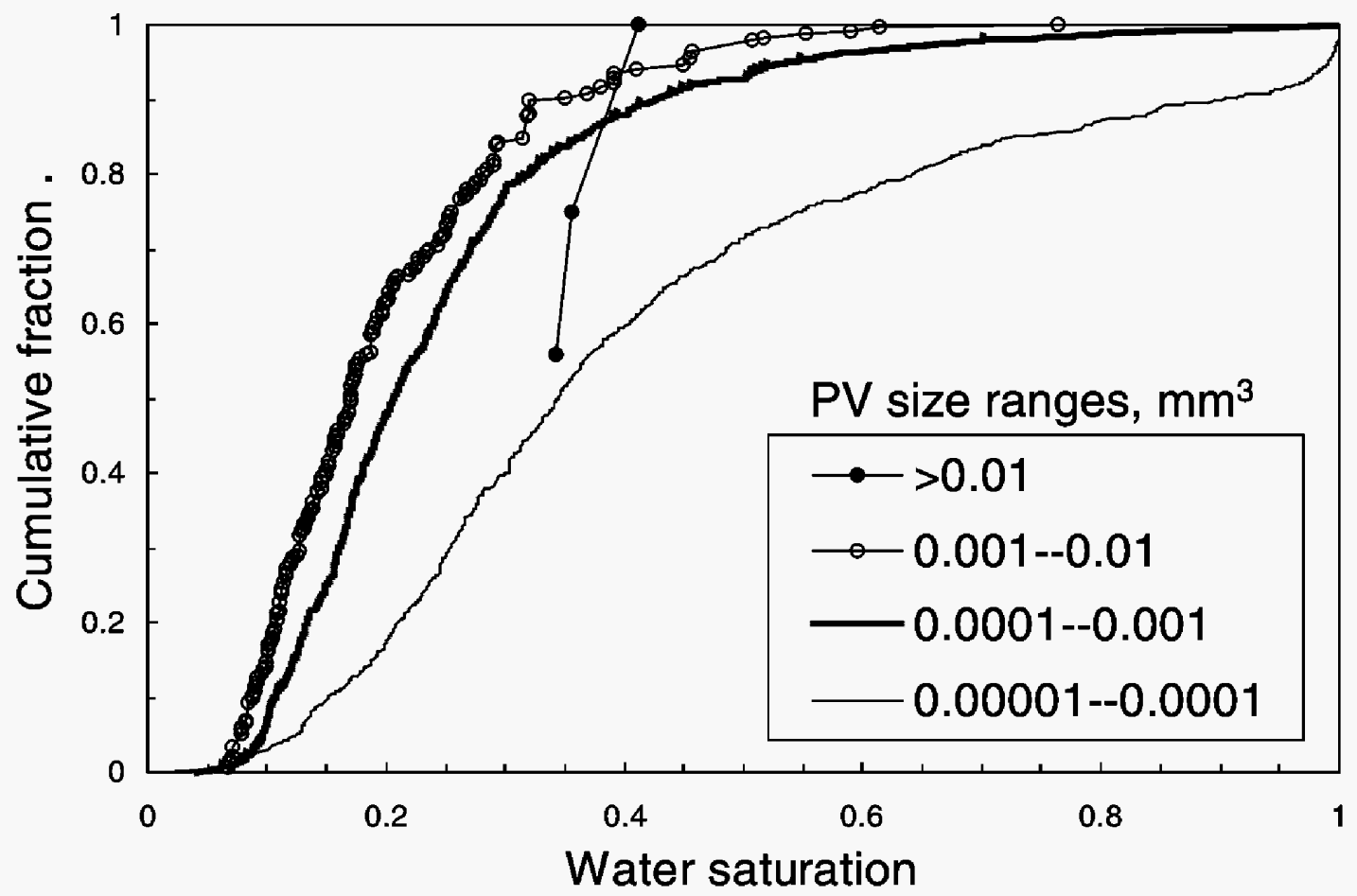

Fig. 26-Water saturation distributions at $S_{w r}$ before gel. $1^{\text {st }}$ Berea core.

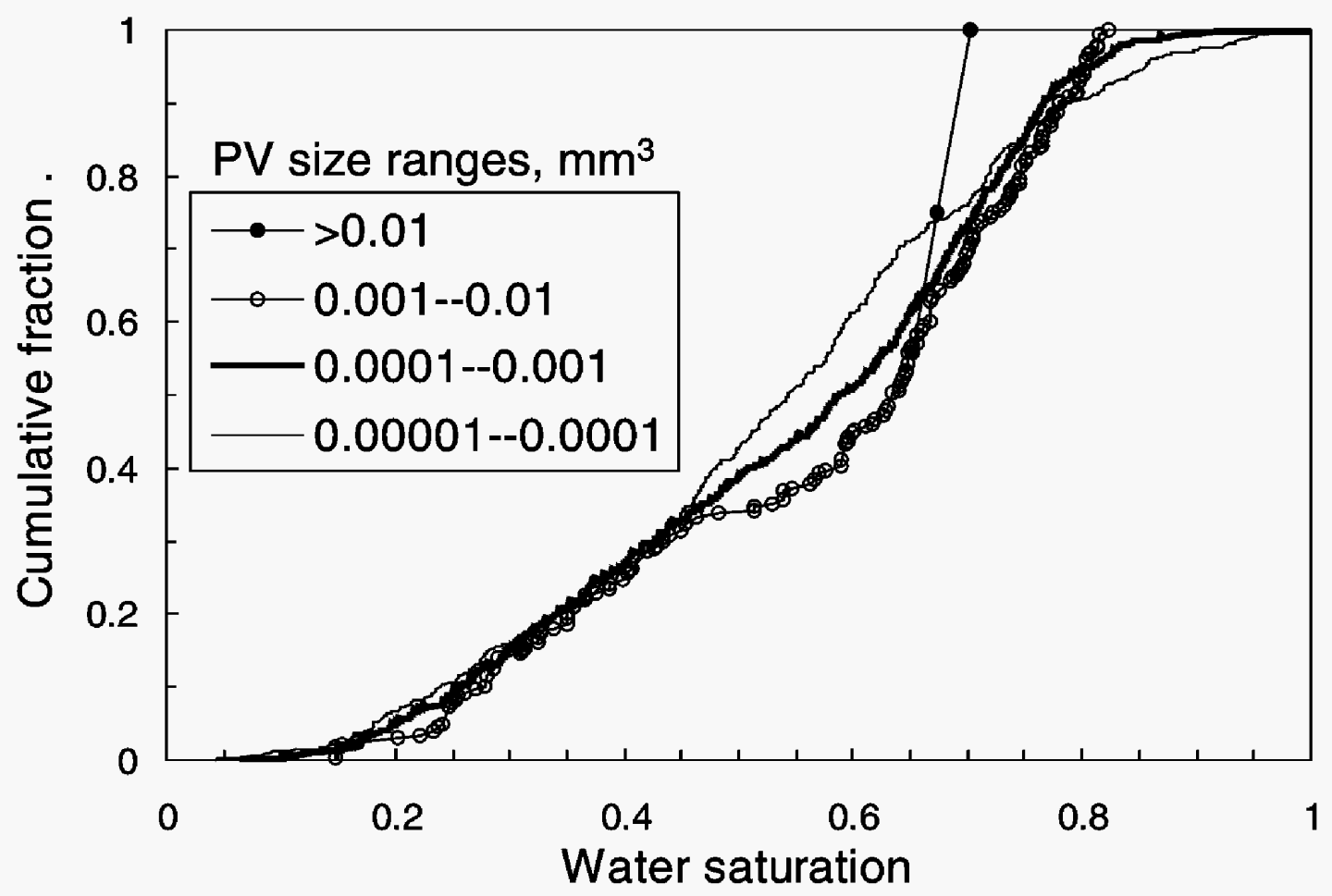

Fig. 27-Water saturation distributions at $S_{o r}$ before gel. $1^{\text {st }}$ Berea core. 


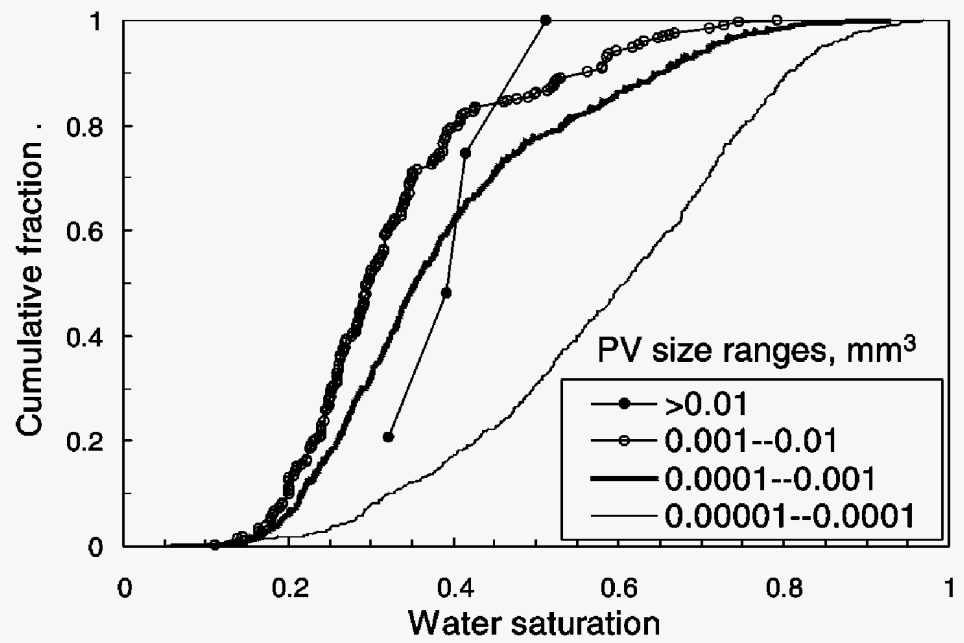

Fig. 28-Water saturation distributions at $1^{\text {st }} S_{w r}$ before gel. $2^{\text {nd }}$ Berea core.

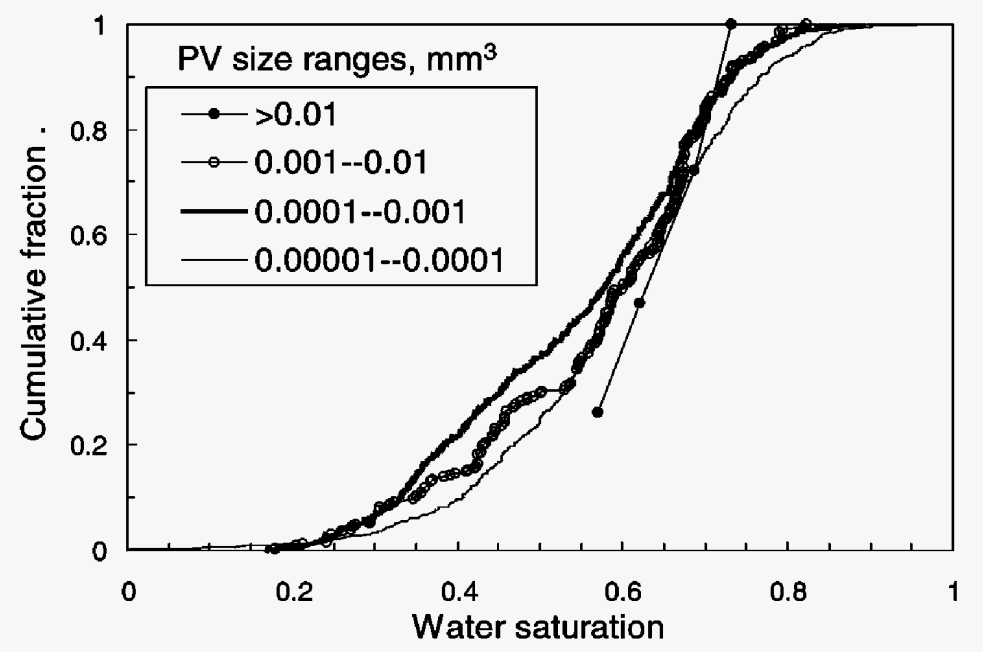

Fig. 29-Water saturation distributions at $S_{\text {or }}$ before gel. $2^{\text {nd }}$ Berea core.

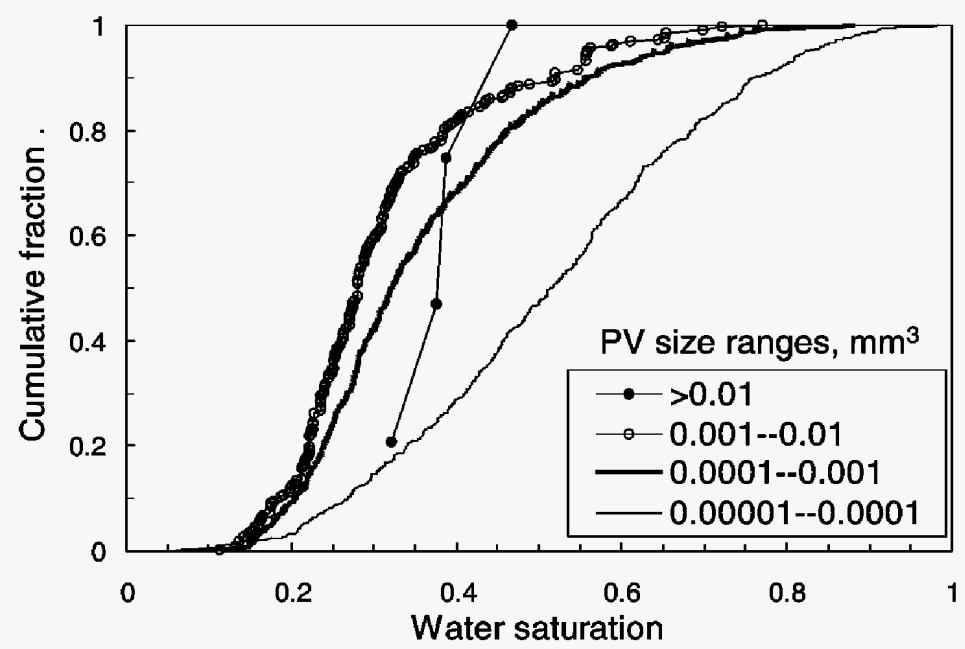

Fig. 30-Water saturation distributions at $2^{\text {nd }} S_{w r}$ before gel. $2^{\text {nd }}$ Berea core. 
Table 4-Properties for Various Pore Size Ranges for the $1^{\text {st }}$ Berea Core

\begin{tabular}{|l|c|c|c|c|}
\hline Pore size range & $>10^{-2} \mathrm{~mm}^{3}$ & $10^{-3}-10^{-2} \mathrm{~mm}^{3}$ & $10^{-4}-10^{-3} \mathrm{~mm}^{3}$ & $10^{-5}-10^{-4} \mathrm{~mm}^{3}$ \\
\hline Number of pores & 3 & 149 & 976 & 608 \\
\hline$\%$ of total pores & 0.2 & 8.6 & 56.2 & 35 \\
\hline$\%$ of total PV & 10 & 39 & 47 & 4 \\
\hline & \multicolumn{3}{|c|}{ Averages and Standard Deviations of $S_{w}$ Values } \\
\hline At $S_{w r}$ before gel & $36.2 \% \pm 3.7 \%$ & $20.2 \% \pm 11.9 \%$ & $24.4 \% \pm 16.6 \%$ & $42.3 \% \pm 27.2 \%$ \\
\hline At $S_{\text {or }}$ before gel & $66.8 \% \pm 2.5 \%$ & $56.8 \% \pm 19.3 \%$ & $54.5 \% \pm 19.1 \%$ & $53.2 \% \pm 21.1 \%$ \\
\hline After gel placement & $56.0 \% \pm 4.8 \%$ & $44.7 \% \pm 19.9 \%$ & $48.1 \% \pm 20.5 \%$ & $52.8 \% \pm 22.6 \%$ \\
\hline At $S_{w r}$ after gel & $39.1 \% \pm 3.6 \%$ & $24.1 \% \pm 14.2 \%$ & $29.6 \% \pm 19.1 \%$ & $45.5 \% \pm 24.4 \%$ \\
\hline At $S_{\text {or } \text { after gel }}$ & $35.4 \% \pm 2.4 \%$ & $21.3 \% \pm 11.3 \%$ & $18.6 \% \pm 13.0 \%$ & $17.6 \% \pm 20.6 \%$ \\
\hline
\end{tabular}

Table 5-Properties for Various Pore Size Ranges for the $2^{\text {nd }}$ Berea Core

\begin{tabular}{|l|c|c|c|c|}
\hline Pore size range & $>10^{-2} \mathrm{~mm}^{3}$ & $10^{-3}-10^{-2} \mathrm{~mm}^{3}$ & $10^{-4}-10^{-3} \mathrm{~mm}^{3}$ & $10^{-5}-10^{-4} \mathrm{~mm}^{3}$ \\
\hline Number of pores & 4 & 168 & 860 & 689 \\
\hline$\%$ of total pores & 0.2 & 9.8 & 50 & 40 \\
\hline$\%$ of total PV & 7 & 49 & 39 & 5 \\
\hline & \multicolumn{4}{|c|}{ Averages and Standard Deviations of $S_{w}$ Values } \\
\hline At $1^{\text {st }} S_{w r}$ before gel & $41.4 \% \pm 7.9 \%$ & $33.3 \% \pm 13.7 \%$ & $39.2 \% \pm 17.0 \%$ & $58.9 \% \pm 18.4 \%$ \\
\hline At $S_{o r}$ before gel & $65.5 \% \pm 7.1 \%$ & $57.1 \% \pm 14.8 \%$ & $54.7 \% \pm 15.5 \%$ & $59.1 \% \pm 16.0 \%$ \\
\hline At $2^{\text {nd }} S_{w r}$ before gel & $39.1 \% \pm 6.1 \%$ & $31.2 \% \pm 12.8 \%$ & $35.5 \% \pm 15.1 \%$ & $51.5 \% \pm 19.8 \%$ \\
\hline After gel placement & $45.4 \% \pm 7.3 \%$ & $42.4 \% \pm 9.2 \%$ & $39.1 \% \pm 15.3 \%$ & $30.8 \% \pm 20.8 \%$ \\
\hline At $S_{o r}$ after gel & $36.5 \% \pm 9.0 \%$ & $28.9 \% \pm 9.8 \%$ & $30.9 \% \pm 13.1 \%$ & $30.7 \% \pm 16.4 \%$ \\
\hline At $S_{w r}$ after gel & $27.4 \% \pm 3.1 \%$ & $20.9 \% \pm 9.1 \%$ & $20.3 \% \pm 10.8 \%$ & $23.7 \% \pm 17.5 \%$ \\
\hline
\end{tabular}

For pores with volumes between 0.0001 and $0.001 \mathrm{~mm}^{3}, 976$ pores were present, representing $56 \%$ of the pores and $47 \%$ of the volume. The average water saturation was $24.4 \% \pm 16.6 \%$. For pores with volumes between 0.001 and $0.01 \mathrm{~mm}^{3}, 149$ pores were present, representing <9\% of the pores and $39 \%$ of the volume. The average water saturation was $20.2 \% \pm 11.9 \%$. Fig. 26 shows similar distributions for pores with sizes ranging from 0.0001 to $0.01 \mathrm{~mm}^{3}$. This combined population accounted for $65 \%$ of the pores and $86 \%$ of the volume. Thus, these two curves (in Fig. 26) were most representative of the behavior at $S_{w r}$.

Only three pores had pore volumes greater than $0.01 \mathrm{~mm}^{3}$ (accounting for $10 \%$ of the volume). With this small population, it is not surprising that corresponding distribution curve differed somewhat from the other curves (Fig. 26).

For the first Berea core, Fig. 27 shows the distributions of water saturations at $S_{\text {or }}$ before gelant placement. The average $S_{o r}$ was $43.5 \%$-meaning that $S_{w r}$ averaged $56.5 \%$. For the three size ranges from 0.00001 to $0.01 \mathrm{~mm}^{3}$, the saturation distributions were quite similar, exhibiting $S_{w}$ standard deviations around $20 \%$ (Table 4). 
The behavior in the second Berea core was generally consistent with that observed in the first core (see Figs. 28-30 and Table 5). The image volume for the second core contained 1,721 pores with volumes greater than $10^{-5} \mathrm{~mm}^{3}$-compared to 1,736 pores imaged in the first core. Interestingly, for all pore size ranges, the water saturations at $S_{w r}$ were significantly higher in the second Berea core than in the first. We have no explanation for this difference. In contrast, the saturations at $S_{o r}$ were very similar for the two cores (compare Tables 4 and 5). A comparison of Figs. 28 and 30 and the entries in Table 5 confirms that very little hysteresis occurred between the first and second $S_{w r}$ conditions. Figs. 27 and 29 reveal that at $S_{o r}$, virtually all pores contained at least $20 \%$ oil and half the pores contained at least $45 \%$ oil. Assuming that spherical oil droplets were trapped in spherical pores and that the non-wetting saturation was proportional to the one-third power of droplet radius, these results indicate that virtually all pores (at $S_{o r}$ ) contained oil droplets with radii that were at least $60 \%$ of the pore radius. This result is quite believable since $70 \%$ of the pores had aspect ratios greater than 2. (And from Fig. 11, most pores with aspect ratios below 2 were very small.)

One feature of these XMT studies is that we can monitor the saturation differences for individual pores from one flooding stage to the next. Figs. 31-34 plot these changes in water saturation for individual pores during oil and water flooding before gel placement. In each figure, the solid line plots the average change in water saturation for a given pore size. These solid lines are related to Fig. 25. For example, the solid line in Fig. 31 shows the difference between the open-circle curve (i.e., $S_{o r}$ for the first Berea core) from the solid-circle curve (i.e., $S_{w r}$ for the first Berea core) in Fig. 25. Figs. 31-34 reveal that the average behavior results from a large variety of $S_{w}$ changes that occur in individual pores. Fig. 34 is particularly revealing in this regard. Recall that viewing average behavior (Figs. 25, 28, and 30 and Table 5) indicated that very little hysteresis occurred between the first and second $S_{w r}$ conditions in the second Berea core. Fig. 34 confirms that the saturation differences are certainly smaller than for other flooding transitions (i.e., Figs. 32 and 33). Nevertheless, significant pore-level saturation differences are evident-especially for the smaller pores (in Fig. 34).

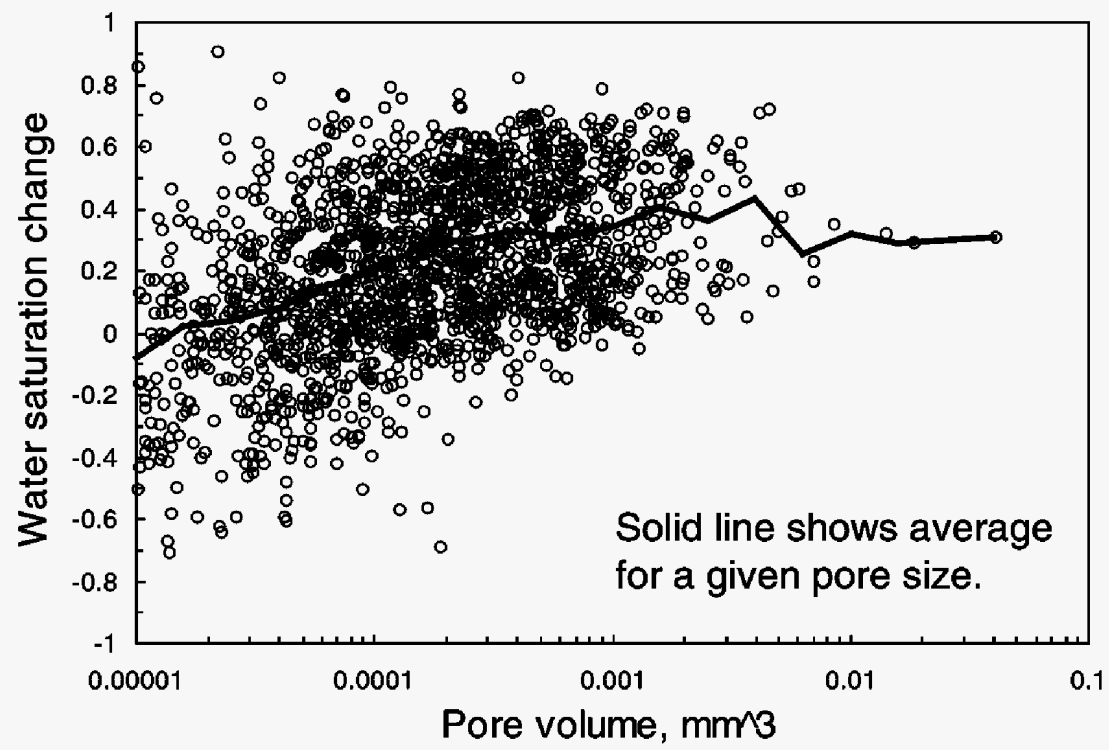

Fig. $31-S_{w}$ changes from $S_{w r}$ to $S_{o r}$ for individual pores in the first Berea core. 


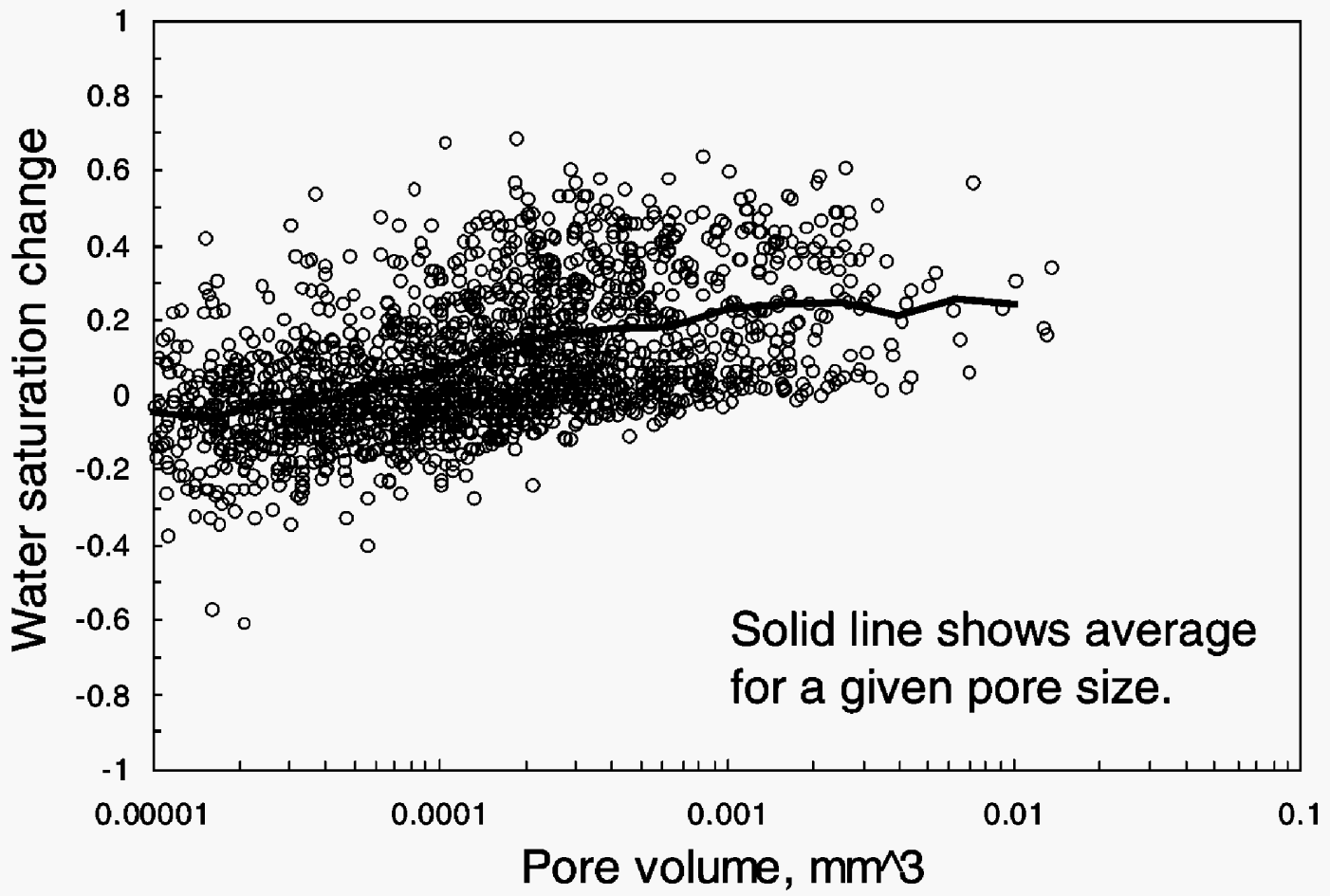

Fig. $32-S_{w}$ changes from $1^{\text {st }} S_{w r}$ to $S_{o r}$ for individual pores in the $2^{\text {nd }}$ Berea core.

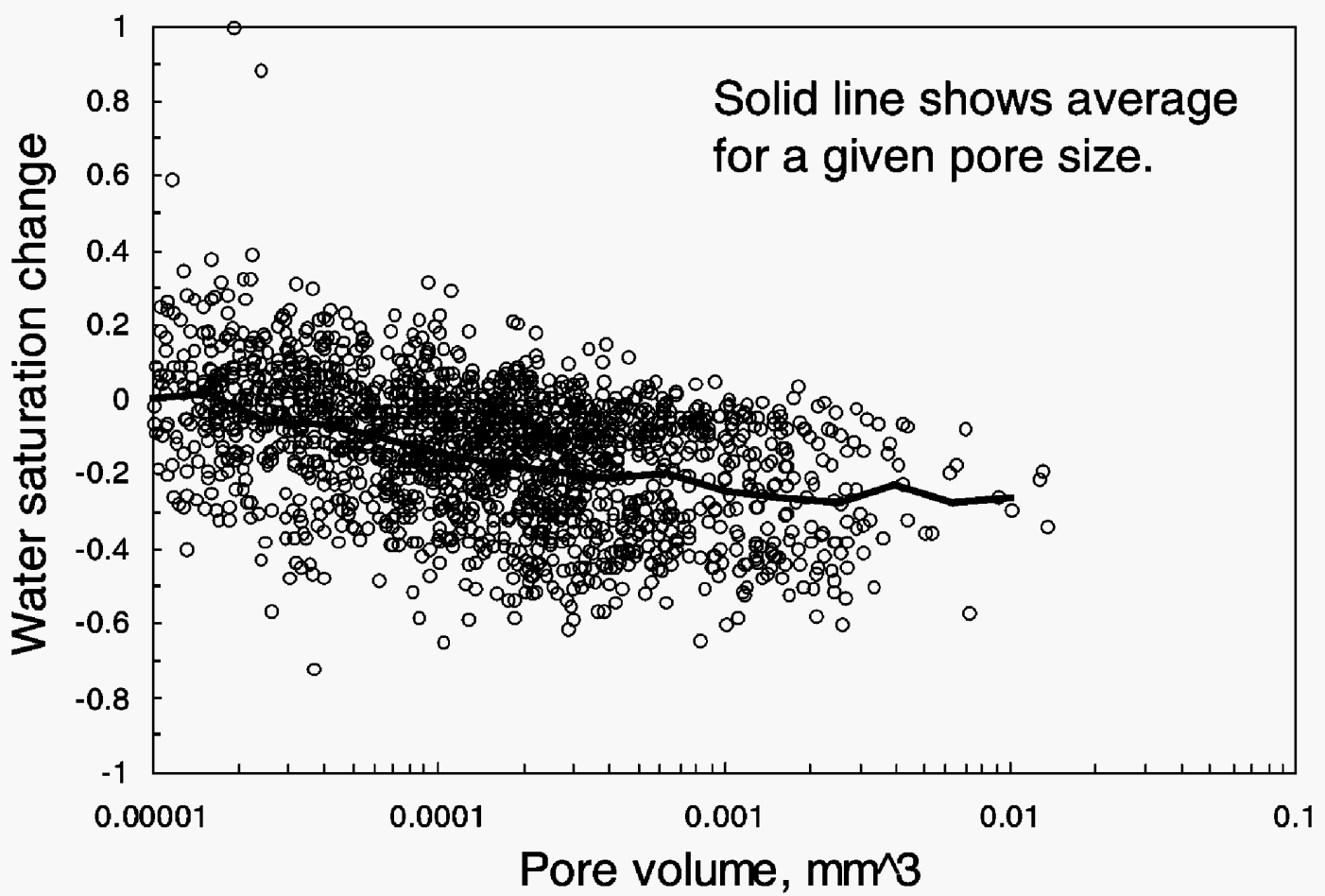

Fig. 33- $S_{w}$ changes from $S_{o r}$ to $2^{\text {nd }} S_{w r}$ for individual pores in the $2^{\text {nd }}$ Berea core. 


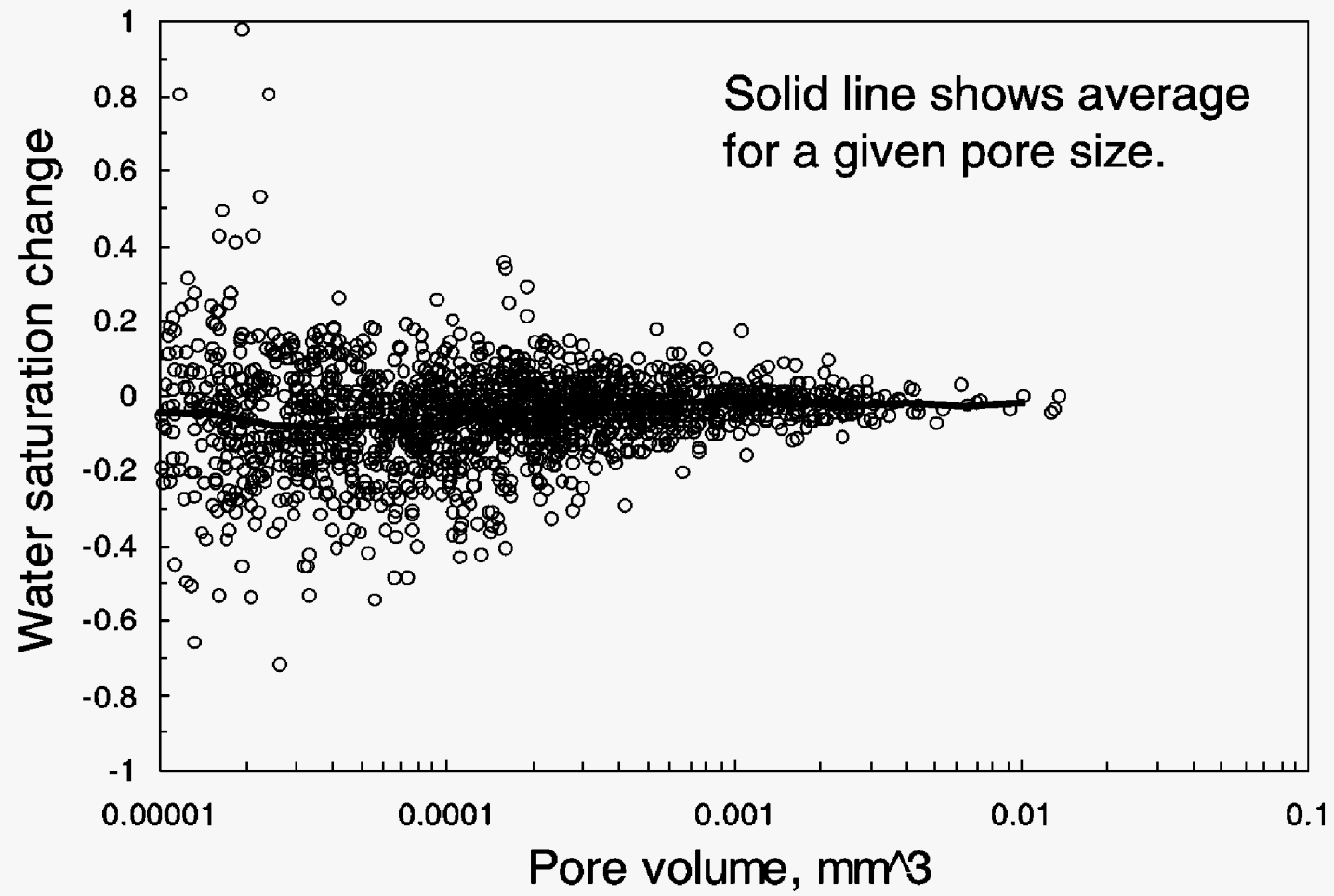

Fig. 34- $S_{w}$ changes from $1^{\text {st }} S_{w r}$ to $2^{\text {nd }} S_{w r}$ for individual pores in the $2^{\text {nd }}$ Berea core.

During Gelant Injection. After establishing a residual oil saturation in the first Berea core, the 20-cp $\mathrm{Cr}$ (III)-acetate-HPAM gelant (10 core pore volumes) was injected using a pressure gradient of $17 \mathrm{psi} / \mathrm{ft}$. After gel placement, the core was shut in for twelve hours $\left(\right.$ at $60^{\circ} \mathrm{C}$ ) and then scanned (at room temperature). The gelation time for this formulation was 1 to 1.5 hours at $60^{\circ} \mathrm{C}$.

A comparison of Figs. 15 and 16 suggests that fluid saturations changed somewhat during gelant injection. In particular, oil apparently was displaced from one of the larger pores. A detailed analysis of the three-dimensional images (open and solid circles in Fig. 35) confirmed that fluid saturations changed during gelant injection-specifically, average water saturations decreased slightly in the medium to large pores during gelant injection. Also, the overall average water saturation decreased from $56.5 \%$ to $47.7 \%$ (Table 2). On first consideration, these observations surprisingly suggest that oil was generated when gelant (containing no oil) was injected. However, the reader should recall that the imaged volume constituted only $10 \%$ of the total core volume. Conceivably, oil was displaced from upstream portions of the core during gelant injection, and this oil became trapped in the imaged volume by coincidence. Presumably, the overall oil content of the core either stayed the same or decreased slightly during gelant injection. Fig. 36 confirms that many individual pores experienced saturation changes during the process of gelant injection. 


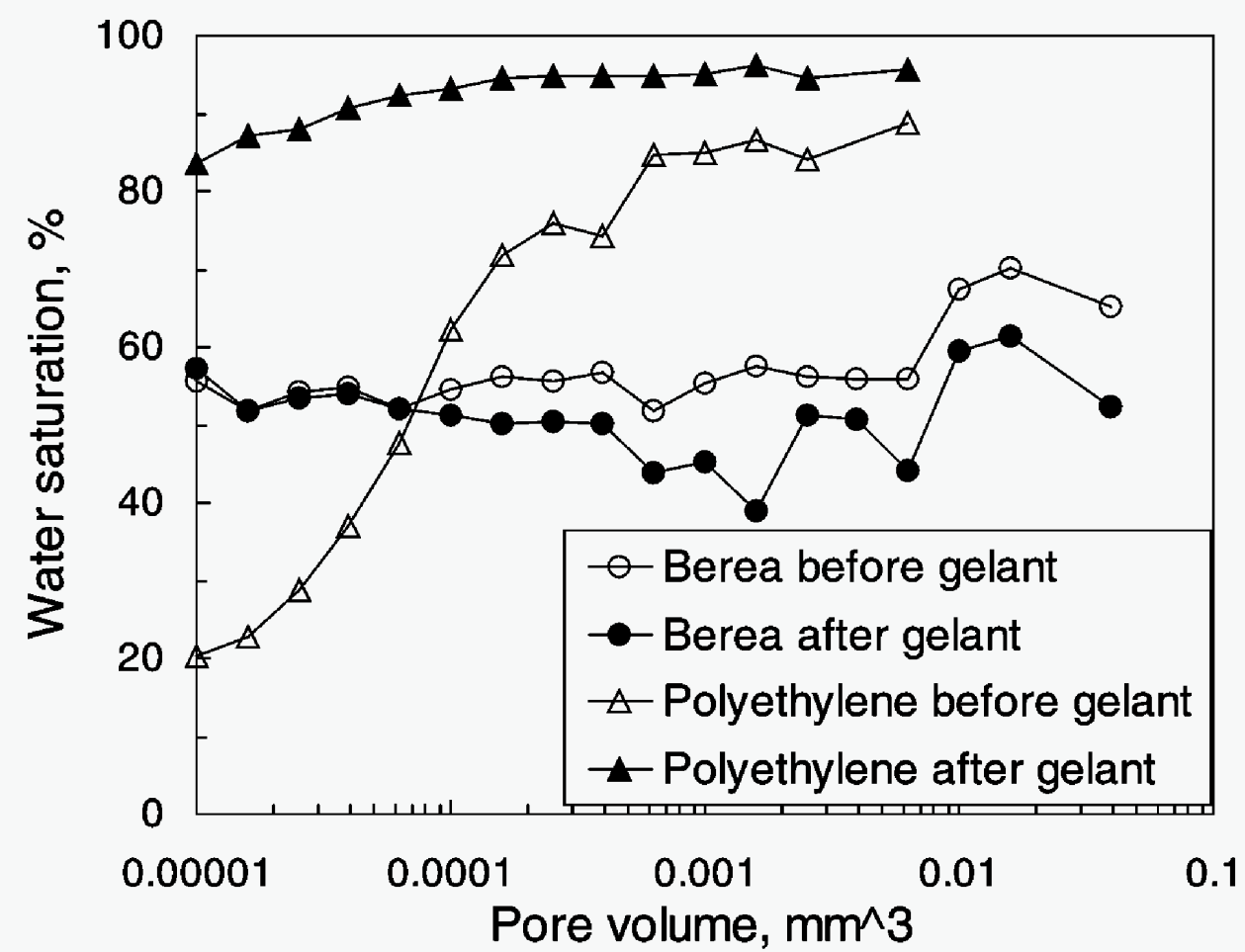

Fig. 35-Water saturations at $S_{o r}$ immediately before versus immediately after gel placement.

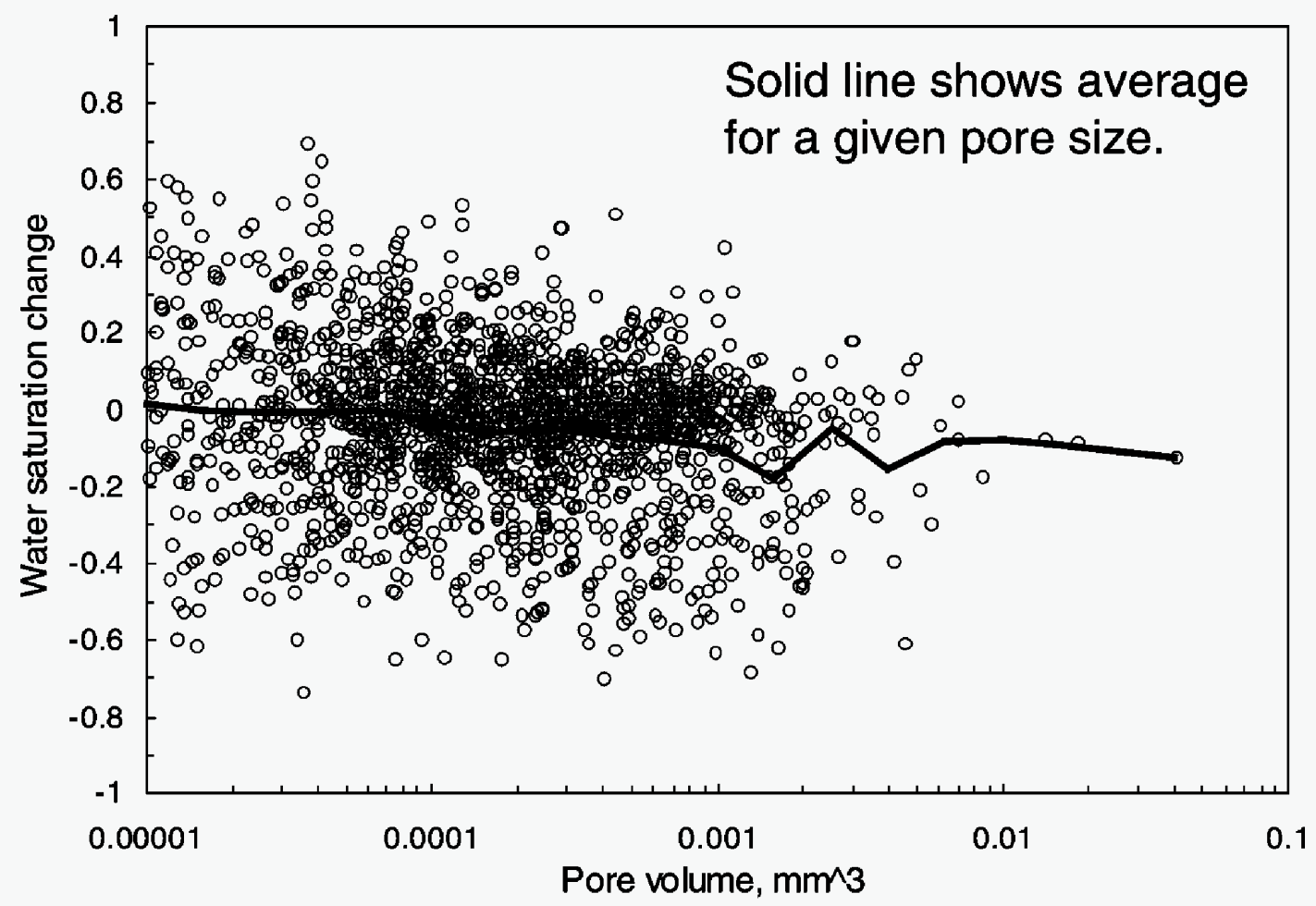

Fig. $36-S_{w}$ changes during gelant injection for individual pores in the $1^{\text {st }}$ Berea core. 
After Gel Placement. After gel placement, oil ( $\sim 20$ core pore volumes) was injected to measure the oil residual resistance factor, $F_{r r o}$-recording a value of 15 . This value means that at $S_{w r}$, the gel reduced the permeability to oil by a factor of 15 . The core was scanned after oil injection to visualize oil pathways after gel (Fig. 17). A comparison of Figs. 14 and 17 indicates that most of the pathways open to oil flow before gel placement remained accessible to oil after the gel treatment. This result suggests that the gel occupied only a small fraction of the pore space. Tracer results from a previous experiment in a high-permeability Berea core revealed that gel with an $F_{\text {rro }}$ value of 20 occupied less than $5 \%$ of the pore space. ${ }^{4}$

The solid symbols in Fig. 37 compare distributions of water saturations at $S_{w r}$ before versus after gel placement. The two distributions were remarkably similar, confirming that most of the pathways that were open to oil flow before gel placement were also open to oil flow after gel placement. As mentioned above, this suggestion is consistent with the relatively low oil residual resistance factor (i.e., 15). Since the gel was placed and formed at high water saturation in the core, the result also suggests either (1) gel did not form in all the aqueous pore space (i.e., gelation was incomplete) or (2) oil flooding after gel placement moved, concentrated, or destroyed much of the gel that formed in the oil pathways.

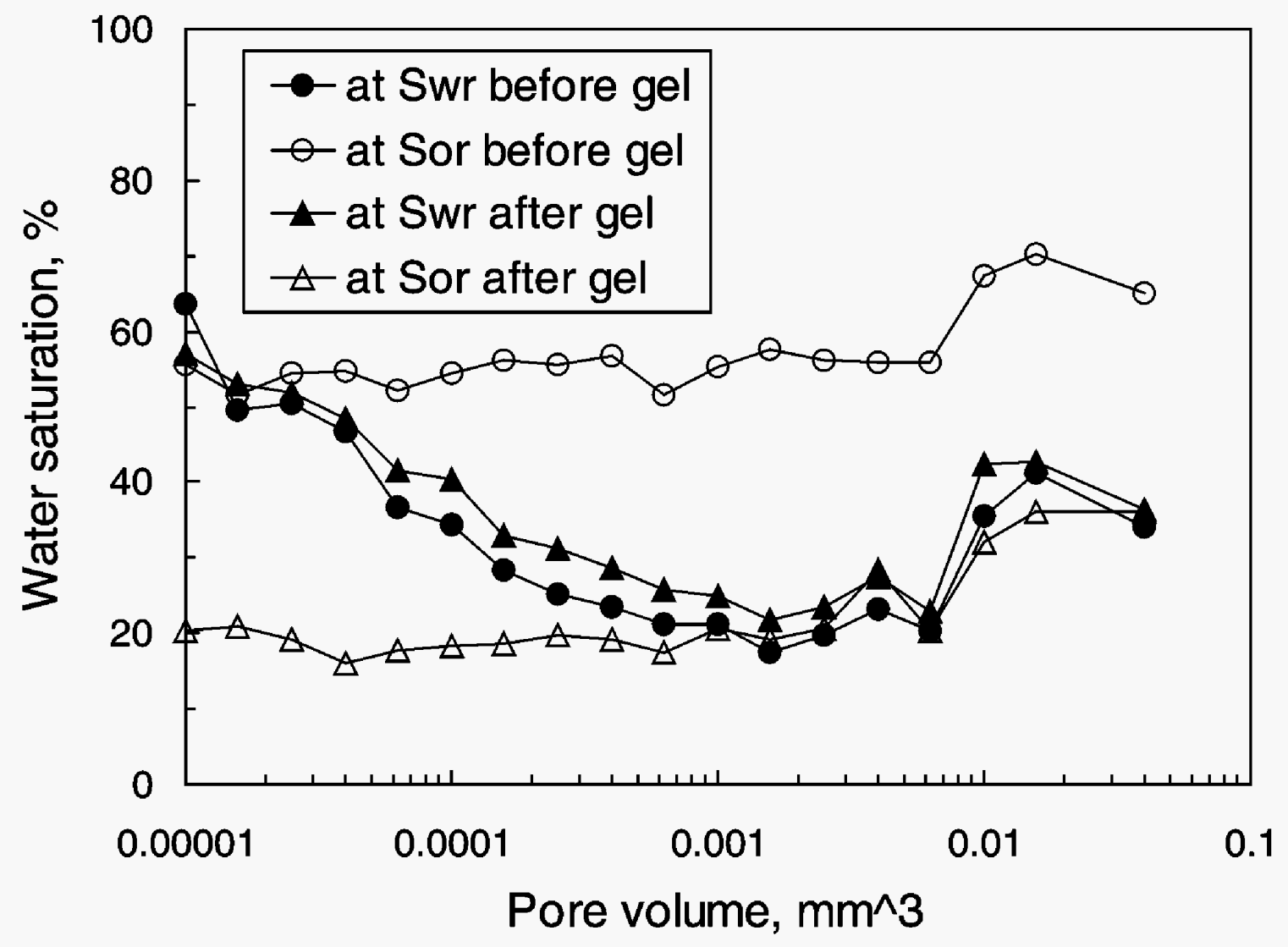

Fig. 37-Effect of gel on $S_{w r}$ and $S_{o r}$ in Berea sandstone. 
Finally, brine ( 2.5 core pore volumes) was injected to measure the water residual resistance factor, $F_{r r w}$. The $F_{r r w}$ value was 1,220 -meaning that at $S_{o r}$, the gel reduced the permeability to water by a factor of 1,220 . This gel reduced the permeability to water 81 times more than that to oil $\left(F_{r r m} / F_{r r o}=81\right)$. Fig. 18 shows the core scan after brine injection. A comparison of Figs. 14, 15, 17 , and 18 shows that water did not have access to most of the pathways that were open to oil flow after the gel treatment.

The open symbols in Fig. 37 compare distributions of water saturations at $S_{o r}$ before versus after gel placement. For reasons yet to be explained, water saturations in the smallest pores $(<0.0005$ $\mathrm{mm}^{3}$ ) at $S_{o r}$ after gel placement were less than those at $S_{w r}$. However, more importantly (because the total pore volume was dominated by the largest pores), the distribution of water saturations in the largest pores $\left(>0.001 \mathrm{~mm}^{3}\right)$ after gel placement during water flooding (open triangles) was similar to that during the previous oil floods (solid symbols in Figs. 25 and 37). Therefore, the gel treatment apparently trapped substantial additional volumes of oil during water flooding (i.e., much higher $S_{o r}$ values). Perhaps, this result occurred because gel was strategically positioned in pore throats to increase aspect ratios. With the larger pores permanently occupied by oil, water was forced to flow through narrow films, through the smallest pores, and through the gel itselfexplaining the large water residual resistance factor (i.e., 1,220). In contrast, oil pathways remained relatively free from constriction by the gel, so the oil residual resistance factor was much less (i.e., 15).

Saturation changes for individual pores during oil and water injection after gel placement are shown in Figs. 38 and 39. During oil injection after gel placement, a sizeable number of pores experienced very little saturation change (Fig. 38). Of course, many other pores gained in oil saturation. Very few pores gained significantly in water saturation. Fig. 38 appears quite similar to Fig. 33, which was associated with the transition from $S_{o r}$ to $S_{w r}$ before gel placement.

During water injection after gel placement (Fig. 39), many pores also experienced only small saturation changes. Many other pores experienced significant changes, with many gaining water while others gained in oil. The scatter in Fig. 39 suggests that a significant amount of saturation rearrangement occurred during water injection, but the overall saturation did not change greatly (i.e., the overall water saturation changed from $29.0 \%$ to $21.3 \%$, from Table 2).

Fig. 40 compares saturation differences for individual pores before versus after gel placement when the core was at $S_{w r}$. Consistent with our earlier observations, at $S_{w r}$, most pores appeared to have about the same saturation after gel placement as before gel placement. This observation was most noticeable for the medium to large pores and was less valid for the smallest pores (i.e., those smaller than $10^{-4} \mathrm{~mm}^{3}$.

Fig. 41 compares saturation differences for individual pores before versus after gel placement when the core was at $S_{o r}$. This figure confirms that most pores (of all sizes) contained significantly more oil at $S_{o r}$ after gel placement than before gel placement. Thus, during water injection, the gel appeared to inhibit water flow by increasing the trapped oil saturation in most pores. 


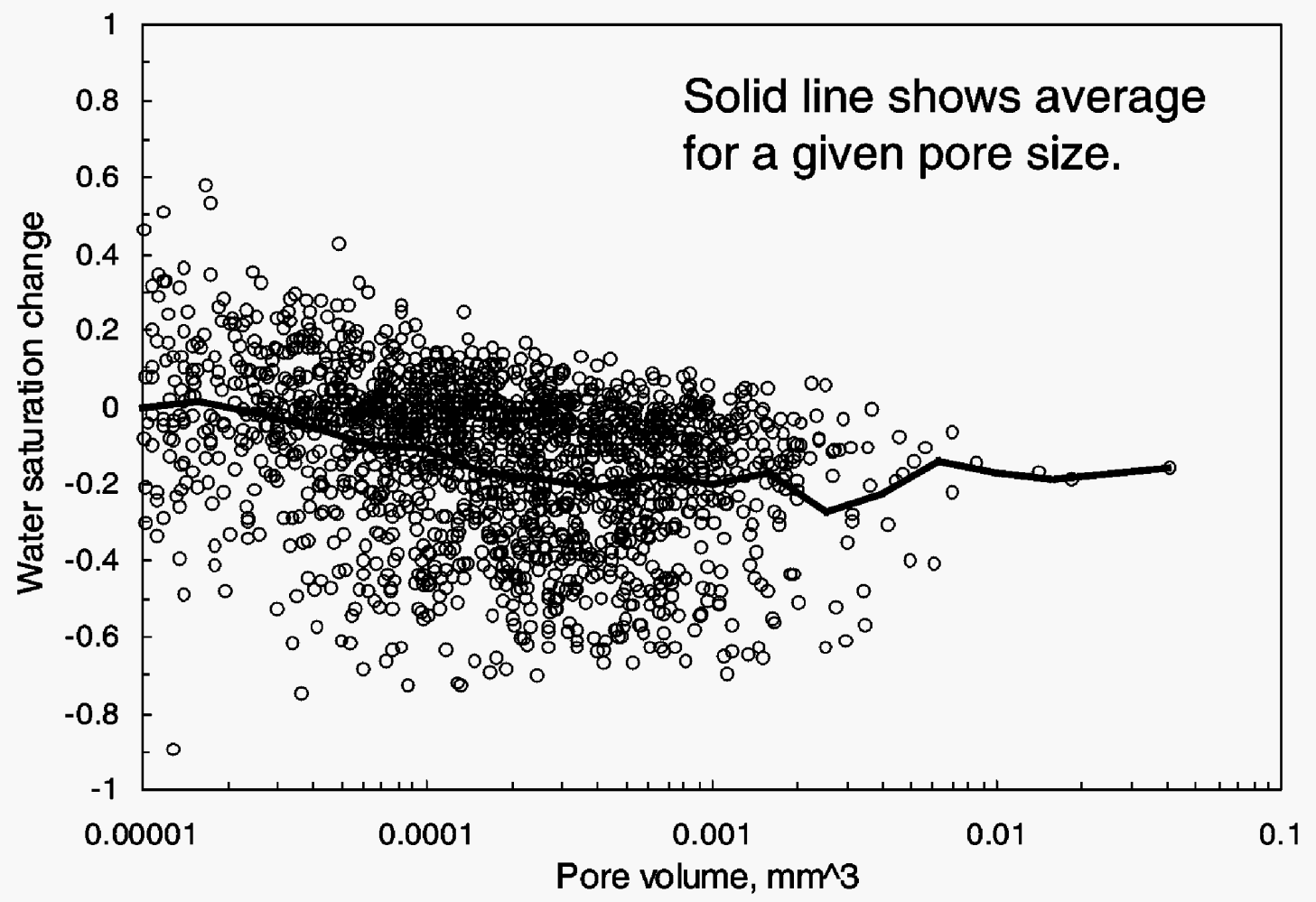

Fig. $38-S_{w}$ changes for individual pores in Berea during oil injection after gelation.

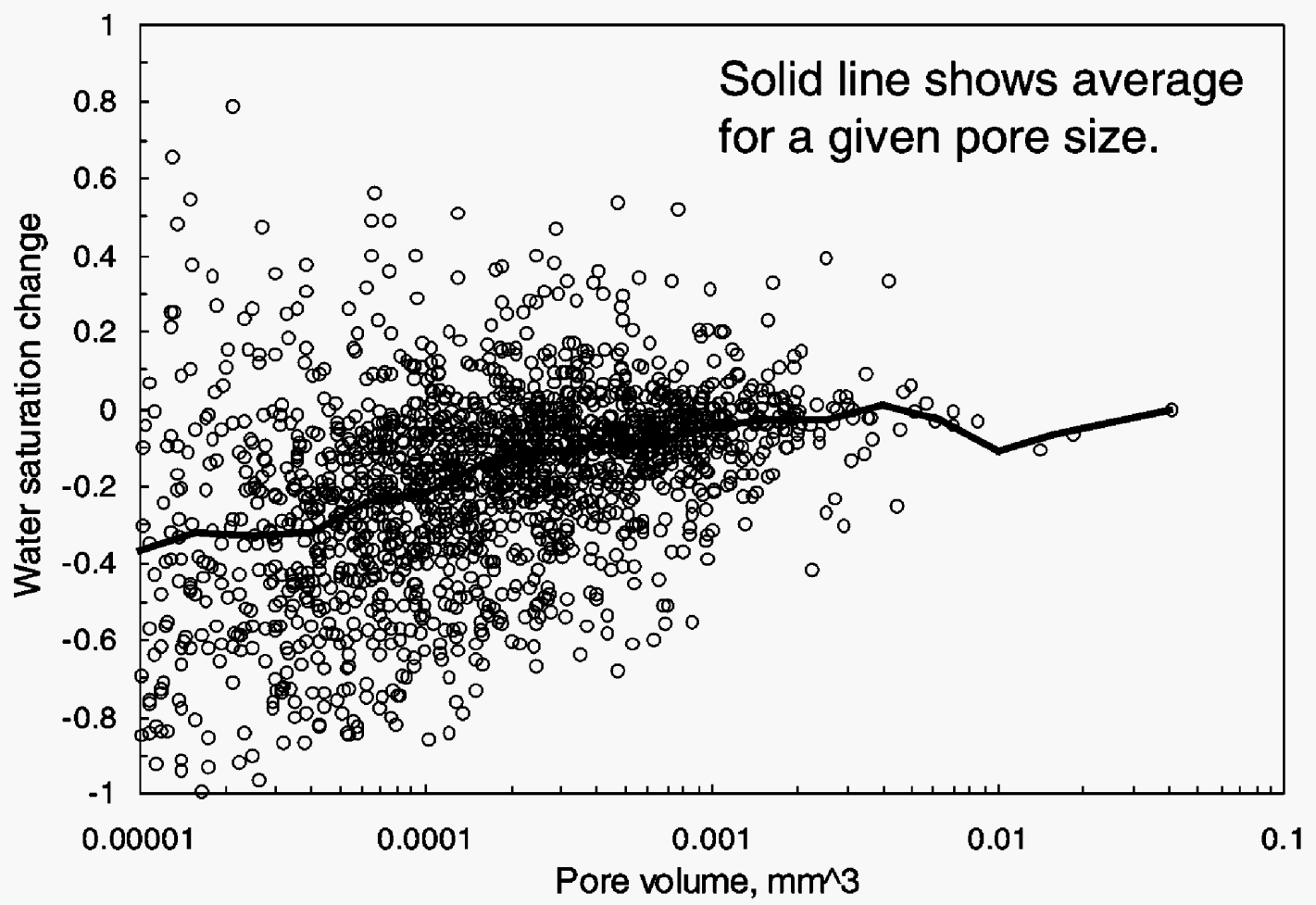

Fig. $39-S_{w}$ changes for individual pores in Berea during water injection after gelation. 


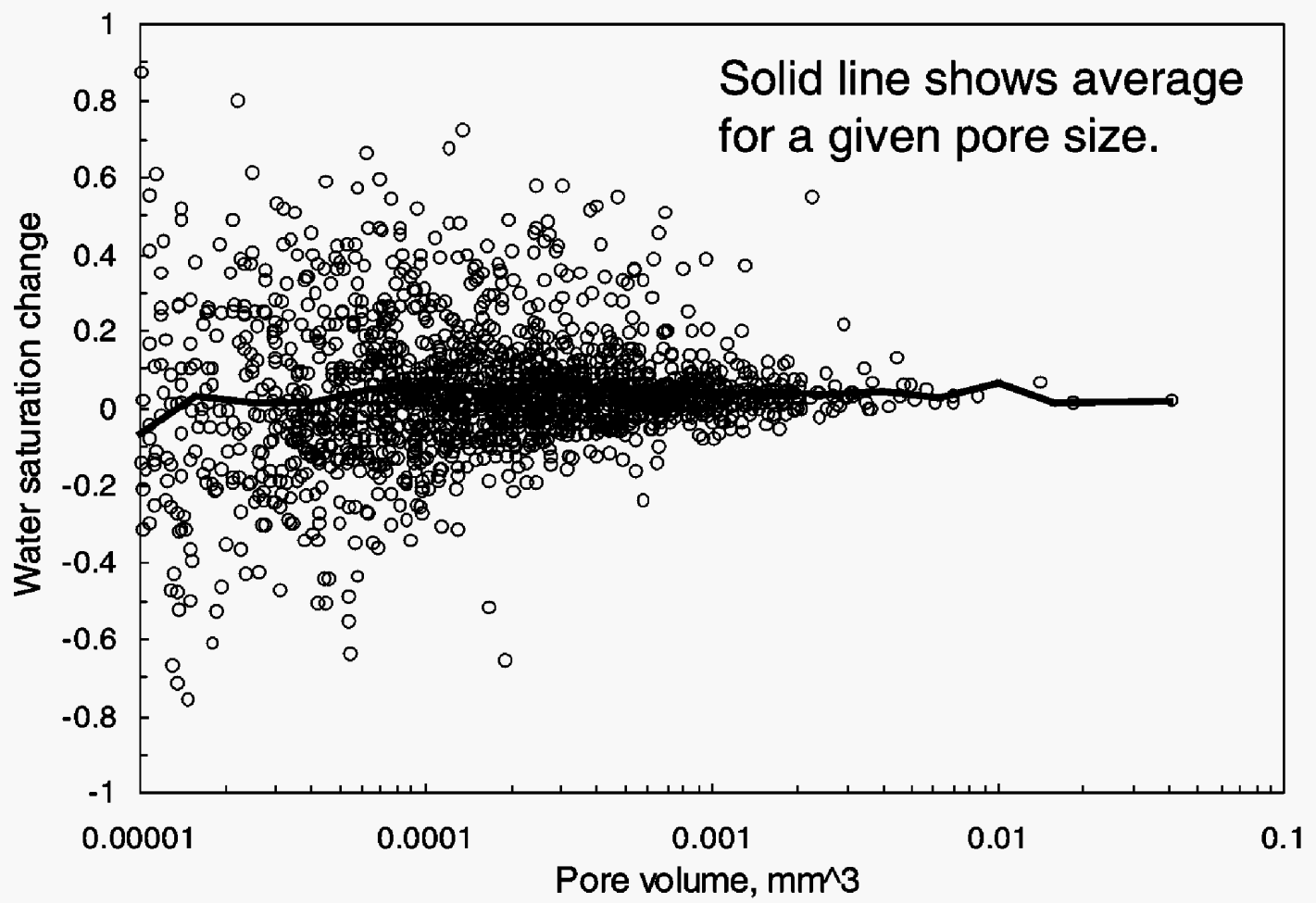

Fig. $40-S_{w}$ differences for individual pores in Berea at $S_{w r}$ before versus after gel placement.

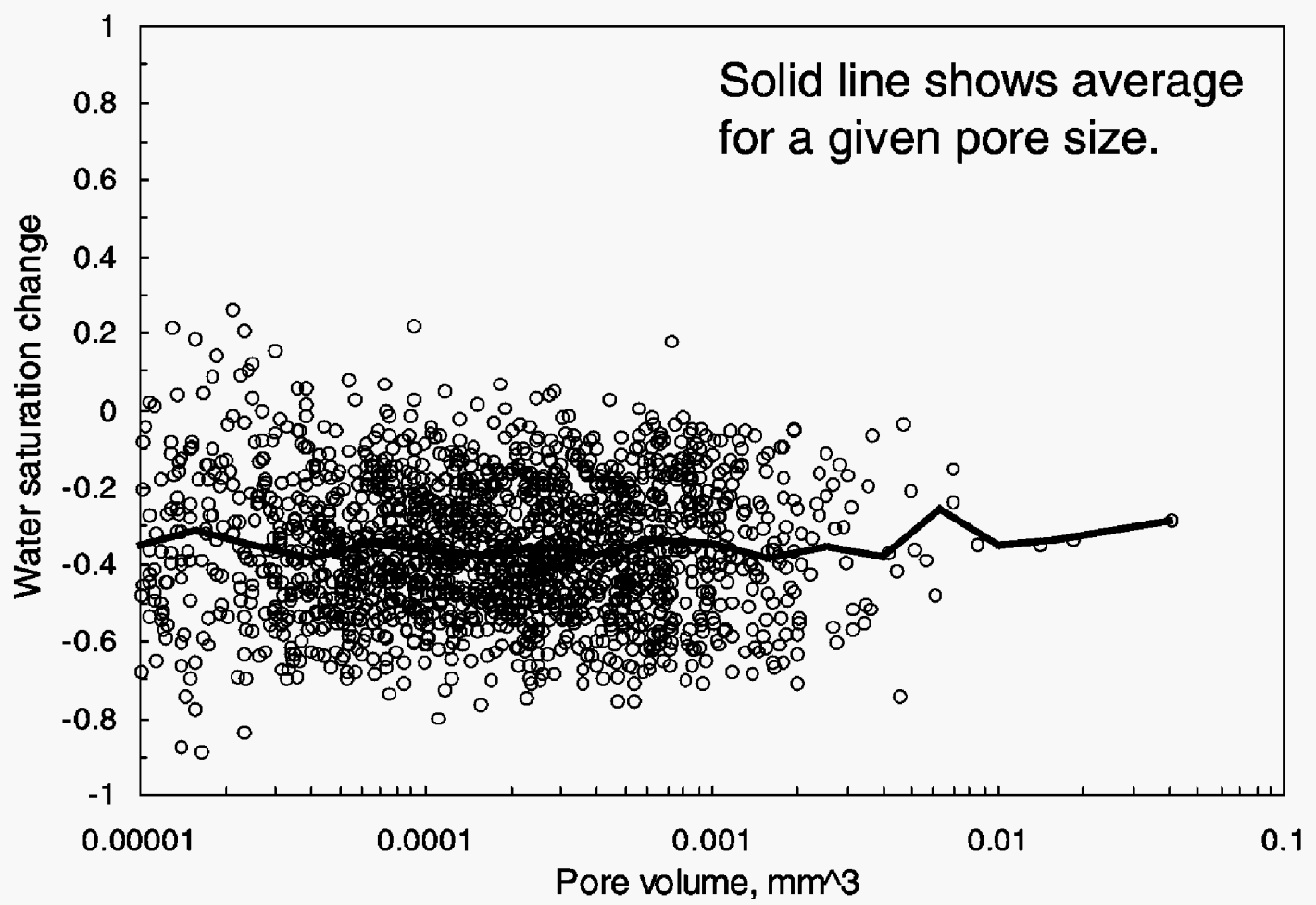

Fig. $41-S_{w}$ differences for individual pores in Berea at $S_{o r}$ before versus after gel placement. 


\section{Polyethylene Image Analyses}

Before Gelant Injection. In the polyethylene core, the first scan viewed the core with $100 \%$ oil saturation (Fig. 2). Second, the core was water flooded ( 70 core pore volumes) and scanned at residual oil saturation (Fig. 19). Water invaded most pores while the residual oil appeared dominantly in small pores and films between water and the polyethylene. The oil films were less evident than the water films in Berea (compare Figs. 14 and 19); however, careful examination reveals that the oil films were present on the polyethylene. In reality, the liquid films should be much thinner than we can resolve with the XMT method. The appearance that water films on Berea sandstone were thicker than oil films on polyethylene may be caused by the greater surface roughness in Berea (compare Figs. 5 to 7). Greater surface roughness creates folds of the film and fluid accumulations in nooks and crannies. Although the actual film thickness may be only a few tens of nanometers at a given point, the film folds and small fluid accumulations are interpreted to be much wider using our imaging technique (because the resolution is limited to the micrometer scale).

Third, oil ( $\sim 35$ core pore volumes) was injected to drive the core to residual water saturation (Fig. 20). Residual water was noted in pores with a wide range of sizes. Also, water often appeared at the polyethylene interface-suggesting either very thin oil films or partial water wetting of the plastic.

Water ( $\sim 70$ core pore volumes) was again injected to establish $S_{\text {or }}$ (Fig. 21). The similarity of Figs. 19 and 21 indicates little hysteresis during the cycle of water and oil injection. The similarity of water saturations $(77.7 \%$ versus $75.0 \%)$ and relative permeabilities $(0.50$ versus 0.49 ) for the two water floods at $S_{\text {or }}$ supports this suggestion (Tables 2 and 3). Fig. 42 provides additional support. This figure plots water saturations as a function of pore size before gelant injection. The solid circles show the distribution of water saturations at $S_{w r}$ before gel placement. The open circles and triangles show the two distributions at $S_{o r}$. The similarity of the two distributions at $S_{o r}$ confirms that hysteresis was not significant.

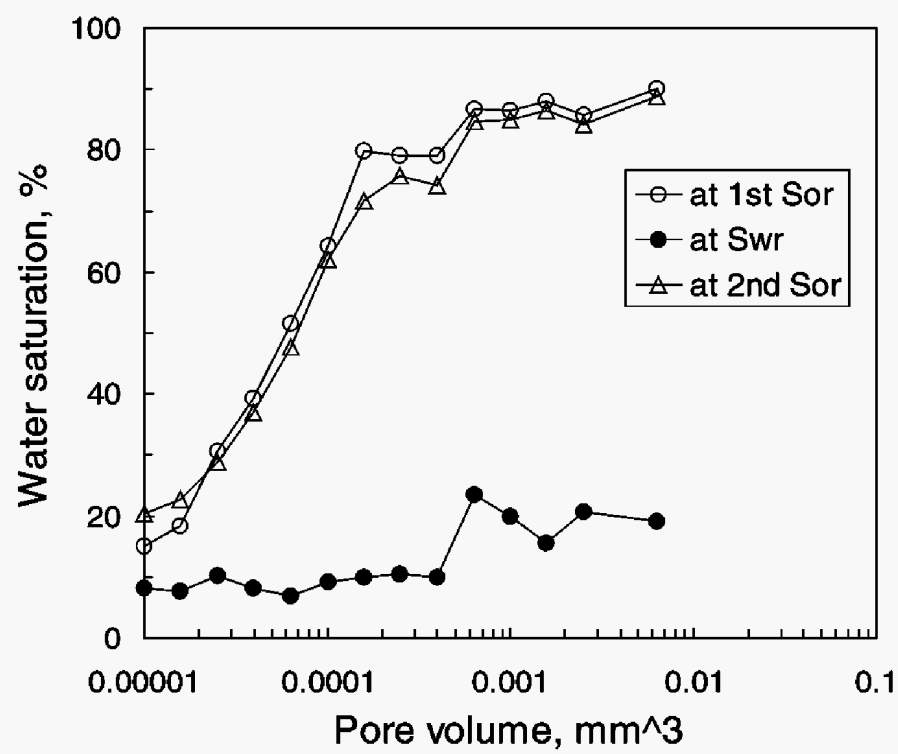

Fig. 42-Water saturations at $S_{w r}$ and $S_{o r}$ before gel placement in the polyethylene core. 
A comparison of Figs. 25 and 42 reveals significant differences in the saturation distributions for Berea versus polyethylene. Most notably, the intermediate-to-large pores exhibited a substantially greater saturation difference between $S_{w r}$ and $S_{o r}$ for polyethylene $(\sim 15 \%$ versus $\sim 85 \%)$ than for Berea $(\sim 30 \%$ versus $\sim 60 \%)$. For the smallest pores in both porous media, the distributions at $S_{w r}$ converged with those at $S_{o r}$. However, the water saturation for this convergence occurred at a significantly lower value for polyethylene (10\%-20\%) than for Berea (50\%-60\%). For polyethylene, the average water saturation at $S_{w r}$ was nearly independent of pore size. However, in Berea, the average water saturation at $S_{\text {or }}$ was nearly independent of pore size. For polyethylene at $S_{o r}$, the water saturation increased significantly with increased pore size. In contrast, for Berea at $S_{w r}$, the water saturation decreased significantly with increased pore size. Presumably, these differences reflect the preference for water to occupy the smallest pores in water-wet Berea and not to occupy the smallest pores in the oil-wet polyethylene (i.e., because the ratio of surface area to volume increased with decreased pore size).

For the polyethylene core, Fig. 43 shows the distributions of water saturations at $S_{o r}$ before gelant placement. Table 6 summarizes averages and standard deviations of the water saturation distributions. There were 386 pores in the total population, and the overall average water saturation was $77.7 \%$. For the smallest pores considered $\left(0.00001\right.$ to $\left.0.0001 \mathrm{~mm}^{3}\right)$, 193 pores were present, representing $50 \%$ of the pores but only $6 \%$ of the total pore volume. For these pores, the average water saturation was $31.2 \% \pm 30.4 \%$. In strongly oil-wet polyethylene, low water saturations were expected in the smallest pores. One might have expected the water saturations for these smallest pores to be even lower than the observed values.

Table 6-Properties for Various Pore Size Ranges for the Polyethylene Core

\begin{tabular}{|l|c|c|c|}
\hline Pore size range & $10^{-3}-10^{-2} \mathrm{~mm}^{3}$ & $10^{-4}-10^{-3} \mathrm{~mm}^{3}$ & $10^{-5}-10^{-4} \mathrm{~mm}^{3}$ \\
\hline Number of pores & 30 & 163 & 193 \\
\hline$\%$ of total pores & 7.8 & 42.2 & 50 \\
\hline$\%$ of total PV & 55 & 39 & 6 \\
\hline & \multicolumn{3}{|c|}{ Averages and Standard Deviations of $S_{w}$ Values } \\
\hline At $1^{\text {st }} S_{\text {or }}$ before gel & $86.5 \% \pm 5.1 \%$ & $74.4 \% \pm 30.3 \%$ & $31.2 \% \pm 30.4 \%$ \\
\hline At $S_{w r}$ before gel & $20.6 \% \pm 20.3 \%$ & $9.7 \% \pm 10.8 \%$ & $8.5 \% \pm 10.2 \%$ \\
\hline At $2^{\text {nd }} S_{o r}$ before gel & $84.8 \% \pm 4.9 \%$ & $69.8 \% \pm 25.9 \%$ & $30.9 \% \pm 25.4 \%$ \\
\hline After gel placement & $95.4 \% \pm 1.3 \%$ & $94.3 \% \pm 18.3 \%$ & $88.5 \% \pm 12.8 \%$ \\
\hline At $S_{w r}$ after gel & $83.5 \% \pm 4.5 \%$ & $71.5 \% \pm 27.6 \%$ & $41.1 \% \pm 26.5 \%$ \\
\hline At $S_{o r}$ after gel & $93.4 \% \pm 2.4 \%$ & $92.1 \% \pm 19.9 \%$ & $86.7 \% \pm 12.9 \%$ \\
\hline
\end{tabular}

For pores with volumes between 0.0001 and $0.001 \mathrm{~mm}^{3}, 163$ pores were present, representing $42.2 \%$ of the pores and $39 \%$ of the volume. The average water saturation was $74.4 \% \pm 30.3 \%$. For pores with volumes between 0.001 and $0.01 \mathrm{~mm}^{3}, 30$ pores were present, representing $<8 \%$ of the pores and $55 \%$ of the volume. The average water saturation was $86.5 \% \pm 5.1 \%$. Fig. 43 shows similar distributions for pores with sizes ranging from 0.0001 to $0.01 \mathrm{~mm}^{3}$. This combined population accounted for $50 \%$ of the pores and $94 \%$ of the volume. Thus, these two curves (in 
Fig. 43) were most representative of the behavior at $S_{o r}$ Even so, the curves show a distinct shift as the pore size changes.

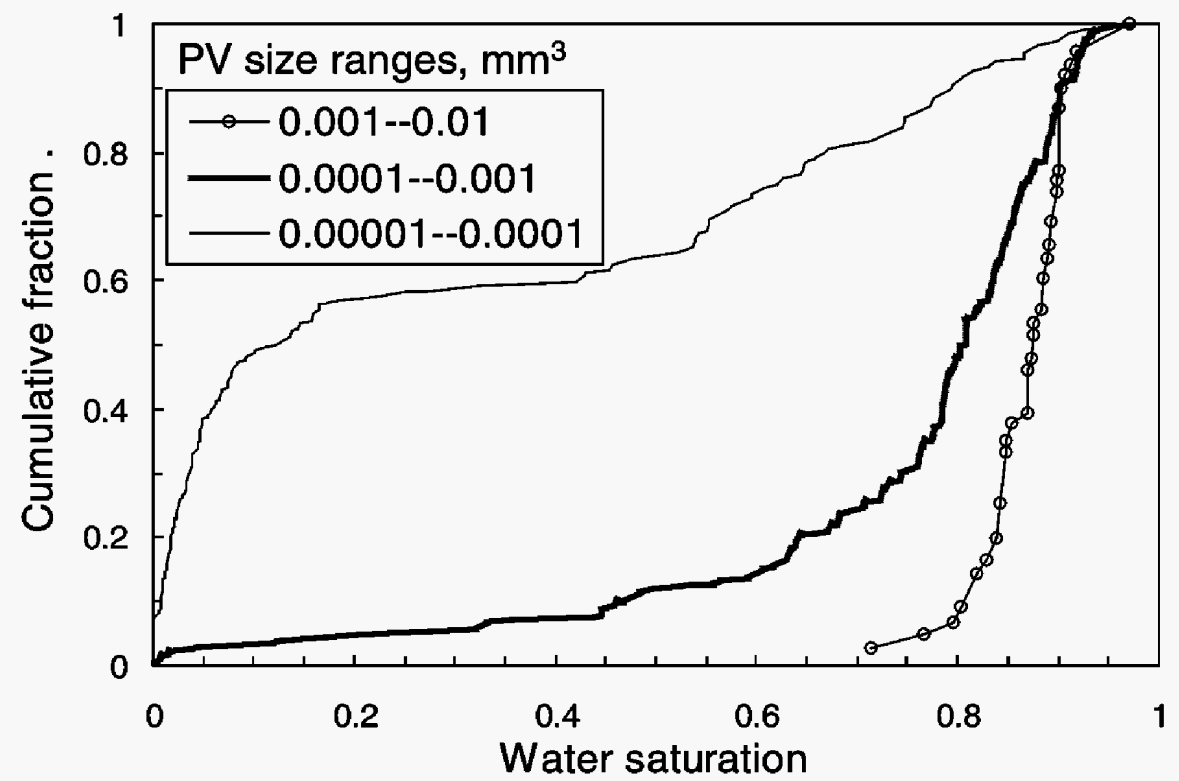

Fig. 43-Water saturation distributions at first $S_{o r}$ before gel. Polyethylene core.

For the polyethylene core, Fig. 44 shows distributions of water saturations at $S_{w r}$ before gelant placement. Overall, $S_{w r}$ averaged $15.2 \%$ (Table 2). For the size ranges from 0.00001 to 0.001 $\mathrm{mm}^{3}$, the saturation distributions were similar, exhibiting $S_{w r}$ standard deviations around $9 \%$ (Table 6). For the largest pores, the distribution showed greater differences from the other two.

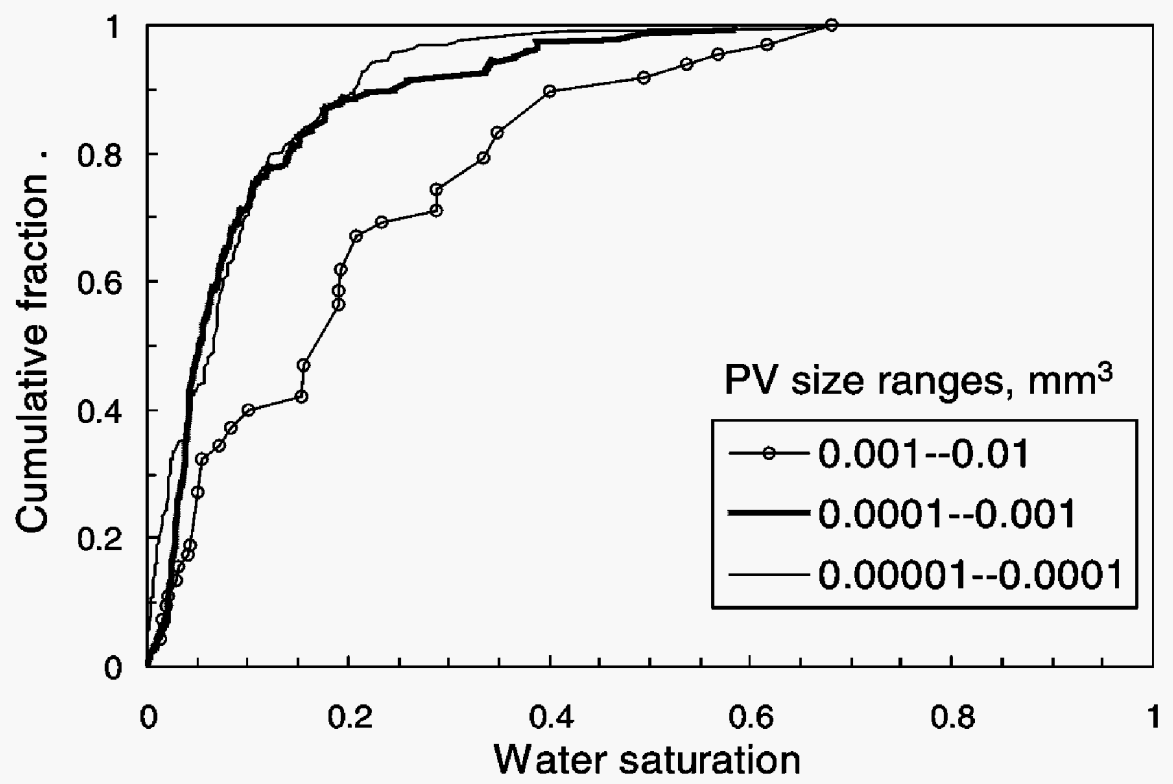

Fig. 44-Water saturation distributions at $S_{w r}$ before gel. Polyethylene core. 
A comparison of Figs. 43 and 45 and the entries in Table 6 confirms that very little hysteresis occurred between the first and second $S_{\text {or }}$ conditions (although some differences are noted for the distributions associated with smallest pores).

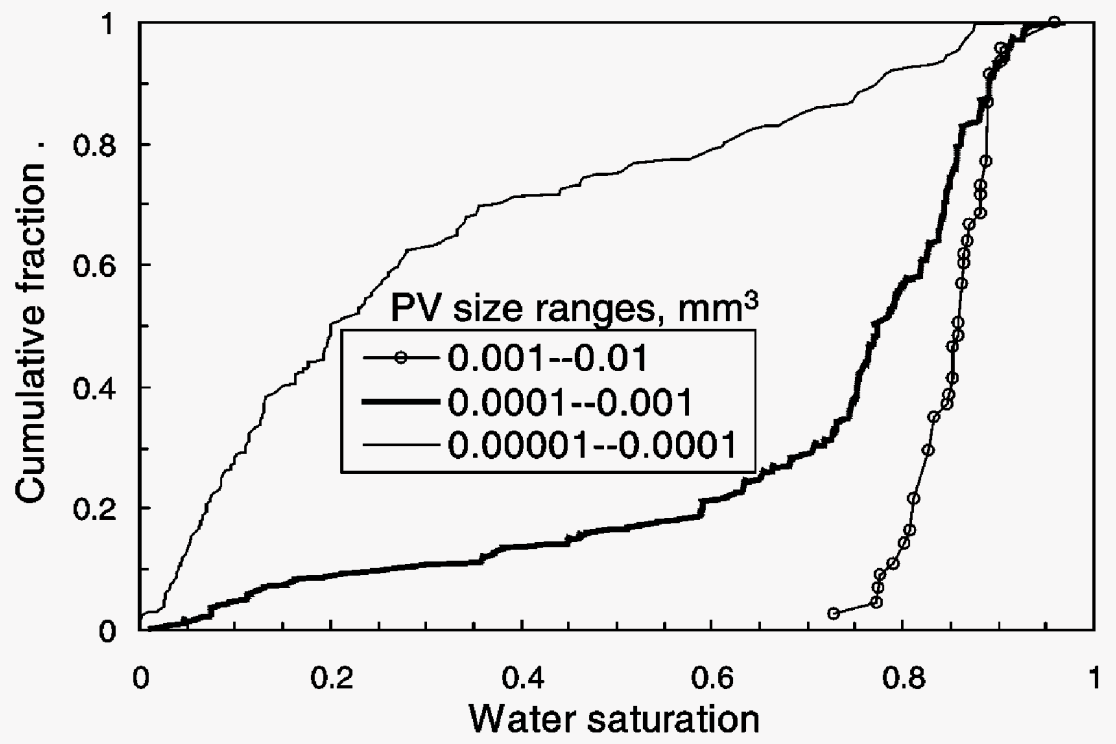

Fig. 45-Water saturation distributions at second $S_{\text {or }}$ before gel. Polyethylene core.

Figs. 46-48 plot changes in water saturation for individual pores during oil and water flooding before gel placement. Figs. 46 and 47 show that changes in water saturation were small for pores smaller than $10^{-4} \mathrm{~mm}^{3}$. In larger pores, large saturation changes were noted, but they did not depend strongly on pore size. Fig. 48 confirms that little hysteresis occurred between the first and second $S_{o r}$ conditions (except perhaps in the smallest pores).

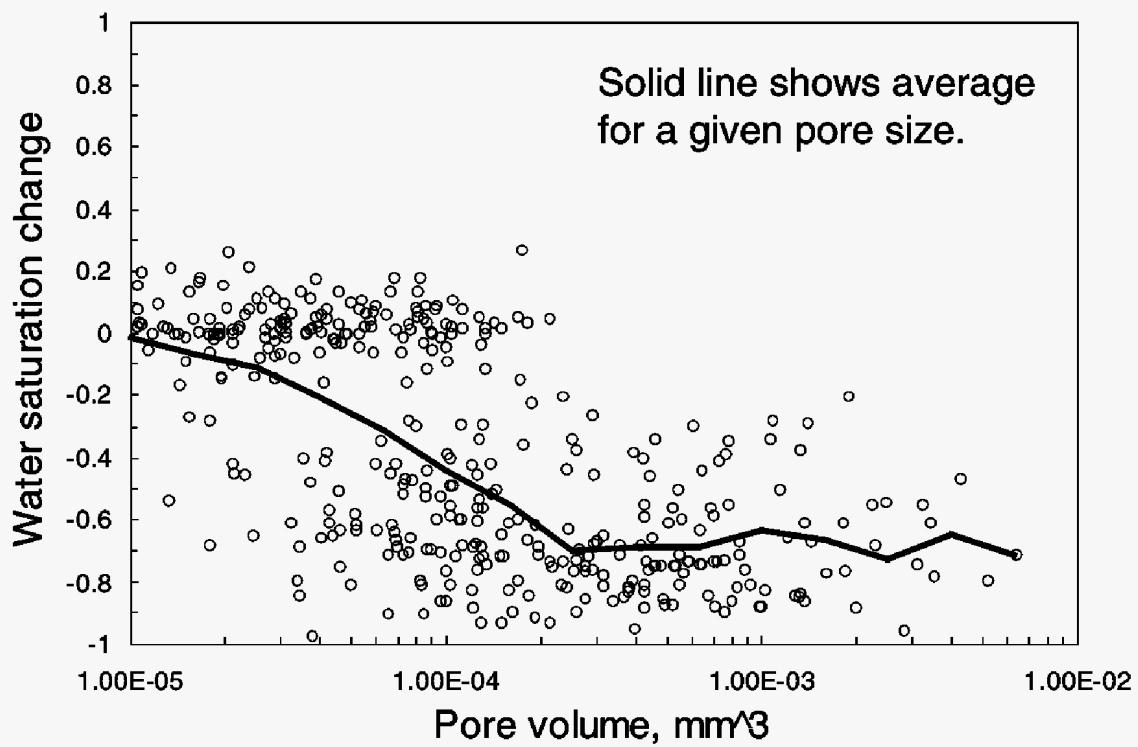

Fig. 46- $S_{w}$ changes from the $1^{\text {st }} S_{o r}$ to $S_{w r}$ for individual pores in the polyethylene core. 


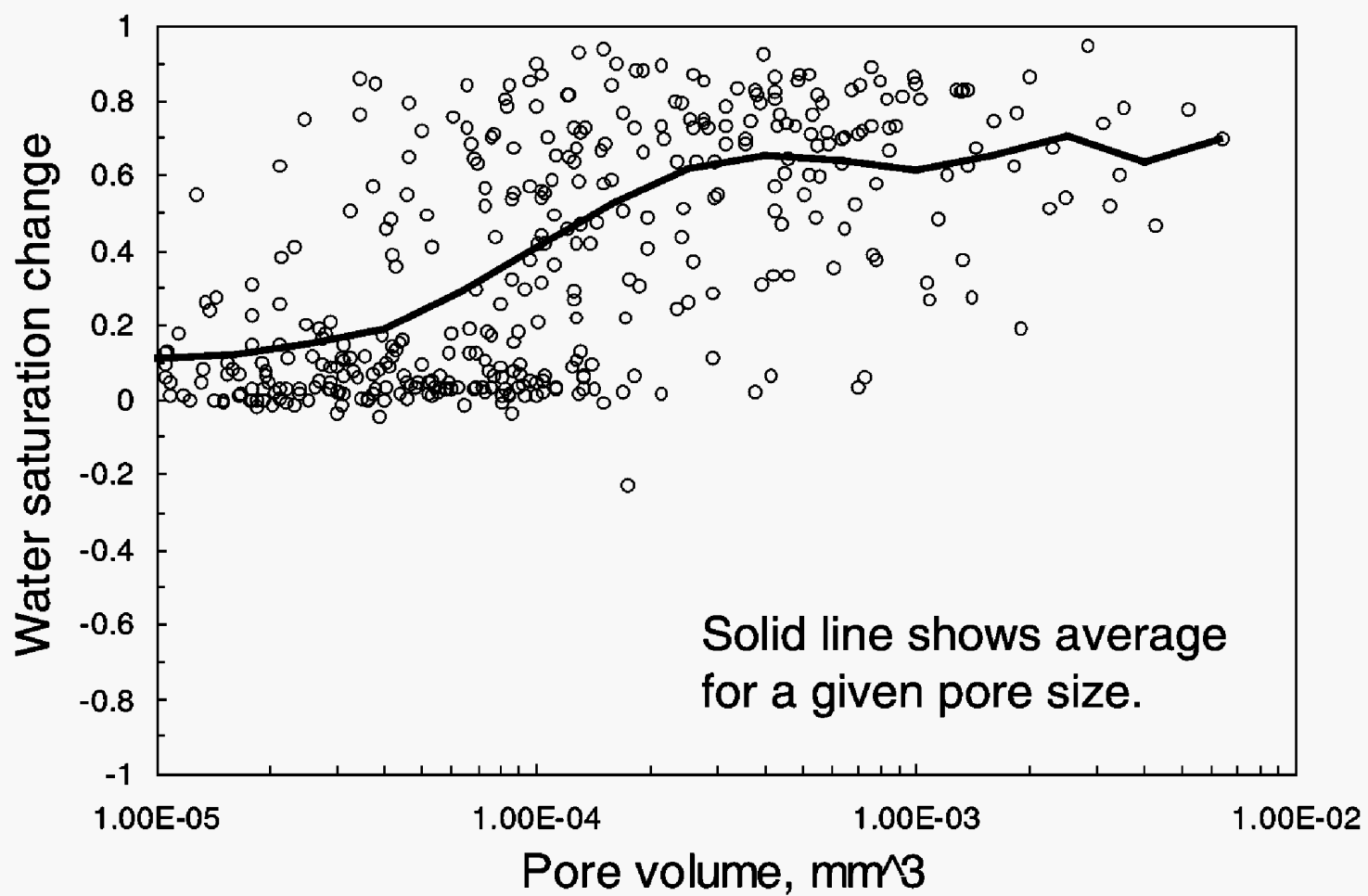

Fig. $47-S_{w}$ changes from $S_{w r}$ to the $2^{\text {nd }} S_{o r}$ for individual pores in the polyethylene core.

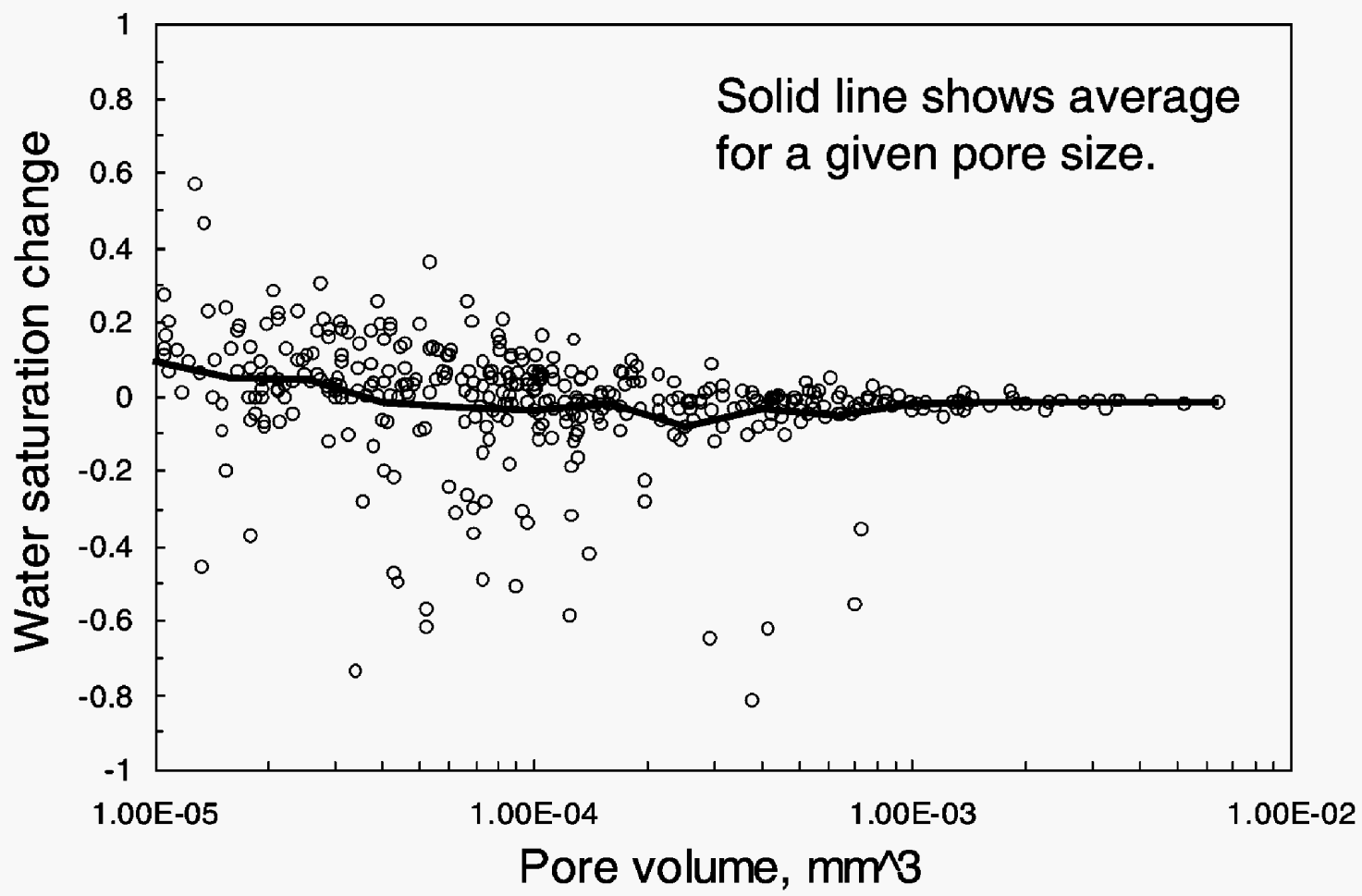

Fig. $48-S_{w}$ changes from the $1^{\text {st }} S_{o r}$ to the $2^{\text {nd }} S_{o r}$ for individual pores in the polyethylene core. 
During Gelant Injection. In the next step, gelant (10 core pore volumes) was injected using a pressure gradient of $23 \mathrm{psi} / \mathrm{ft}$. After gel placement, the core was shut in for 14 hours $\left(\right.$ at $\sim 70^{\circ} \mathrm{C}$ ) and scanned (at room temperature). A comparison of Figs. 21 and 22 indicates that oil was mobilized during gelant injection. Immediately after gel placement, most remaining oil appeared as a film attached to the polyethylene. Although a water residual resistance factor was not measured at this point, in a separate study, ${ }^{16}$ an $F_{r r w}$ value of 25,000 was measured for this gel and core material immediately after gel placement. This high residual resistance factor indicated that the gel occupied virtually all of the aqueous pore space and reduced the core permeability to about $200 \mu \mathrm{D}$.

A detailed analysis of the three-dimensional images (Fig. 35) confirmed that fluid saturations changed during gelant injection. The open and solid triangles in Fig. 35 reveal that average water saturations increased substantially in the small-to-medium pores during gelant injection in polyethylene. Also, the overall average water saturation increased from $75.0 \%$ to $94.4 \%$ (Table 2). Fig. 49 confirms that many small pores experienced saturation changes during the process of gelant injection. On the one hand, an increase in water saturation might be expected since the injected gelant was 20 times more viscous than the displaced water. However, on the other hand, the pressure gradient during gelant placement ( $23 \mathrm{psi} / \mathrm{ft}$ ) was intentionally kept below that used during the other flooding steps ( $35 \mathrm{psi} / \mathrm{ft}$ ) to avoid mobilization of the residual phase. Three arguments could be offered to rationalize the observed behavior. First, because polyethylene was oil-wet, a continuous oil film may have existed throughout the porous medium. Thus, true irreducible oil saturation may not exist. With increased gelant or water throughput, oil in the continuous film may be able to drain slowly from the porous medium. A second explanation is that the gelant may have changed the wettability of the porous medium to more water-wet. However, although some argue in favor of this type of mechanism, ${ }^{29}$ it is counterintuitive and requires much more convincing support. A third possible mechanism was suggested by Wang $e t$ $a l .^{30}$ Specifically, at a fixed capillary number, viscoelastic polymer solutions (e.g., our gelant) redistribute forces on a microscopic scale in a manner that drives residual phases to lower than expected values. These possibilities will be explored during future work.

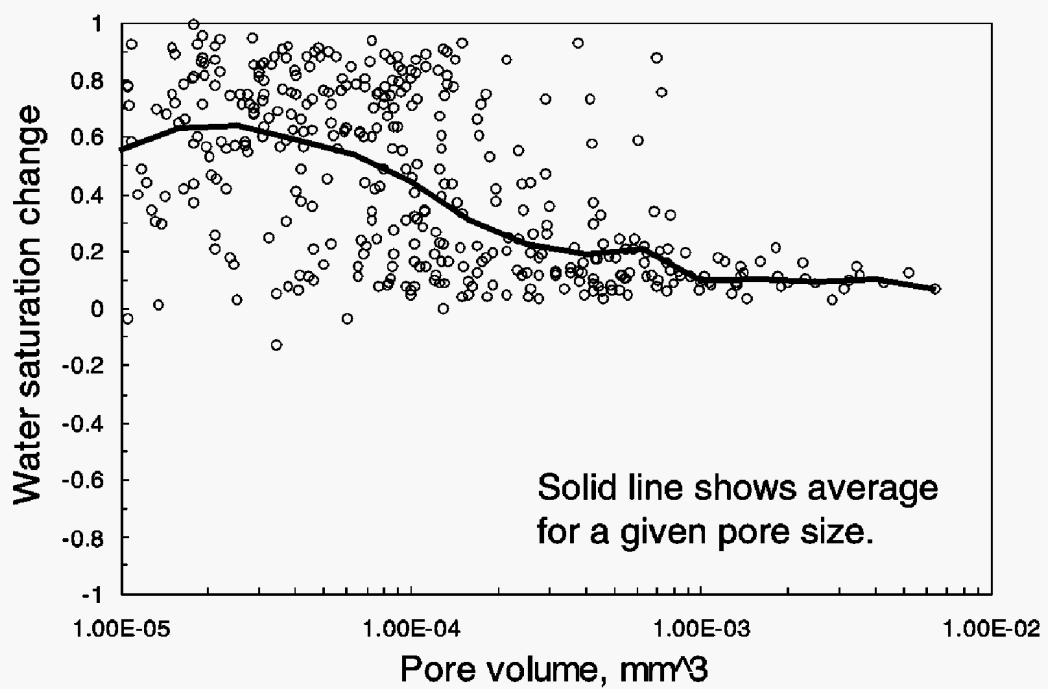

Fig. $49-S_{w}$ changes during gelant injection for individual pores in the polyethylene core. 
After Gel Placement. After the shut-in period, oil (20 core pore volumes) was injected and a value of 24 was measured for the oil residual resistance factor. This value was quite similar to the corresponding value measured in Berea (i.e., 15, from Table 3). However, a comparison of the XMT scans (Figs. 17 and 23) suggests that the oil saturations and oil pathways were very different in polyethylene than in Berea. In Berea, the overall oil saturation was quite high (71\%, from Table 2). In polyethylene, the oil saturation was much lower (24.3\%, from Table 2 ). Interestingly, the oil locations in Fig. 23 were very similar to those in Figs. 19 and 21. Thus, in polyethylene, the oil locations during oil injection after gel placement were virtually the same as those during water injection before gel placement. This observation receives further support from the plots of water saturation versus pore size. In Fig. 50, the saturation distribution at $S_{o r}$ before gel placement (open circles) was virtually the same as that at $S_{w r}$ after gel placement (solid triangles).

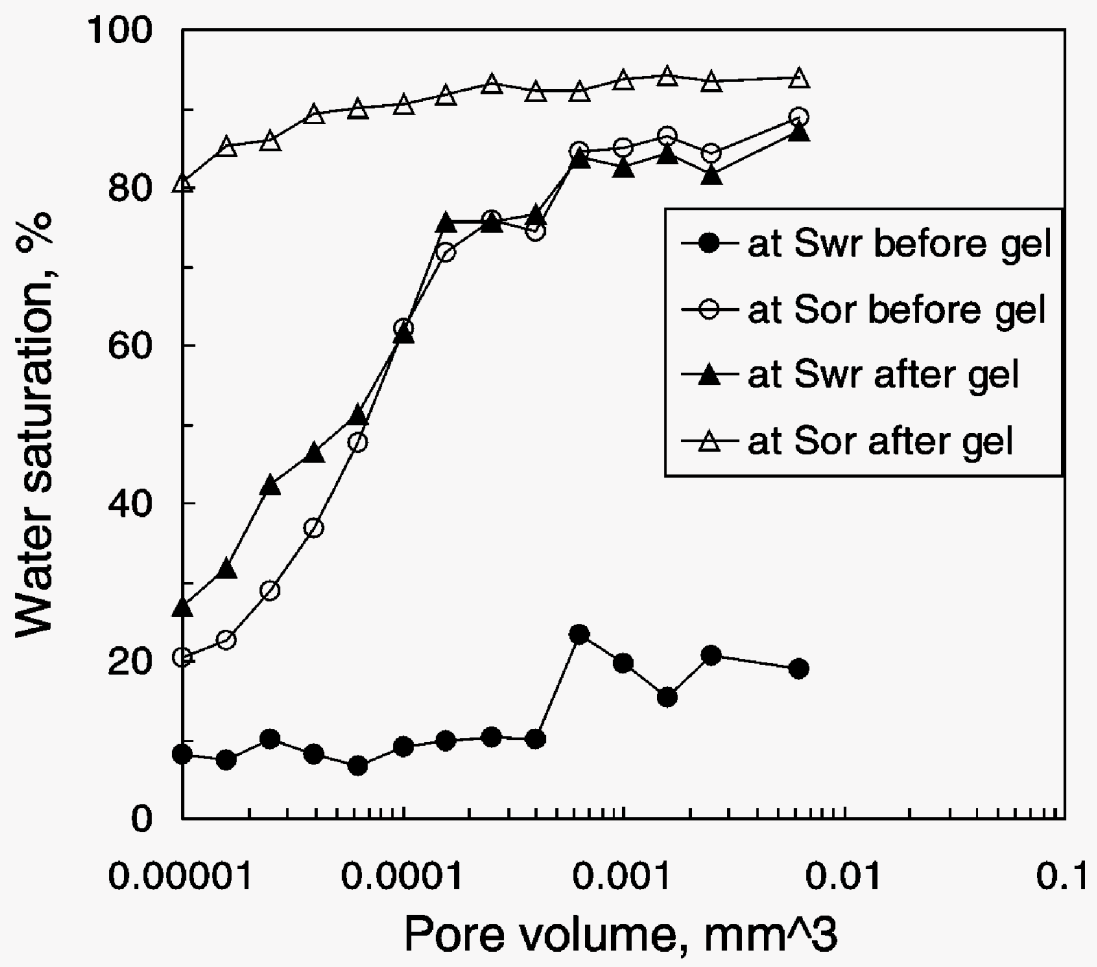

Fig. 50-Effect of gel on $S_{w r}$ and $S_{o r}$ in polyethylene.

Finally, water ( 2.5 core pore volumes) was injected and a value of 2,130 was measured for $F_{r r w}$. This value was comparable to that for Berea (i.e., 1,220 , from Table 3). Also, the ratio, $F_{r r w} / F_{r r o}$, was 89 in polyethylene versus 81 in Berea. In spite of the similarity of $F_{r w}$ values, the water saturations and water pathways appear very different in polyethylene than in Berea (compare Figs. 18 and 24). In Berea, a comparison of Figs. 17 and 18 suggests that the dramatic permeability reduction for water was caused by gel trapping a high residual oil saturation. In contrast, in polyethylene (Fig. 24), the oil saturation was very low (7.6\% from Table 2). Interestingly, the images shown in Figs. 22 and 24 are very similar. This observation receives further support from the plots of water saturation versus pore size. The saturation distribution at 
$S_{\text {or }}$ immediately after gel placement (solid triangles in Fig. 35) was very similar to that after the final water flood after gel placement (open triangles in Fig. 50).

Presumably during gelant injection, virtually all water was displaced by the aqueous gelant. As mentioned earlier, some "residual" oil was displaced also. After gelation, an effective gel permanently occupied locations that were previously occupied by water at $S_{\text {or }}$ before gelant injection. Thus, oil could no longer flow through those locations. The only flow paths available for oil were those through locations that were occupied by oil at $S_{o r}$ before gelant injection. This scenario explains why the distribution of saturations at $S_{o r}$ before gelant injection was the same as that at $S_{w r}$ after gel placement (Figs. 21, 23, and 50). However, at the condition associated with $S_{o r}$, why should oil be able to flow at all? Perhaps a continuous oil film on the polyethylene allowed flow-i.e., the oil was not trapped as discontinuous drops at $S_{o r}$. Considering that $F_{r r o}$ was 24 for this experiment, the above suggestion implies that if no gel was present, the permeability to oil at a water saturation of $75.7 \%$ (from Table 2) should be 24 times less than the permeability to oil at a water saturation of $15.2 \%$. In other words, perhaps our core was not at true irreducible oil saturation when water was injected. We will explore this possibility in future work.

Recall that the process of gel placement drove $S_{\text {or }}$ from $25.0 \%$ to $5.6 \%$ (Table 2). However, during oil flooding after gel placement, oil returned to those locations where gelant had previously removed residual oil (see Figs. 21-23 and Figs. 35 and 50). Why did gel not permanently block these locations? Considering the size of these locations (red areas of Figs. 2123) and the inert nature of polyethylene, it seems likely that gel formed here as effectively as in other locations. Possibly, during the oil flood after gel placement, the topography of the porous medium, combined with capillary forces, allowed the oil to rip $^{12,13}$ or dehydrate ${ }^{18}$ gel to form pathways in the regions occupied by the original oil saturation. As mentioned earlier, this mechanism may have been operable in Berea also. However, in Berea, the gel trapped oil associated with saturations at $S_{w r}$ before gel placement. In polyethylene, the gel trapped oil associated with saturations at $S_{\text {or }}$ before gel placement. At first, we thought that the thin filaments that bridged the smaller pores in polyethylene (Fig. 6) acted as guide wires, allowing oil to breach the gel and re-occupy the observed locations. However, subsequent work indicated that these filaments dissolved shortly after the core was saturated with hexadecane (Fig. 7).

After gel placement, the permeability to water was dramatically less than that to oil. This result suggests that the largest oil pathways shown in Figs. 21 and 23 were generally not open to water flow. Why not? One proposed possibility was that a new residual oil saturation was established in these pathways during the final water flood. ${ }^{18}$ However, careful examination of Figs. 21-24 and Figs. 35 and 50 reveals that this did not happen. A second possibility is that elastic forces associated with the gel closed the largest oil pathways during the final water flood. ${ }^{12,13}$ In this theory, capillary forces keep the oil pathways open during oil flooding. ${ }^{12,13}$ (By proper labeling of our gel and fluids, we may be able to test this hypothesis in future XMT studies.) A third possibility is that the oil pathways were open during oil flooding but closed during water flooding because gels "shrink in the presence of oil but swell in the presence of water." "This proposed mechanism is troubling because in the absence of osmotic effects, the available evidence indicates that our gels do not shrink in the presence of oil and swell in the presence of water. $^{10,12}$ 
Figs. 51 and 52 plot changes in water saturation for individual pores during oil and water flooding after gel placement. Consistent with Fig. 50, these figures show that changes in water saturation were small for pores larger than $3 \times 10^{-4} \mathrm{~mm}^{3}$. In smaller pores, significant saturation changes were noted, but they were scattered in magnitude.

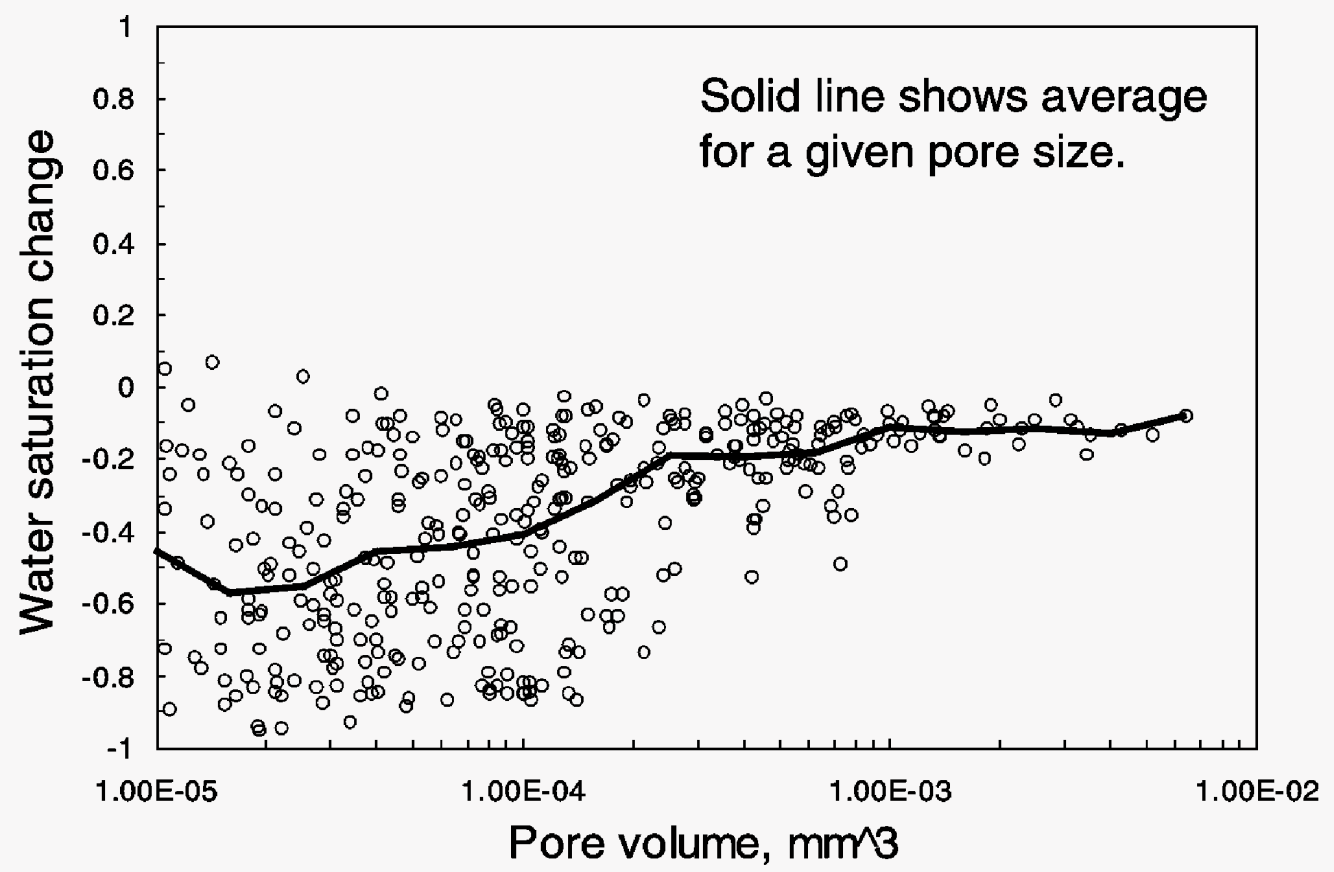

Fig. $51-S_{w}$ changes for individual pores in polyethylene during oil injection after gelation.

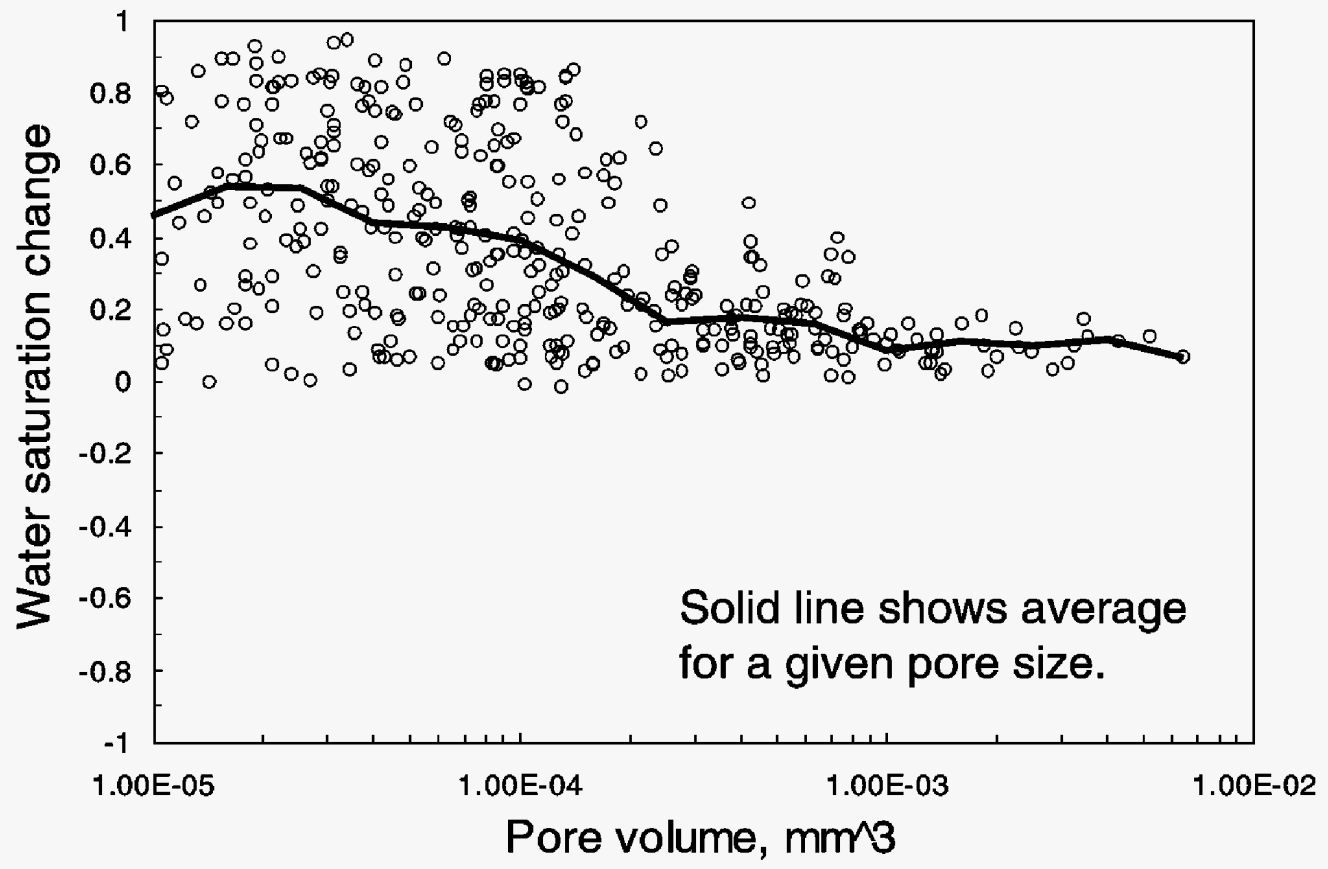

Fig. $52-S_{w}$ changes for individual pores in polyethylene during water injection after gelation. 
In Fig. 51, note that during oil injection after gel placement, virtually no pores experienced a gain in water saturation. In contrast, during oil injection into Berea sandstone after gel placement (Fig. 38), many of the small to intermediate pores gained in water saturation. Analogously in Fig. 52 , note that during water injection after gel placement in polyethylene, virtually no pores experienced a gain in oil saturation. In contrast, during water injection into Berea sandstone after gel placement (Fig. 39), many of the small to intermediate pores gained in oil saturation.

Fig. 53 compares saturation differences for individual pores before versus after gel placement when the core was at $S_{w r}$. Consistent with the solid symbols in Fig. 50, at $S_{w r}$, the gel caused substantial increases in water saturation in the medium to large pores (i.e., those larger than $3 \times 10^{-4} \mathrm{~mm}^{3}$ ). Presumably, most of this increase was associated with water that was tied up as immobile gel. Thus, when oil was injected, it was unable to displace the gel and increase the oil saturation significantly in the medium to large pores. In contrast, many of the smaller pores appeared to have about the same saturation after gel placement as before gel placement.

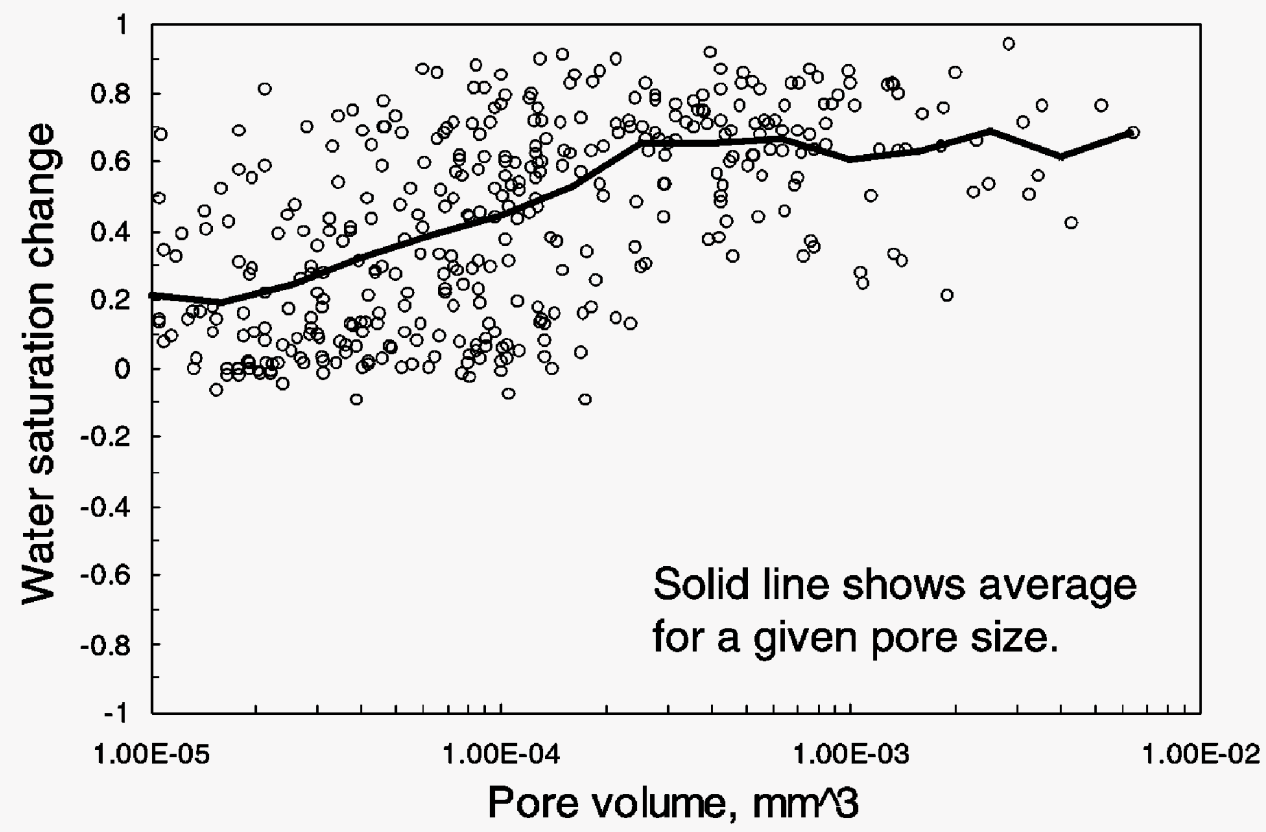

Fig. 53- $S_{w}$ differences in polyethylene pores at $S_{w r}$ before versus after gel placement.

Fig. 54 compares saturation differences for individual pores before versus after gel placement when the core was at $S_{o r}$. Again, very few large pores experienced significant saturation changes. This finding provides further support for the idea that an immobile gel occupied the larger pores. In the small to medium pores, water saturations at $S_{o r}$ were generally significantly higher after gel placement than before gel placement. This results was attributed to gelant penetration into the small to medium pores during gelant injection (see Figs. 35 and 49). 


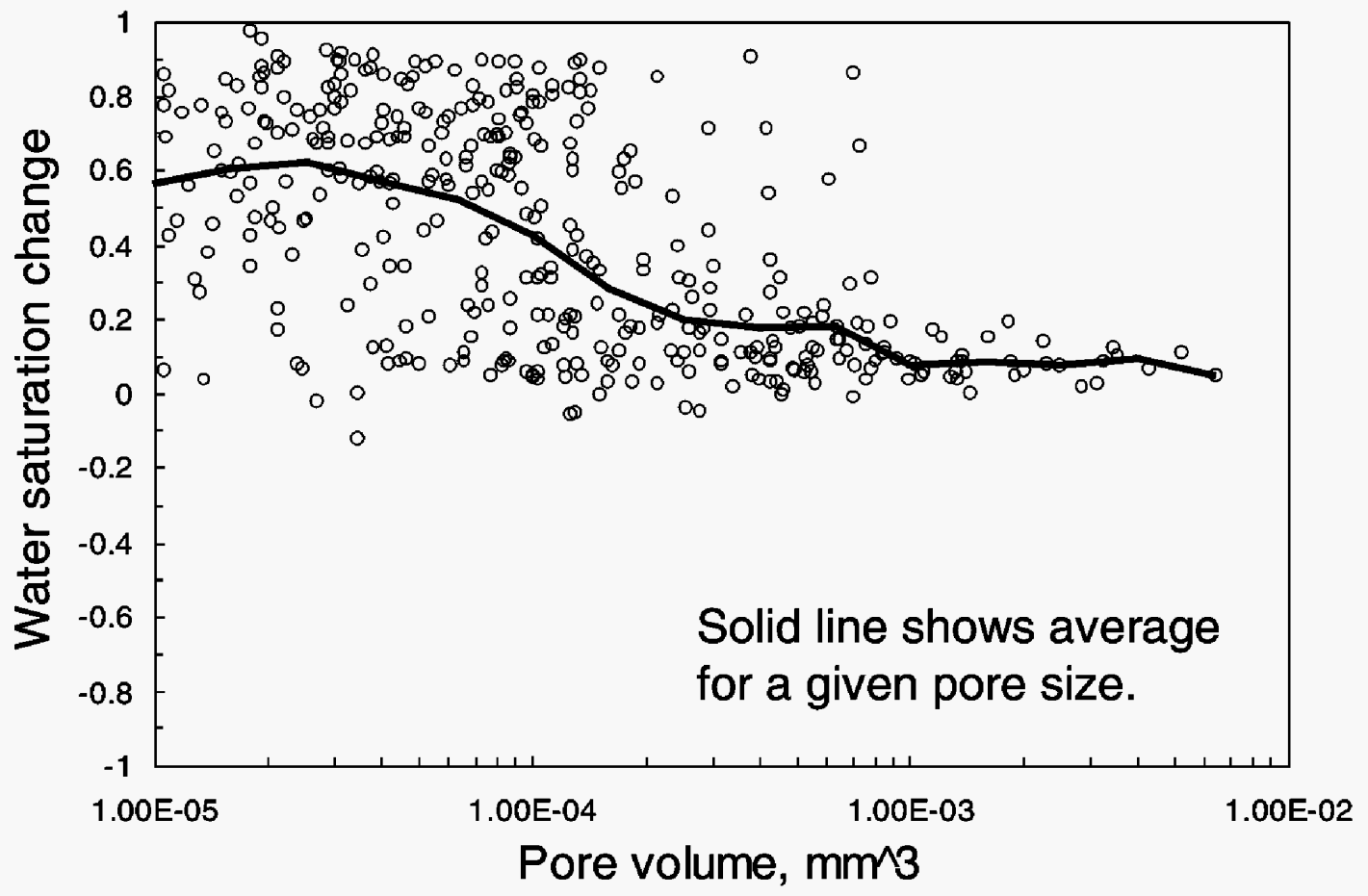

Fig. $54-S_{w}$ differences in polyethylene pores at $S_{o r}$ before versus after gel placement.

Of course, additional work will be performed to address the questions and test the hypotheses raised in this chapter.

\section{Conclusions}

$\mathrm{X}$-ray computed microtomography was used to investigate why gels reduce permeability to water more than that to oil in strongly water-wet Berea sandstone and in an oil-wet porous polyethylene core. The following conclusions were reached:

1. Although the two porous media had very different porosities ( $22 \%$ versus $40 \%$ ), the distributions of pore sizes and aspect ratios were similar.

2. A Cr(III)-acetate-HPAM gel caused comparable oil and water permeability reductions in both porous media. In both cores, the gel reduced permeability to water by a factor 80 to 90 times more than that to oil.

3. The distributions of water and oil saturations (versus pore size) were substantially different before, during, and after gel placement.

4. The disproportionate permeability reduction appeared to occur by different mechanisms in the two porous media. In Berea, gel caused disproportionate permeability reduction by trapping substantial volumes of oil that remained immobile during water flooding. With this high trapped oil saturation, water was forced to flow through narrow films, through the smallest pores, and through the gel itself. In contrast, during oil flooding, oil pathways remained relatively free from constriction by the gel. 
5. In the polyethylene core, oil trapping did not contribute significantly to the disproportionate permeability reduction. Instead, oil films and a relatively small number of pore pathways provided conduits for the oil. For reasons yet to be understood, the small pore pathways appeared largely unavailable for water flow. 


\section{GEL PROPERTIES IN FRACTURES}

Gel treatments currently provide the most effective means to reduce channeling through fractures. ${ }^{31-37}$ Except in narrow fractures, extruded gels have a placement advantage over conventional gelant treatments. To explain, during conventional gel treatments, a fluid gelant solution typically flows into a reservoir through porous rock and fractures. After placement, chemical reactions (i.e., gelation) cause an immobile gel to form. During gelant injection, fluid velocities in the fracture are usually large enough that viscous forces dominate over gravity forces. ${ }^{38}$ Consequently, for small-volume treatments, the gelant front is not greatly distorted by gravity during gelant injection. However, after gelant injection stops, even a small density difference (e.g., 1\%) between the gelant and the displaced reservoir fluids allows gravity to rapidly drain gelant from at least part of the fracture. ${ }^{38}$ Generally, gelation times cannot be controlled well enough to prevent gravity segregation between gelant injection and gelation.

Alternative to conventional gelant treatments, formed gels can be extruded into fractures. Since these gels are $10^{3}$ to $10^{6}$ times mores viscous than gelants, ${ }^{39}$ gravity segregation is much less important than for gelants. In fact, for the most successful treatments in fractured reservoirs, formed gels were extruded through fractures during most of the placement process. ${ }^{32-37}$ A need exists to determine how much gel should be injected in a given application and where that gel distributes in a fractured reservoir. These parameters depend critically on the properties of gels in fractures. Therefore, we have a research program to determine these properties and to understand how gels extrude through fractures.

\section{Previous Experimental Work}

Gels do not flow through porous rock after gelation. ${ }^{38}$ This behavior is advantageous since the gel is confined to the fractures-it does not enter or damage the porous rock. Thus, after gel placement, water, oil, or gas can flow unimpeded through the rock, but flow through the fracture is reduced substantially.

However, extrusion of gels through fractures introduces new issues that are not of concern during placement of fluid gelant solutions. First, the pressure gradients required to extrude gels through fractures are greater than those for gelant flow. Previously, ${ }^{2,3,38-44}$ we demonstrated that a minimum pressure gradient was required to extrude a given gel through a fracture. Once this minimum pressure gradient was exceeded, the pressure gradient during gel extrusion was insensitive to the flow rate ${ }^{38,40,43}$ For a $\mathrm{Cr}(\mathrm{III})$-acetate-HPAM gel, the pressure gradient required for extrusion varied inversely with the square of fracture width (Fig. 55 and Eq. 1).

$d p / d l=0.02 /\left(w_{f}\right)^{2}$,

where pressure gradient, $d p / d l$, has units of $\mathrm{psi} / \mathrm{ft}$, while fracture width, $w_{f}$, has units of inches. In contrast, a force balance during gel extrusion predicts that the pressure gradient should vary linearly with fracture width. ${ }^{45}$ Although we have not definitively identified the origin of this behavior, we have demonstrated that it is directly linked to the extremely strong apparent shearthinning behavior during extrusion. ${ }^{45}$ This behavior suggests that a very thin lubricating layer of liquid at the gel-fracture interface enhances gel extrusion. Apparently, the thickness of the lubricating layer increases with increased superficial velocity. 


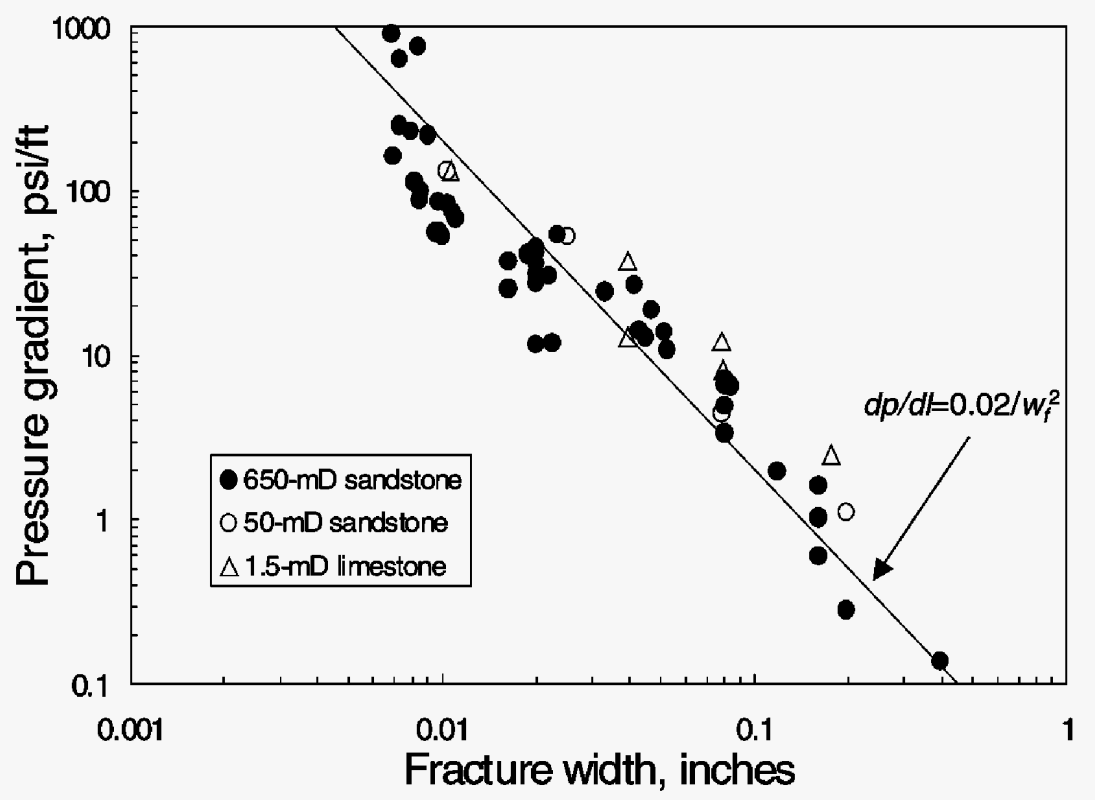

Fig. 55-Pressure gradients required for gel extrusion through open fractures.

A second concern is that gels can concentrate (dehydrate) during extrusion through fractures. ${ }^{2,30-43}$ Depending on fracture width (see Fig. 56) and injection rate, this dehydration effect can significantly retard gel propagation (e.g., by factors up to 50). Figs. 55 and 56 apply to a one-day-old $\mathrm{Cr}$ (III)-acetate-HPAM gel at $41^{\circ} \mathrm{C}$. This same gel was used for many of the experiments described in this chapter. Specifically, our experiments used an aqueous gel that contained $0.5 \%$ Ciba Alcoflood 935 HPAM (molecular weight $\approx 5 \times 10^{6}$ daltons; degree of hydrolysis $5 \%$ to $10 \%$ ), $0.0417 \% \mathrm{Cr}$ (III) acetate, $1 \% \mathrm{NaCl}$, and $0.1 \% \mathrm{CaCl}_{2}$ at $\mathrm{pH}=6$. Most experiments to date were performed at $41^{\circ} \mathrm{C}\left(105^{\circ} \mathrm{F}\right)$. The gelant formulations were aged at $41^{\circ} \mathrm{C}$ for 24 hours ( 5 times the gelation time) before injection into a fractured core. We designate this gel as our standard $1 \mathrm{X} \mathrm{Cr}(\mathrm{III})$-acetate-HPAM gel.

In earlier work, ${ }^{41,43}$ we showed that when large volumes of gel were extruded through a fracture, progressive plugging (i.e., continuously increasing pressure gradients) was not observed. Effluent from the fracture had the same appearance and a similar composition as those for the injected gel, even though a concentrated, immobile gel formed in the fracture. During gel extrusion, water leaks off from the gel, and the gel concentrates to become immobile in the vicinity where dehydration occurred. The driving force for gel dehydration (and water leakoff) is the pressure difference between the fracture and the adjacent porous rock. Fresh gel (i.e., mobile gel, with the original composition) must wormhole through the concentrated gel in order to advance the gel front. With time at a given position along the fracture, the average gel concentration increases and the fracture area contacted by wormholes (i.e., mobile gel) decreases. Even so, water leakoff from the concentrated, immobile gel is generally small compared with leakoff from the mobile gel. During gel extrusion through a fracture of a given width, the pressure gradients along the fracture and the dehydration factors were the same for fractures in $650-\mathrm{mD}$ sandstone as in $50-\mathrm{mD}$ sandstone and $1.5-\mathrm{mD}$ limestone (Figs. 55 and 56 ). 


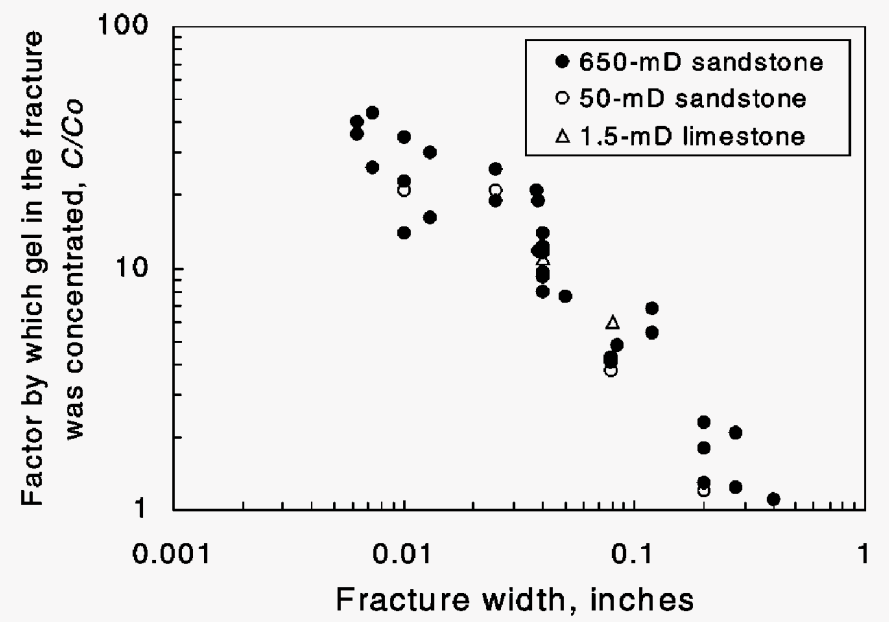

Fig. 56-Degree of gel dehydration versus fracture width (from Ref. 41).

With an understanding of the mechanism for gel extrusion and dehydration in fractures, we ultimately hope to predict conditions, compositions, and volumes that provide the optimum gel placement in fractured reservoirs. Of course, dehydration reduces the rate of gel propagation through fractures. This dehydration has been quantified for a significant range of conditions. For fracture widths from 0.02 to 0.16 inches, fracture lengths from 0.5 to $32 \mathrm{ft}$, fracture heights from 1.5 to 12 inches, and injection fluxes from 129 to $66,200 \mathrm{ft} / \mathrm{d}$, the average rate of gel dehydration and leakoff $\left(u_{l}\right.$, in $\mathrm{ft} / \mathrm{d}$ or $\left.\mathrm{ft}^{3} / \mathrm{ft}^{2} / \mathrm{d}\right)$ was described reasonably well using Eq. 2.

$$
u_{l}=0.05 t^{-0.55} \text {, }
$$

where $t$ is time in days. Fig. 57 summarizes the results from these leakoff experiments. ${ }^{2,3,43}$

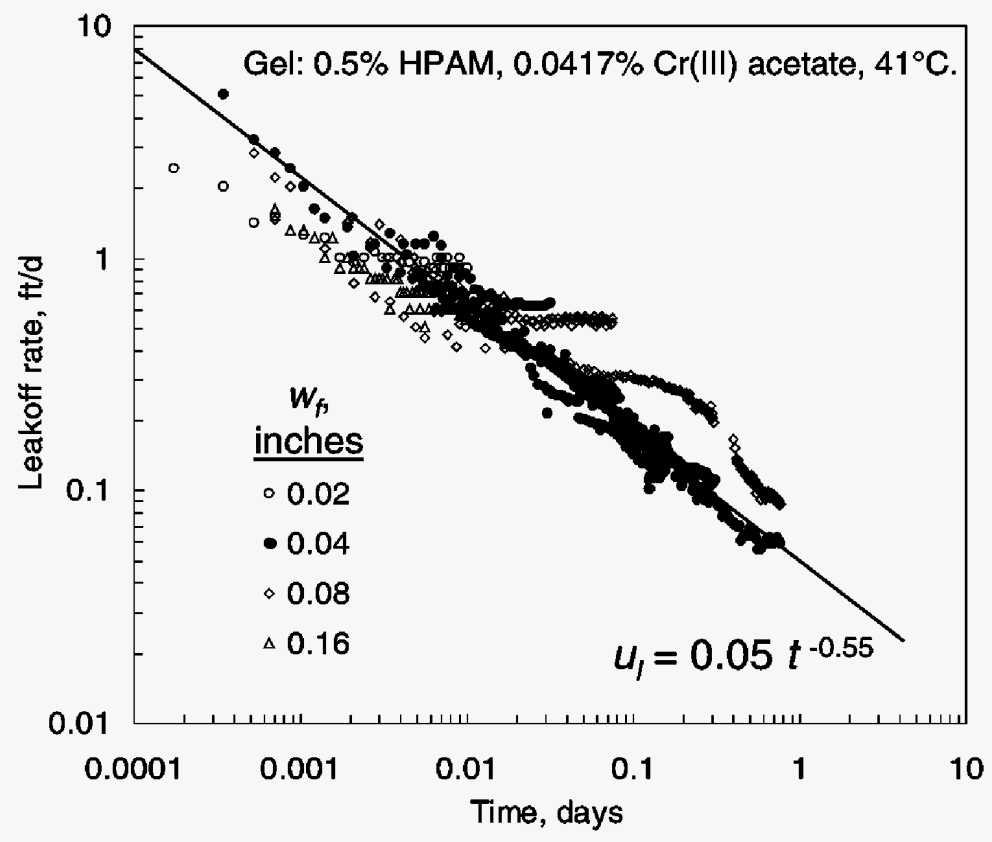

Fig. 57-Summary of leakoff data at $41^{\circ} \mathrm{C}$. 


\section{New Mechanistic Model}

To date, we have examined three models for gel propagation and dehydration in fractures. ${ }^{2,3,41,43}$ The most successful model, Model 2, was based on the leakoff equation that is illustrated in Fig. 57 (Eq. 2). Although Model 2 effectively quantifies gel propagation and dehydration, it is based on an empirical two-parameter fit. We seek a mechanistic understanding of the leakoff behavior to increase our confidence in predictions made by our gel propagation and dehydration models.

A new mechanistic model (Model 4) was developed that accounts for the most important elements of gel propagation and dehydration in fractures. This model assumes the following:

1. The only mobile gel has the same composition as the injected gel.

2. When an element of mobile gel dehydrates, that gel becomes immobile. For a given vicinity and time $(t)$ in a fracture of width $\left(w_{f}\right)$, the average gel concentration $\left(C / C_{o}\right.$, which gives the gel concentration relative to the concentration for the injected gel, $C_{o}$ ) is

$C / C_{o}=1+\int u_{l} d t / w_{f}$

where $u_{l}$ is the average leakoff rate for that vicinity.

3. At a given point along the fracture, the fracture surface is covered by either mobile gel (with fractional area, $A_{m}$ ) or immobile gel (with fractional area, $A_{c}$ ) so that

$A_{m}+A_{c}=1$

The fracture surface that contacts mobile gel decreases with time as more immobile gel forms. The fractional area covered by concentrated gel at a given time and vicinity is

$A_{c}=\left[C / C_{o}-1\right] /\left[C / C_{o}\right]$

4. Wormhole pathways for mobile gel through the immobile gel have the same width as the fracture (i.e., the distance between the two fracture faces). Presumably, as mobile gel in a wormhole dehydrates, a very thin layer of concentrated gel forms at the fracture surface. However, this thin layer is continually stripped aside by the leakoff water or mobile gel, and the concentrated gel is added to the accumulation of immobile gel at the sides of the wormhole.

5. The water leakoff contribution from immobile (dehydrated) gel $\left(u_{c}\right)$ is negligible compared to that from the mobile gel $\left(u_{m}\right)$. (The immobile gel continues to concentrate and lose water with time. However, this leakoff rate is small compared to that from the much more permeable mobile gel.)

$u_{m} \gg u_{c}$ 
6. The mobile gel has a finite permeability to water $\left(k_{g e l}\right)$ that provides a fixed local leakoff flux $\left(u_{m}\right)$ for the fraction of the fracture surface that is in direct contact with mobile gel (i.e., the wormhole area that is in contact with the fracture faces).

$u_{l} \approx A_{m} u_{m}$

The above assumptions are supported by results from various experiments that we reported earlier. ${ }^{2,3,41,43}$ Combining Eqs. 3 to 7 yields Eq. 8, which is the basis of our Model 4. Model 4 predicts the leakoff rate (i.e., the rate of gel dehydration) at a given time and distance along the gel-contacted portion of a fracture.

$u_{l}=u_{m} /\left[1+\int u_{l} d t / w_{f}\right]$

The denominator of Eq. 8 reflects the rate of loss of fracture surface that is contacted by mobile gel (i.e., the wormhole-contact area). For our 24-hr-old Cr(III)-acetate-HPAM gel, $u_{m}$ has a value around $4 \mathrm{ft} / \mathrm{d}$, which translates to a $k_{g e l}$ value around $1 \mathrm{mD}$. The latter value was confirmed from independent experiments. ${ }^{2}$ Leakoff predictions using Eq. 8 are plotted in Fig. 58. The predictions are quite good considering that Eq. 8 was derived strictly from mechanistic considerations, whereas Model 2 was based on an empirical two-parameter fit (Eq. 2).

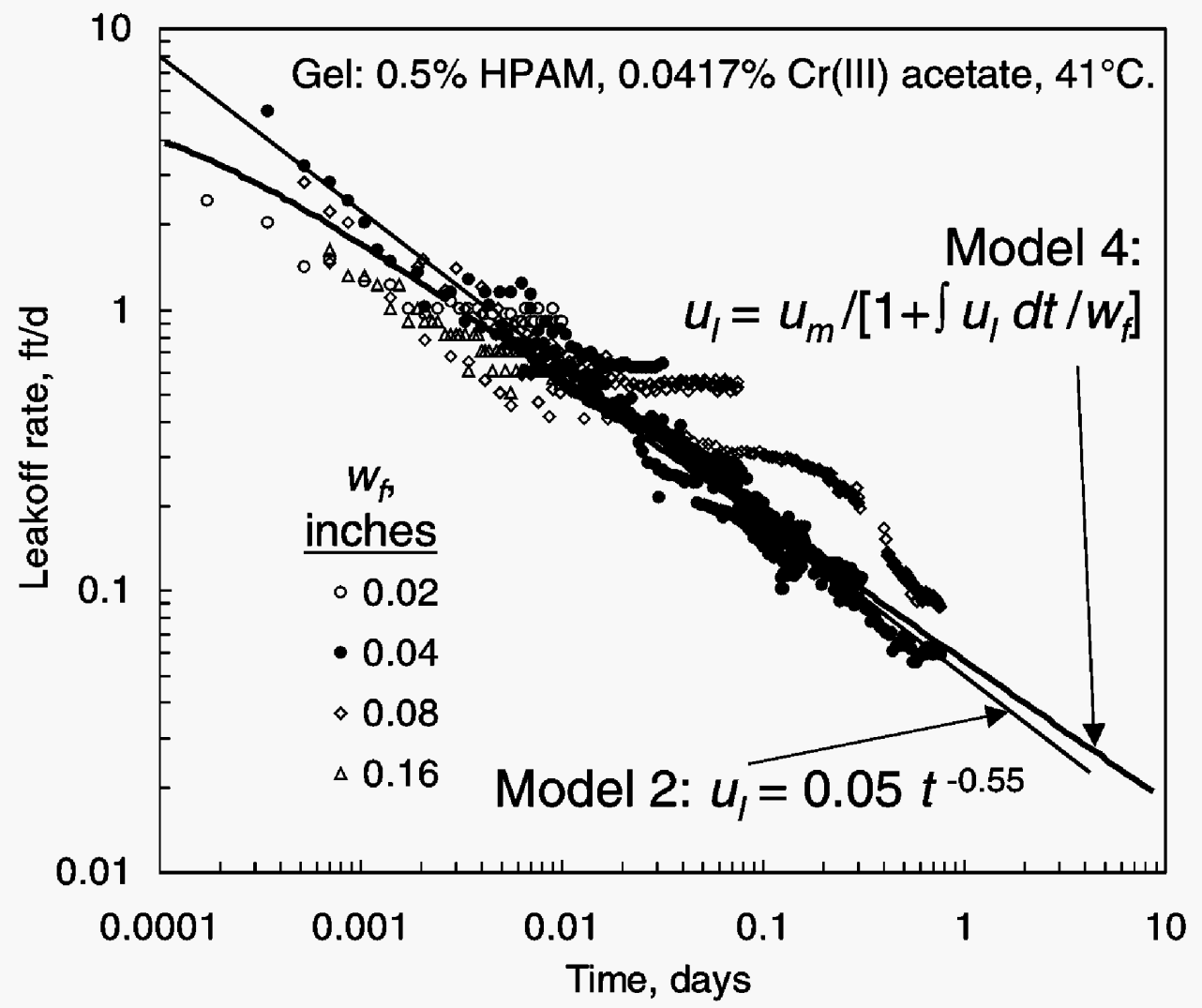

Fig. 58-Comparison of Models 2 and 4. 


\section{Effect of Temperature}

Most of our experiments to date were performed at $41^{\circ} \mathrm{C}$. Of course, many reservoirs and field applications exist at other (mostly higher) temperatures. Therefore, a need exists to determine gel extrusion and dehydration properties at other temperatures. Using temperatures ranging from $20^{\circ} \mathrm{C}$ to $80^{\circ} \mathrm{C}$, extrusion experiments were performed using $650-\mathrm{mD}$ Berea sandstone cores that had lengths of either 6 or 48 inches. In each case, the fracture width was 0.04 inches and the fracture height was 1.5 inches. Pressure taps along each four-ft-long fracture divided the core into five sections of equal length. A single set of pressure taps were used for the 6-inch-long fractures. Effluent from the fracture and matrix were collected separately. We used our standard $\mathrm{Cr}$ (III)-acetate-HPAM gel (0.5\% Alcoflood $935 \mathrm{HPAM}, 0.0417 \% \mathrm{Cr}$ (III) acetate) that was aged for 24 hours at $41^{\circ} \mathrm{C}$ before injection. The fractured core was equilibrated at the test temperature well before gel injection started. During injection of 3.7 liters of gel, the rate was fixed at 2,000 $\mathrm{cm}^{3} / \mathrm{hr}$-translating to a flux in the fracture of $4,130 \mathrm{ft} / \mathrm{d}$. Four sets of experiments were performed.

First Set: With Heat Exchanger. In the first set, before entering the fracture, the gel passed through a heat exchanger $\left(53 \mathrm{~cm}^{3}\right.$ holdup volume, $0.2-\mathrm{cm}$-diameter flow path) to change the gel temperature to the desired value. (The gel was originally at $40^{\circ} \mathrm{C}$.) Gel temperatures were measured inline both at the fracture inlet and exit to ensure that the desired temperature was reached and maintained. The heat exchanger and inlet flow lines were filled with gel to the fracture inlet before beginning the experiment. At $2,000 \mathrm{~cm}^{3} / \mathrm{hr}$, the average time for gel transit through the heat exchanger was 1.6 minutes.

The steady state pressure gradients observed during extrusion through the fractures were 1.6, 1.3, 1.7 , and $1.7 \mathrm{psi} / \mathrm{ft}$ at temperatures of $20^{\circ} \mathrm{C}, 40^{\circ} \mathrm{C}, 60^{\circ} \mathrm{C}$, and $80^{\circ} \mathrm{C}$. For comparison, in previous floods at $41^{\circ} \mathrm{C}$ the pressure gradient averaged $12.5 \mathrm{psi} / \mathrm{ft}$ using the same conditions, except that the heat exchanger was not used. Thus, we were concerned that passage through the heat exchanger substantially damaged the gel. Indeed, the effluent from the heat exchanger appeared mechanically degraded to a large extent. In contrast, effluent from fractured cores at $41^{\circ} \mathrm{C}$ showed little degradation when the heat exchanger was not used. Of course, we wondered why the differences in degradation occurred. The heat exchanger pathway was a 55-ft-long tube with an inside diameter of 0.08 in. Interestingly, no significant degradation was observed after forcing the gel through a 32 -ft-long, 0.08 -in.-wide fracture. ${ }^{3} \mathrm{We}$ can speculate about an explanation. In a fracture, perhaps the water freed during the bond-rupture process is removed through leakoff, while the disrupted crosslinked polymer becomes immobile as concentrated gel. Thus, the gel that remains mobile has not experienced any serious mechanical breakdown. In contrast in a tube, no exit exists for the water through the tube wall. Along with convection associated with the extrusion process, this free water may create a fine dispersion-i.e., small gel particles are dispersed in the water freed during the bond disruption process. This gel dispersion, formed by passage through our heat exchanger tube, would appear less viscous and more mechanically degraded, and would exhibit a lower pressure gradient during subsequent extrusion through a fracture. As mentioned, this explanation is speculative at this point.

For the experiments performed with the heat exchanger, the water leakoff results during gel extrusion are plotted in Fig. 59. The leakoff values generally fell below the predictions from the equation, $u_{l}=0.05 t^{-0.55}$ (solid line in Fig. 59). This result also suggests that gel propagation 
during the experiments with the heat exchanger was different than that without the heat exchanger.

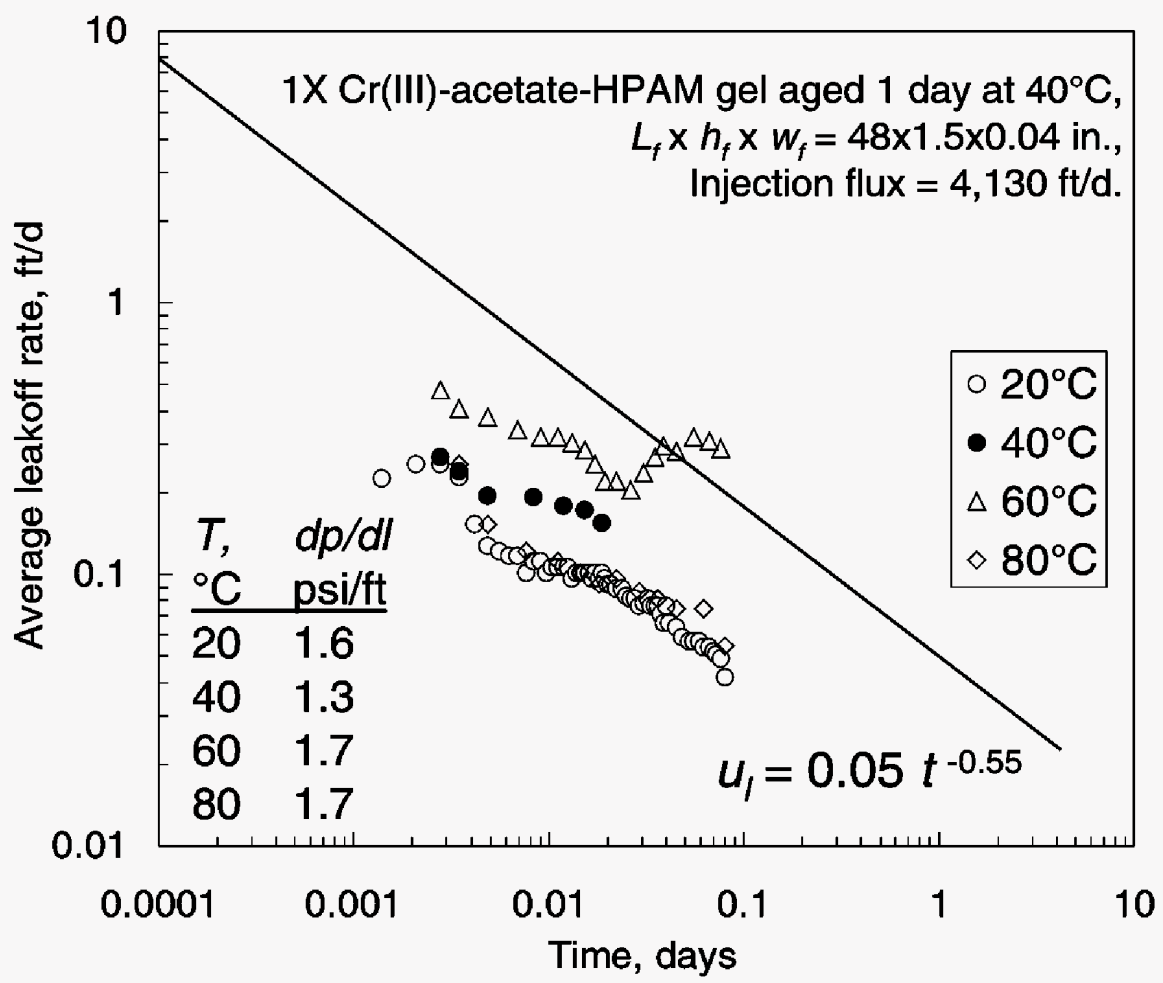

Fig. 59-Effect of temperature on leakoff when long heat exchanger was used.

Second Set: No Heat Exchanger. A second set of experiments was performed using a different method to heat the gel before injection. The 55-ft-long tube heat exchanger was not used. Instead, the gel was heated or cooled from $40^{\circ} \mathrm{C}$ to the desired temperature in a bottle. Between 2 and 3 hours were required to heat $\sim 4$ liters of gel to $60^{\circ} \mathrm{C}$. All other conditions were the same as those in the first set of experiments. In the second set, experiments were performed at $20^{\circ} \mathrm{C}$, $40^{\circ} \mathrm{C}$, and $60^{\circ} \mathrm{C}$. In these experiments, the steady state pressure gradients during gel extrusion were $11.9 \mathrm{psi} / \mathrm{ft}, 13.8 \mathrm{psi} / \mathrm{ft}$ and $10.3 \mathrm{psi} / \mathrm{ft}$, respectively. These values were close to the 12.5 $\mathrm{psi} / \mathrm{ft}$ average observed during many earlier experiments at $41^{\circ} \mathrm{C}$, where no separate gel heating stage was employed. Also, the gel effluent from the fractures did not appear mechanically degraded. Furthermore, the leakoff behavior (Fig. 60) was similar to that observed earlier (Fig. 58). Consequently, we have greater confidence in our results with the new heating system than those where the long heat exchanger was used (Fig. 59). We also note that the leakoff behavior at the three temperatures $\left(20^{\circ} \mathrm{C}, 40^{\circ} \mathrm{C}\right.$, and $60^{\circ} \mathrm{C}$ ) was about the same (Fig. 60). We attempted experiments at $80^{\circ} \mathrm{C}$, but the epoxy-cast cores failed (leaked) at this temperature.

Third Set: 6-Inches-Long. Of course, we wish to extend our experiments to higher temperatures. Because of concern that our epoxy-cast cores would not withstand temperatures of $80^{\circ} \mathrm{C}$ or more, we performed the third set of experiments using fractured cores that were cast in a metal alloy (Cerrotru®). Unfortunately, because of limitations associated with our core-casting 
method, these cores were only about 6 inches in length. With the exception of core length and casting material, the experiments were performed in a manner very similar to that for the second set of experiments described above. The results are shown in Fig. 61.

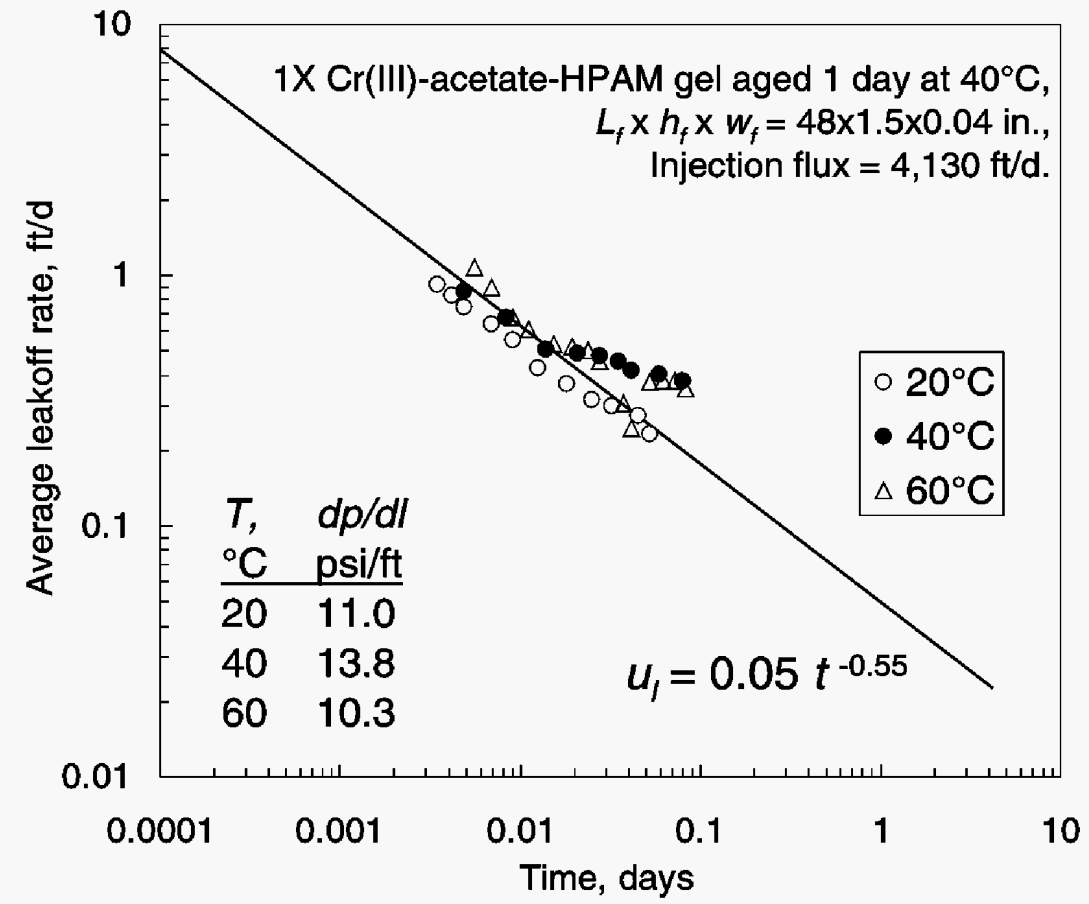

Fig. 60-Leakoff in 4-ft-long fractures without using the long heat exchanger.

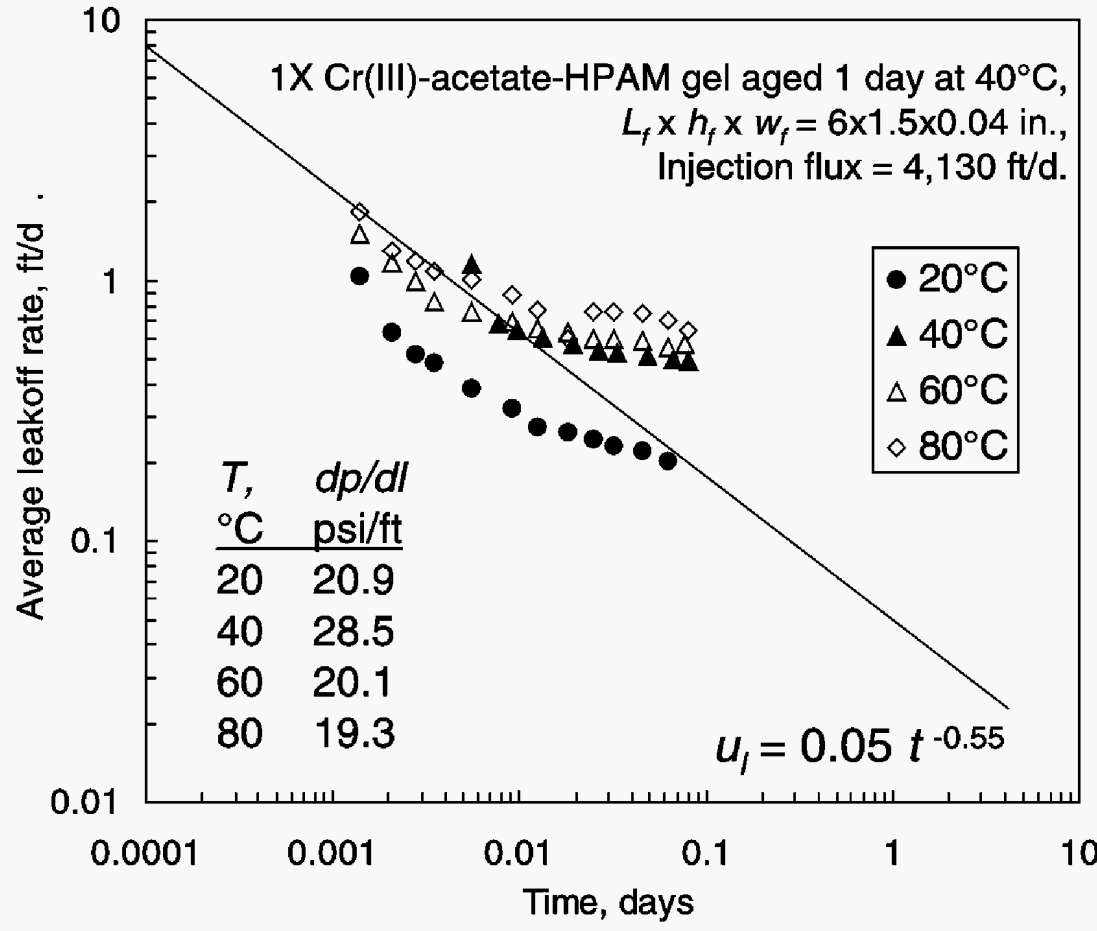

Fig. 61-Leakoff in 6-inch-long fractures without using the long heat exchanger. 
For all four temperatures, the pressure gradients during gel extrusion were similar-between 19 and $29 \mathrm{psi} / \mathrm{ft}$ (see the table in Fig. 61). Consistent with the behavior observed in the two previous sets of experiments, the pressure gradient was not sensitive to temperature. However, the pressure gradients during this third set of experiments were noticeably higher than for the second set. We attribute this difference to the short core lengths for the third set. Pressure drops were measured over the entire core, which included constrictions associated with fittings at the inlet and outlet of the 6-inch-long cores. Thus, the measured pressure gradients included contributions associated with gel flow through these fittings. In contrast, for the 4-ft-long cores for the first and second sets of experiments, no fittings were present for the internal fracture segments. Therefore, we have greater confidence in the pressure gradients measured in 4-ft-long cores than in the short cores. This points out one reason for preferring long cores to short cores for these tests.

For the three highest temperatures tested, the leakoff curves in Fig. 61 were very similar. This result further supports our observation that the leakoff behavior was not sensitive to temperature. For times shorter than 0.01 days, the leakoff data at $40^{\circ} \mathrm{C}, 60^{\circ} \mathrm{C}$, and $80^{\circ} \mathrm{C}$ were very consistent with the Model 2 trend line (solid curve in Fig. 61). For times longer than 0.01 days, the leakoff results exceeded the predictions associated with Model 2. We suspect that this deviation was an artifact associated with the use of short fractures. In particular, some of the concentrated gel may be dislodged and produced from short fractures-thus, permitting greater wormhole-fracture surface areas and higher leakoff rates for longer time periods. In longer fractures, any dislodged concentrated gel probably should be immobilized before being produced from the fracture. This concept will be tested in the future. It also points out a second reason why longer cores may be preferred to short cores for these experiments.

For the $20^{\circ} \mathrm{C}$ data in Fig. 61, the leakoff data points were consistently below the data for the other temperatures. We have no explanation for this result. We note that the $20^{\circ} \mathrm{C}$ data in Fig. 60 fell on the same trend as that for two other temperatures. Therefore, for the present, we view the $20^{\circ} \mathrm{C}$ data in Fig. 61 as an unexplained anomaly.

Fourth Set: 4-ft-Long Contained in a Pressure Vessel. Because of concerns about artifacts associated with the 6-inch-long cores, we wished to return to the use of longer cores. However, to perform experiments at higher temperatures, we need to overcome the problem of leaks associated with epoxy-cast cores at elevated temperatures. To accomplish this, we designed and purchased a pressure vessel (internal dimensions were 58-inches long and 6-inches in diameter) that could completely contain our 4-ft-long epoxy-cast cores. Tubes fed through the end caps of the pressure vessel allowed (1) gel injection into the fracture, (2) separate collection of effluent from the fracture and matrix, and (3) monitoring of pressures along the length of the fracture and/or core matrix. A separate pumping system circulated a constant-temperature fluid (e.g., water, ethylene glycol, or silicone oil) around the 4-ft-long core within the pressure vessel. This pumping system also maintained a constant overburden pressure (350 psi during our first experiments) to compress and prevent mechanical failure of the 4-ft-long cores during the gel extrusion process.

Results from our first experiment with this system are shown in Fig. 62. The procedures used during this experiment (at $60^{\circ} \mathrm{C}$ ) were very similar to those for our second set of experiments described above. 


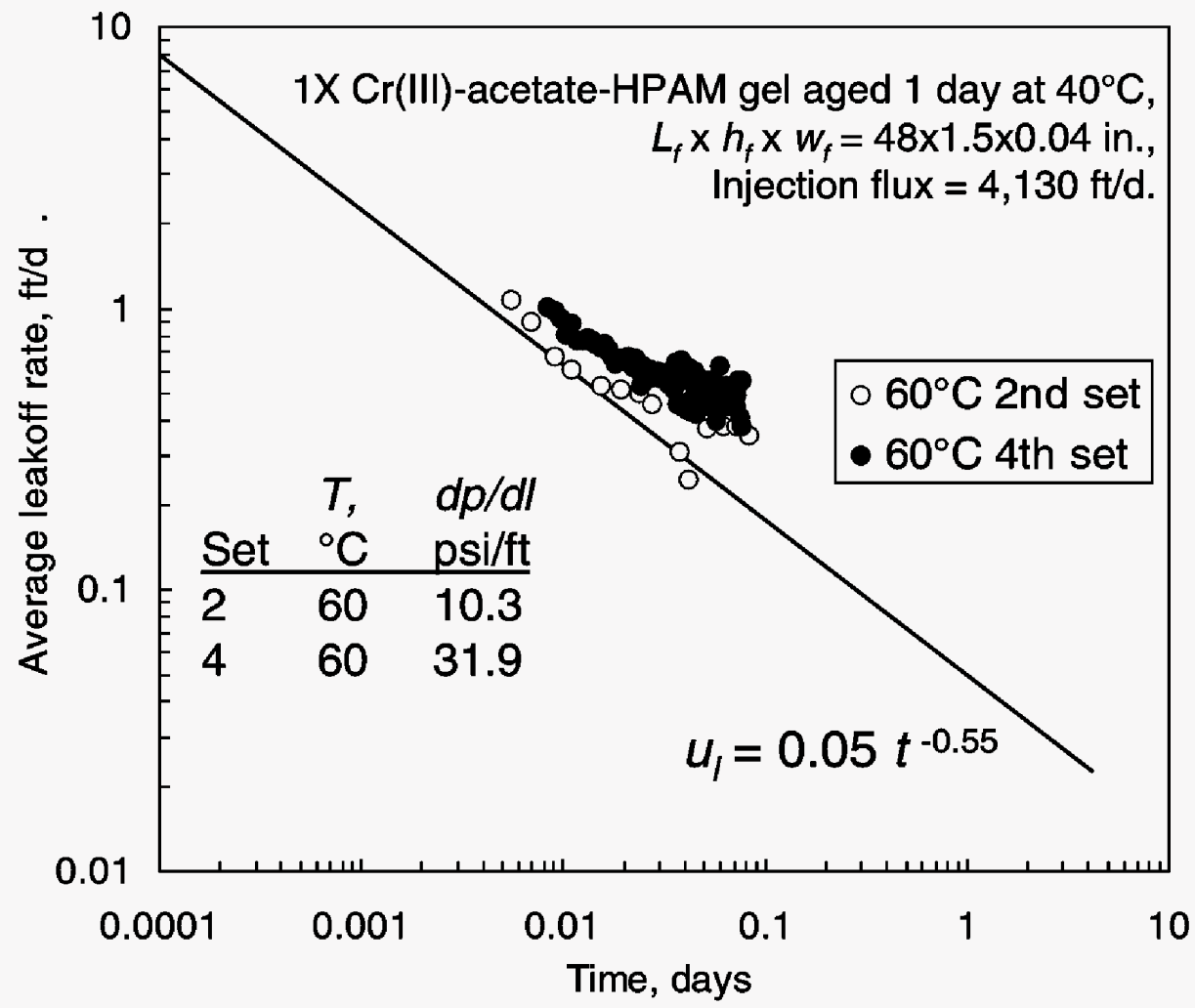

Fig. 62 -Leakoff in 4-ft-long fractures: $4^{\text {th }}$ set versus $2^{\text {nd }}$ set.

The leakoff results during the fourth set of experiments (i.e., within the pressure vessel) were similar to (although slightly greater) than those during the second set of experiments. However, the pressure gradients observed during gel extrusion during the fourth set were three times greater than those during the second set. We suspect that the 350-psi overburden pressure compressed the fracture during the fourth set, thus resulting in higher pressure gradients during gel extrusion. This idea will be tested in future work.

Of course, we intend to perform experiments at higher temperatures. We hope that this system will allow gel extrusion experiments to be performed at temperatures up to $150^{\circ} \mathrm{C}$.

\section{Effect of Gel Composition}

A set of experiments was performed to investigate how gel extrusion and dehydration vary with gel composition. The vast majority of our previous work used our " $1 \mathrm{X}$ " gel that contained $0.5 \%$ $\mathrm{HPAM}, 0.0417 \% \mathrm{Cr}$ (III) acetate, $1 \% \mathrm{NaCl}$, and $0.1 \% \mathrm{CaCl}_{2}$. Recently, we examined a series of six compositions, including $0.6 \mathrm{X}, 1 \mathrm{X}, 1.5 \mathrm{X}, 2 \mathrm{X}, 2.5 \mathrm{X}$, and $3 \mathrm{X} \mathrm{Cr}(\mathrm{III})$-acetate-HPAM gels. Here, the multiplier refers to the HPAM and chromium concentrations relative to those in our standard $1 \mathrm{X}$ gel. In all cases, the HPAM/Cr(III)-acetate ratio was fixed at 12/1, and the gels were aged for one day at $40^{\circ} \mathrm{C}$ before injection at $2,000 \mathrm{~cm}^{3} / \mathrm{hr}$ (flux of $4,130 \mathrm{ft} / \mathrm{d}$ ) into 6-in.-long, 1.5-in.diameter Berea sandstone cores that each contained a 0.04-in.-wide fracture. Because of high pressure gradients anticipated during extrusion of the concentrated gels, we used 6-in.-long cores 
that were cast in a metal alloy. Our standard 48-in.-long cores (that were cast in epoxy) would not withstand the required pressures.

Leakoff results from these six experiments are plotted in Fig. 63. Interestingly, the five most concentrated gels showed similar leakoff behavior. Leakoff data for the $0.6 \mathrm{X}$ gel fell significantly below the other results. We suspect that this occurred because the $0.6 \mathrm{X}$ formulation did not form a proper gel. This composition is close to the sol-gel transition point, where small differences in composition or condition strongly affect whether or not a gel forms.

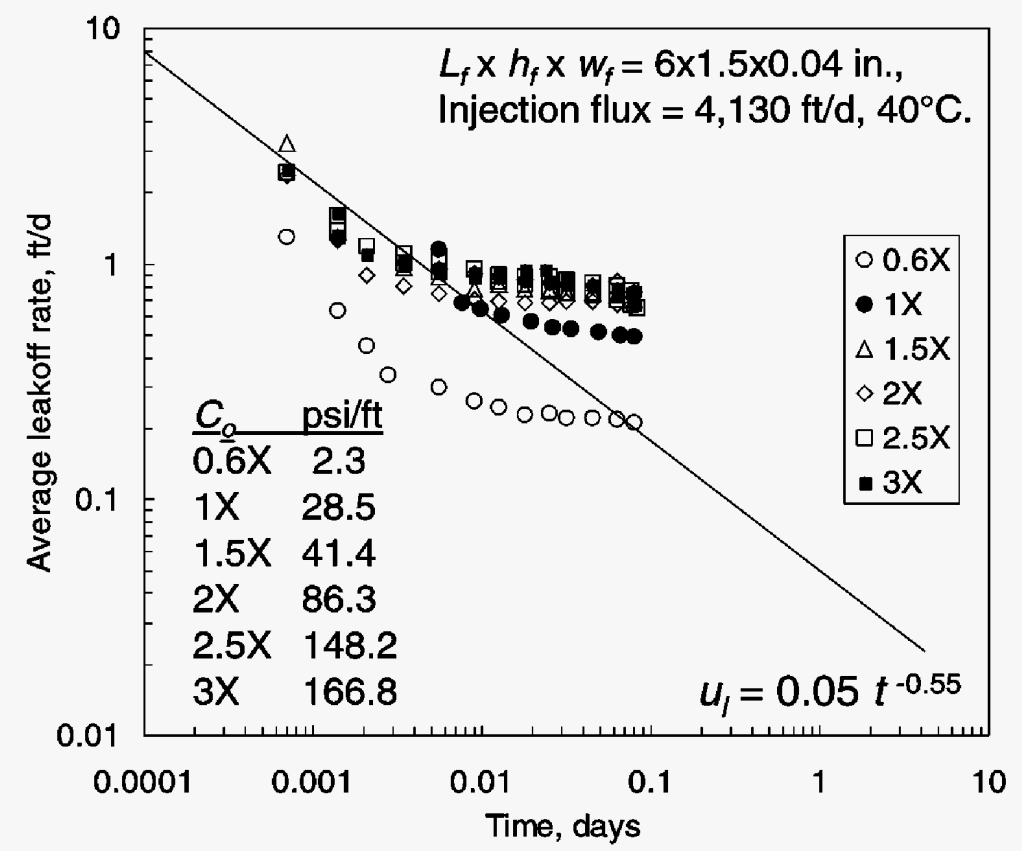

Fig. 63-Effect of gel composition during extrusion.

For the five most concentrated gels, Model 2 (and Model 4) matched the leakoff results quite well for times less than 0.01 days. However, for longer times, the leakoff results exceeded the predictions. We suspect that this deviation was an artifact associated with the use of short (6-in.long) fractures. In particular, some of the concentrated gel may be dislodged and produced from short fractures-thus, permitting greater wormhole-fracture surface areas and higher leakoff rates for longer time periods. In longer fractures, any dislodged concentrated gel probably should be immobilized before being produced from the fracture. This concept will be tested in the future.

Pressure gradients during gel extrusion for the six experiments are plotted using solid circles in Fig. 64. This figure also plots the quantity, $2 G^{\prime} / w_{f}$, using open circles. The elastic modulus, $G^{\prime}$, was measured over a range of gel compositions using a Paar-Physica Model UDS 200 Dynamic Spectrometer. ${ }^{45}$ Based on a force balance, the quantity, $2 G \% w_{f}$, should predict the pressure gradient required to extrude a gel through a fracture of a given width. ${ }^{45}$ Fig. 64 reveals that this force-balance approach typically under-predicts the pressure gradient by a factor of 87 . Thus, more work is needed to relate rheological measurements to our extrusion results. However, the 
$G^{\prime}$ measurements paralleled the extrusion pressure gradients when plotted versus gel composition. In Fig. 64, $2 G^{\prime} / w_{f}$ increased with $e^{2.27 \% \text { HPAM }}$ (where \%HPAM indicates the HPAM concentration in the gel). Also, for the middle four gel compositions ( $1 \mathrm{X}$ to $2.5 \mathrm{X}$ ), the pressure gradient for gel extrusion also varied with $e^{2.27 \% \mathrm{HPAM}}$. For the $0.6 \mathrm{X}$ gel, the pressure gradient $(2.3$ $\mathrm{psi} / \mathrm{ft}$ ) fell substantially below the trend for the other gels. As mentioned earlier, this gel may not have formed properly because the composition is near the sol-gel transition.

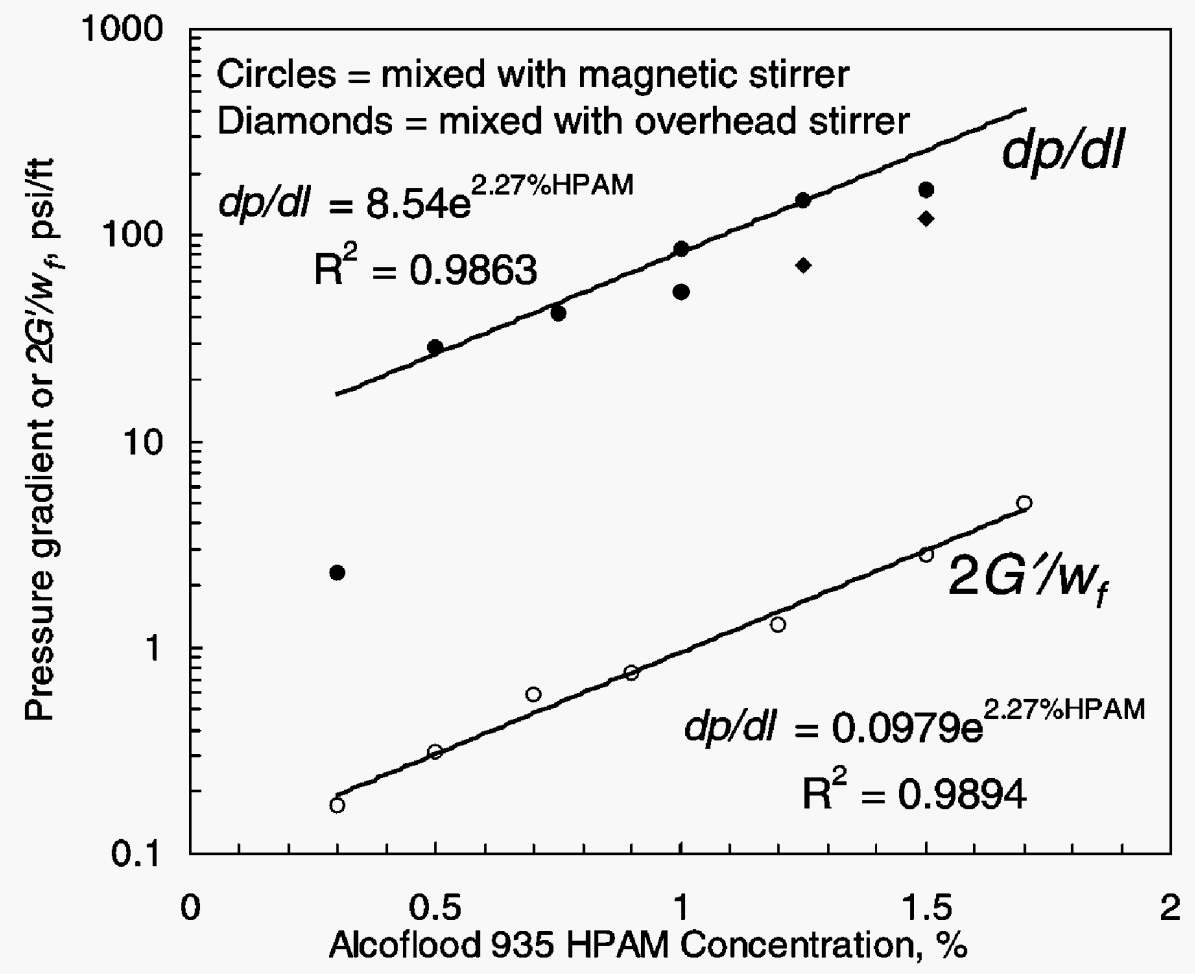

Fig. 64-Pressure gradient and elastic modulus versus HPAM concentration.

\section{Gel Washout}

In many cases, gel treatments were less effective than expected in reducing water production from fractured wells. At the request of our industrial supporters, we are beginning an investigation of why gels mechanically fail in fractures. Previously, we noted that for a given fracture width, a minimum pressure gradient was required for the gel to extrude through the fracture. ${ }^{38-43}$ For our standard $1 \mathrm{X} \mathrm{Cr}(\mathrm{III})$ acetate-HPAM gel at $41^{\circ} \mathrm{C}(0.5 \%$ Alcoflood 935 , $0.417 \% \mathrm{Cr}(\mathrm{III})$ acetate, $1 \% \mathrm{NaCl}, 0.1 \% \mathrm{CaCl}_{2}$ ), the pressure gradient during gel extrusion was insensitive to flow rate and was inversely proportional to the square of fracture width (Fig. 55). ${ }^{43}$

During brine flow after gel placement in a fracture, what pressure gradient is needed to remobilize the gel? To address this question, we performed several experiments where brine was injected at various rates after gel placement. In all cases, the core material was $700-\mathrm{mD}$ Berea sandstone (14-15 cm or $\sim 6$ inches in length and $3.8 \mathrm{~cm}$ or 1.5 inches in diameter). A fracture was placed lengthwise down the middle of each core, yielding a fracture length $\left(L_{f}\right)$ of $\sim 6$ in. and a fracture height $\left(h_{f}\right)$ of $1.5 \mathrm{in}$. Three fracture widths $\left(w_{f}\right)$ were examined $-0.04,0.08$, and 0.16 
inches $(0.1,0.2$, and $0.4 \mathrm{~cm})$. In each fractured core, 3.7 liters of one-day-old $\mathrm{Cr}(\mathrm{III})$-acetateHPAM gel were injected using a rate of $2,000 \mathrm{~cm}^{3} / \mathrm{hr}$. As expected, the pressure gradient during gel injection increased with decreased fracture width and with increased polymer concentration. After gel placement, the core was shut in for one day. (All experiments were performed at $41^{\circ} \mathrm{C}$.) Next, brine was injected at a low rate (e.g., $100 \mathrm{~cm}^{3} / \mathrm{hr}$ ). A steady state was quickly established; the pressure gradient was recorded; and the brine permeability was calculated relative to that in the sandstone matrix (i.e., $700 \mathrm{mD}$ ). Then the brine injection rate was doubled, and the measurements were repeated. This process was repeated in stages up to a final brine injection rate of $16,000 \mathrm{~cm}^{3} / \mathrm{hr}$.

The results from many of these experiments are shown in Fig. 65. The $y$-axis plots the final core permeability relative to the permeability of an unfractured core. A $y$-value of unity or less means that the fracture was basically "healed." As the $y$-value increased above unity, the fracture became more open or conductive-indicating a greater degree of gel washout. The $x$-axis plots the steady-state pressure gradient during brine injection relative to that during gel injection.

Three experiments were performed using our standard 1X gel (open symbols in Fig. 65). Two experiments were performed using a $2 \mathrm{X}$ gel (solid symbols in Fig. 65) that contained twice the HPAM and Cr(III) acetate concentrations of the $1 \mathrm{X}$ gel. For both the $1 \mathrm{X}$ and $2 \mathrm{X}$ gels in 0.04 -in.wide fractures, the $y$-value (core permeability ratio) began near unity and increased moderately for pressure gradient ratios between 0.5 and 1.5. This result indicates that in a 0.04-in.-wide fracture, gel mobilization during brine injection occurred at pressure gradients similar for those during gel injection. In wider fractures (0.08- and 0.16-in.), the $1 \mathrm{X}$ gel experienced mobilization (steep slopes in Fig. 65) at pressure gradient ratios between 0.1 and 0.3 . For the $2 \mathrm{X}$ gel in a 0.08 in.-wide fracture, intermediate mobilization behavior was noted.

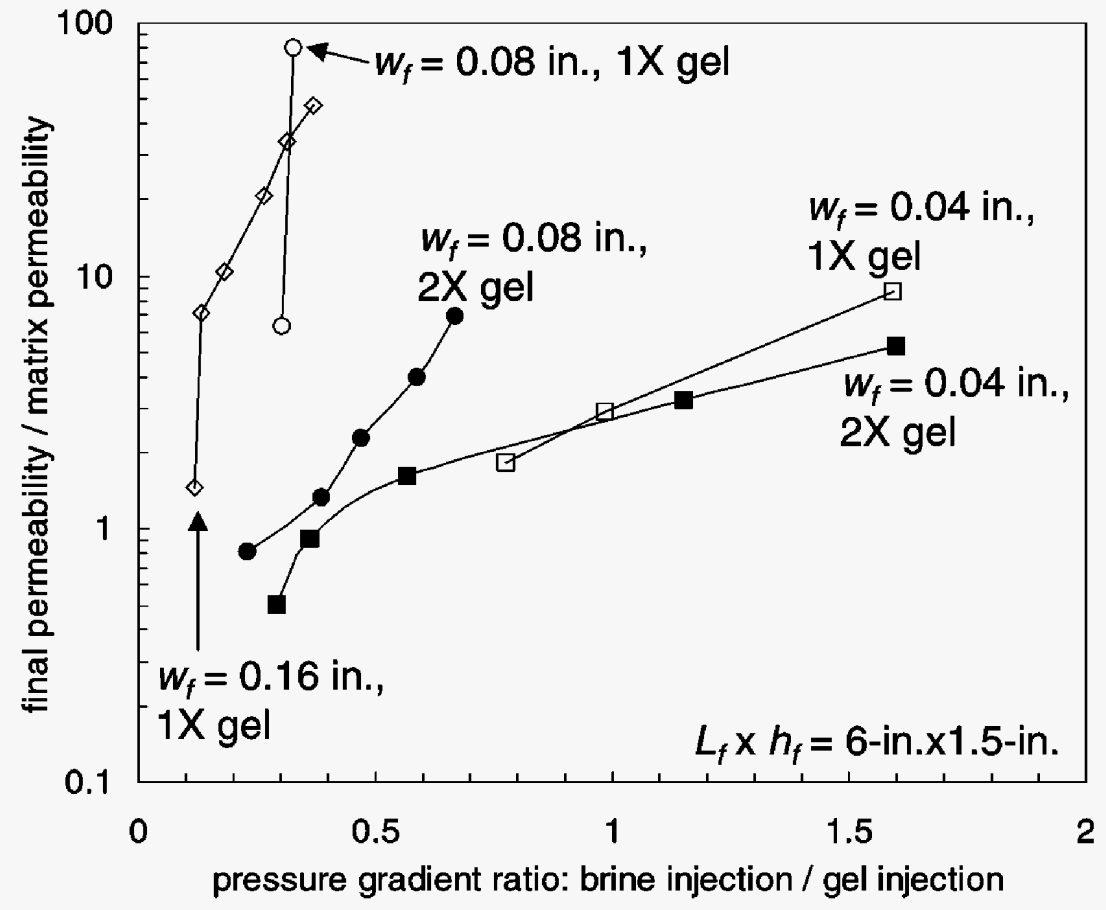

Fig. 65-Gel washout during brine injection after gel placement. 
Of course, we seek methods to maximize the pressure gradient at which gel washout occurs. Thus, we are exploring how incorporation of particulate matter into the gel affects mobilization. Preliminary studies were performed in beakers to examine properties of gels that incorporated one of six particulates, including fine mica (supplied by MI), fine nut plug (MI), diatomaceous earth (Drilling Specialties Diaseal M), celloflakes, shredded ski rope, and fiberglass insulation. For each particulate, suspensions were prepared in our $1 \mathrm{X}$ gelant, and we noted the qualitative strength and appearance of the final gel. The mica and nut plug were significantly denser than the gelant. High stir rates were required to suspend the particulates $(1 \%, 3 \%$, and $5 \%$ concentrations) in the gelant. Once the agitation rate decreased, the particulates immediately separated from the gelant. Also, although the mica and nut plug did not inhibit gelation, we were unable to form a gel with uniformly suspended particles. The diatomaceous earth $(1 \%, 3 \%$, and $5 \%$ concentrations in the gelant) also fell from suspension unless high stir rates were used. Also, this material changed the $\mathrm{pH}$ to high values (i.e., 12), so the gel never formed. The celloflakes (1\% concentration) did not interfere with gelation. However, except at very high agitation rates, they were too light (low density) and did not suspend effectively in the gelant or gel. In contrast, the fiberglass insulation ( $0.1 \%$ to $0.2 \%$ concentrations) and the shredded ski rope (2\% concentration) formed uniform suspensions even at very low stir rates, and they did not appear to interfere with gelation. Even after agitation ceased, the particulates remained suspended quite well.

Gel extrusion and washout experiments were performed using our standard 1X gel that was prepared with and without $0.1 \%-0.2 \%$ suspended fiberglass insulation. These experiments were performed using the same procedures described above (i.e., those associated with Fig. 65). Fig. 66 shows the washout results. The open symbols plot results for gel with no fiberglass (which are the same data shown in Fig. 65), while the solid symbols show results for gel with fiberglass. Fig. 66 demonstrates that the fiberglass reduced gel washout. However, washout was still much greater than desired for the 0.16 -in.-wide fracture. We will continue to explore ways to mitigate gel washout in our future work.

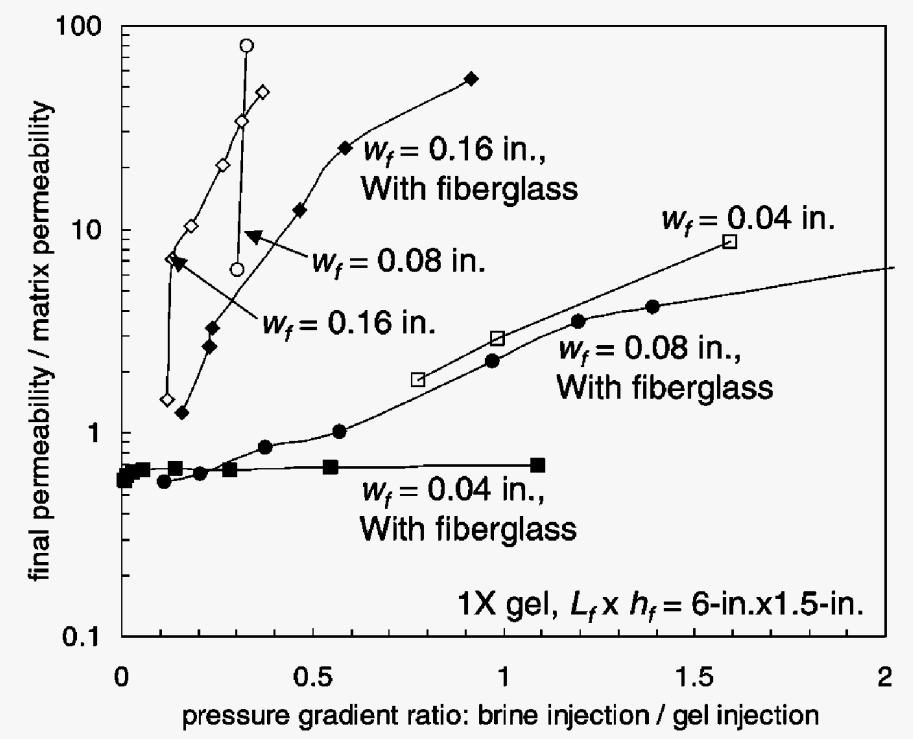

Fig. 66-Effect of 0.1\%-0.2\% fiberglass on gel washout. 


\section{Conclusions}

1. A new model (Model 4) was developed that accounts for the most important elements of gel propagation and dehydration in fractures. Predictions from this model matched experimental data quite well. This model was derived strictly from mechanistic considerations, whereas our previous models were based on an empirical two-parameter fit.

2. We extended our studies of gel extrusion through fractures to different temperatures. For a $\mathrm{Cr}$ (III)-acetate-HPAM gel, pressure gradients and gel dehydration during extrusion were similar at $20^{\circ} \mathrm{C}, 40^{\circ} \mathrm{C}, 60^{\circ} \mathrm{C}$, and $80^{\circ} \mathrm{C}$.

3. We also extended our studies of gel extrusion to include different gel compositions. Similar gel dehydration behavior was observed over a three-fold range of concentration for $\mathrm{Cr}$ (III)acetate-HPAM gels. During extrusion, measurements of pressure gradient versus HPAM concentration paralleled those of elastic modulus versus HPAM concentration.

4. We began an investigation of why gels mechanically fail in fractures during water flow after gel placement. Our first studies indicate that in a 0.04-in.-wide fracture, gel mobilization during brine injection occurs at pressure gradients similar to those during gel injection. In wider fractures (0.08- and 0.16-in.), our standard 1X Cr(III)-acetate-HPAM gel experienced mobilization at lower than expected pressure gradients.

5. We are exploring how incorporation of particulate matter into the gel affects washout. Preliminary studies were performed in beakers using gels that incorporated one of six particulates, including fine mica, fine nut plug, diatomaceous earth, celloflakes, shredded ski rope, and fiberglass insulation. The shredded ski rope and fiberglass insulation formed fairly homogeneous suspensions in the $1 \mathrm{X} \mathrm{Cr}$ (III)-acetate-HPAM gelant and gel. The other materials experienced severe gravity segregation.

6. During gel extrusion through fractures, incorporation of $0.1 \%-0.2 \%$ fiberglass insulation into the $1 \mathrm{X} \mathrm{Cr}$ (III)-acetate-HPAM gel reduced gel washout during subsequent brine injection. However, improved formulations are needed to prevent washout for fractures that are wider than 0.08 inches. 



\section{GELANT TREATMENTS IN FRACTURED PRODUCTION WELLS}

Often, when hydraulic fracturing stimulates production wells, the fracture unintentionally extends through shale or calcite barriers into water zones, causing substantially increased water production. Gelant treatments have frequently been applied to correct this problem. However, the design of the gelant volumes for these applications was strictly empirical, and consequently, the success rates for these treatments were erratic. We developed a sound engineering basis and a simple procedure for sizing gelant treatments in hydraulically fractured production wells. ${ }^{4}$ The procedure was incorporated in user-friendly graphical-user-interface software that can be downloaded from our web site at http://baervan.nmt.edu/randy.

We updated the software to Version 2.0 to incorporate several improvements. First, the units on input parameters may now be either SI or English (oilfield). Previously, only oilfield units could be used. Second, the program can now handle low water-cut cases much better. In the earlier version, when wells with low water cut were considered, the resolution of the output graphs was inadequate. Finally, in addition to oil wells, the program can now handle gas wells with water production problems. Previously, only oil wells could be analyzed. 


\section{FUTURE WORK}

Through the course of this research, many additional questions have been raised that remain to be answered. These questions will be addressed in a new research project, "Conformance Improvement Using Gels," that will begin September 2001 under the support of US DOE contract DE-FC26-01BC15316.

\section{Disproportionate Permeability Reduction}

Of course, our ultimate goals in this area are to determine why gels and polymers can reduce permeability to water more than that to oil or gas, and how to maximize this effect. In working toward that goal, the following questions are among those to be addressed by our research in the near future:

1. At residual non-wetting phase saturation, how does the presence of gel affect whether the non-wetting phase exists in pore singlets, doublets, or larger ganglia?

2. How does gel affect the tortuosity of oil and water pathways?

3. After gel placement in polyethylene cores, why is the permeability to oil so high?

4. What gel, core, and fluid properties control the degree of oil trapping in water-wet sandstone?

\section{Gel Properties in Fractures}

In examining the mechanism for gel extrusion and dehydration in fractures, we ultimately hope to predict conditions, compositions, and volumes that provide the optimum gel placement in fractured reservoirs. A few of the immediate questions that will be addressed in our future work include:

1. During gel placement in fractures, how does gel dehydration and the pressure gradient for gel extrusion depend on fracture width (especially for fractures wider than $0.2 \mathrm{~cm}$ ), temperature (especially for temperatures above $60^{\circ} \mathrm{C}$ ), gel composition (including gels other than $\mathrm{Cr}(\mathrm{III})$-acetate-HPAM), and particulate content and type?

2. During brine or oil flow after gel placement in a fracture, what pressure gradient is needed to re-mobilize or breakdown the gel (as a function of fracture width, gel composition, temperature, and presence of particulates)?

3. How well does our model of gel placement in fractures hold in light of new findings? 



\section{NOMENCLATURE}

$A_{c}=$ fractional area associated with concentrated gel

$A_{m}=$ fractional area associated with mobile gel

$C=$ concentration of dehydrated gel, $\mathrm{g} / \mathrm{m}^{3}$

$C_{o}=$ injected or original concentration, $\mathrm{g} / \mathrm{m}^{3}$

$F_{r r o}=$ oil residual resistance factor

$F_{r r w}=$ water residual resistance factor

$G^{\prime}=$ elastic modulus, psi $[\mathrm{Pa}]$

$h_{f}=$ fracture height, $\mathrm{ft}[\mathrm{m}]$

$k=$ permeability, darcys $\left[\mu \mathrm{m}^{2}\right]$

$k_{f}=$ fracture permeability, darcys $\left[\mu \mathrm{m}^{2}\right]$

$k_{g e l}=$ gel permeability to water, darcys $\left[\mu \mathrm{m}^{2}\right]$

$k_{o}=$ permeability to oil, darcys $\left[\mu \mathrm{m}^{2}\right]$

$k_{r o}=$ endpoint relative permeability to oil, darcys $\left[\mu \mathrm{m}^{2}\right]$

$k_{r w}=$ endpoint relative permeability to water, darcys $\left[\mu^{2}{ }^{2}\right]$

$k_{w}=$ permeability to water, darcys $\left[\mu^{2}\right]$

$L=$ distance along a fracture, $\mathrm{ft}[\mathrm{m}]$

$L_{f}=$ fracture length, $\mathrm{ft}[\mathrm{m}]$

$\Delta p=$ pressure drop, psi $[\mathrm{Pa}]$

$d p / d l=$ pressure gradient, $\mathrm{psi} / \mathrm{ft}[\mathrm{Pa} / \mathrm{m}]$

$R=$ aspect ratio

$r=$ correlation coefficient

$S_{o r}=$ residual oil saturation

$S_{w}=$ water saturation

$S_{w r}=$ residual water saturation

$T=$ temperature, ${ }^{\circ} \mathrm{C}$

$t=$ time, $\mathrm{s}$

$u=$ leakoff rate, $\mathrm{ft} / \mathrm{d}[\mathrm{cm} / \mathrm{s}]$

$u_{c}=$ water leakoff rate associated with concentrated gel, $\mathrm{ft} / \mathrm{d}[\mathrm{cm} / \mathrm{s}]$

$u_{l}=$ water leakoff rate, $\mathrm{ft} / \mathrm{d}[\mathrm{cm} / \mathrm{s}]$

$u_{m}=$ water leakoff rate associated with fresh gel, $\mathrm{ft} / \mathrm{d}[\mathrm{cm} / \mathrm{s}]$

$w_{f}=$ fracture width, in. $[\mathrm{m}]$

$\mu=$ viscosity, $\mathrm{cp}$ [mPa-s]

$\mu_{w}=$ water viscosity, $\mathrm{cp}[\mathrm{mPa}-\mathrm{s}]$ 


\section{REFERENCES}

1. Petrusak, R.L., Freeman, B.D., and Smith, G.E.: "Baseline Characterization of U.S. Exploration and Production Wastes and Waste Management," paper SPE 63097 presented at the 2000 SPE Annual Technical Conference and Exhibition, Dallas, Oct. 1-4.

2. Seright, R.S.: "Using Chemicals to Optimize Conformance Control in Fractured Reservoirs," Annual Technical Progress Report (U.S. DOE Report DOE/BC/15110-2), U.S. DOE Contract DE-AC26-98BC15110 (Sept. 1999).

3. Seright, R.S.: "Using Chemicals to Optimize Conformance Control in Fractured Reservoirs," Annual Technical Progress Report (U.S. DOE Report DOE/BC/15110-4), U.S. DOE Contract DE-AC26-98BC15110 (Sept. 2000).

4. Liang, J., Sun, H., Seright, R.S.: "Reduction of Oil and Water Permeabilities Using Gels," paper SPE 24195 presented at the 1992 SPE/DOE Symposium on Enhanced Oil Recovery, Tulsa, April 22-24.

5. Seright, R.S., Liang, J., and Sun, H.: "Gel Treatments in Production Wells with Water Coning Problems," In Situ (1993) 17(3) 243-272.

6. Liang, J., Lee, R.L., and Seright, R.S.: "Placement of Gels in Production Wells," SPEPF (Nov. 1993) 276-284; Transactions AIME 295.

7. Sparlin, D.D. and Hagen, R.W. Jr.: "Controlling Water in Producing Operations-Part 5," World Oil (June 1984) 137.

8. Dawe, R.A. and Zhang, Y.: "Mechanistic Study of the Selective Action of Oil and Water Penetrating into a Gel Emplaced in a Porous Medium," J. Pet. Sci. Eng. (1994) 12, 113-125.

9. Mennella, A., et al.: "Pore-Scale Mechanism for Selective Permeability Reduction by Polymer Injection," paper SPE 39635 presented at the 1998 SPE/DOE Improved Oil Recovery Symposium, Tulsa, April 19-22.

10. Liang, J., Sun, H., and Seright, R.S.: "Why Do Gels Reduce Water Permeability More Than Oil Permeability?" SPERE (Nov. 1995) 282-286.

11. Zaitoun, A. and Kohler N.: "Thin Polyacrylamide Gels for Water Control in High-Permeability Production Wells" paper SPE 22785 presented at the 1991 SPE Annual Technical Conference and Exhibition, Dallas, Oct. 6-9.

12. Liang, J. and Seright, R.S.: "Further Investigations of Why Gels Reduce $\mathrm{k}_{\mathrm{w}}$ More Than $\mathrm{k}_{\mathrm{o}}$," SPEPF (Nov. 1997) 225-230.

13. Al-Sharji, H.H., et al.: "Pore-Scale Study of the Flow of Oil and Water through Polymer Gels," paper SPE 56738 presented at the 1999 SPE Annual Technical Conference and Exhibition, Houston, Oct. 3-6.

14. Zaitoun, A., Bertin, H., and Lasseux, D.: "Two-Phase Flow Property Modifications by Polymer Adsorption," paper SPE 39631 presented at the 1998 SPE/DOE Improved Oil Recovery Symposium, Tulsa, April 19-22.

15. Nilsson, S., Stavland, A., and Jonsbraten, H. C.: "Mechanistic Study of Disproportionate Permeability Reduction" paper SPE 39635 presented at the 1998 SPE/DOE Improved Oil Recovery Symposium, Tulsa, April 19-22.

16. Liang, J. and Seright, R.S.: "Wall-Effect/Gel Droplet Model of Disproportionate Permeability Reduction," paper SPE 59344 presented at the 2000 SPE/DOE Improved Oil Recovery Symposium, Tulsa, April 3-5. 
17. White, J.L., Goddard, J.E., and Phillips, H.M.: "Use of Polymers To Control Water Production in Oil Wells," JPT (Feb. 1973) 143-150.

18. Willhite, G.P., et al.: "Mechanisms Causing Disproportionate Permeability in Porous Media Treated With Chromium Acetate/HPAAM Gels," paper SPE 59345 presented at the 2000 SPE/DOE Improved Oil Recovery Symposium, Tulsa, April 3-5.

19. Seright, R.S.: "Improved Techniques for Fluid Diversion In Oil Recovery," final report, DOE/BC/14880-15, U.S. DOE (Jan. 1996) 97-108.

20. Dunsmuir, J.H., et al.: X-Ray Microtomography: A New Tool for the Characterization of Porous Media, paper SPE 22860 presented at the 1991 SPE Annual Technical Conference and Exhibition, Dallas, Oct. 6-9.

21. B.P. Flannery, et al.: "Three-Dimensional X-Ray Microtomography," Science, 237, 1389 (1987).

22. Coles, M.E., et al.: "Developments in Synchrotron X-Ray Microtomography with Applications to Flow in Porous Media," SPEREE (Aug. 1998) 288-296.

23. Zhou, M., et al.: "Irreducible Water Distribution in Sandstone Rock: Two Phase Flow Simulations in CT-based Pore Network," Phys. Chem. Earth (A), 25(2), 2000, 169-174.

24. Coles, M.E., et al.: "Pore Level Imaging of Fluid Transport Using Synchrotron X-Ray Microtomography," paper 9628 presented at the 1996 International Symposium of the Society of Core Analysts, Montpellier, France, Sept. 8-10.

25. Hazlett, R.D., Chen, S.Y, and Soll, W.E.: "Wettability and Rate Effects on Immiscible Displacement: Lattice Boltzmann Simulation in Microtomographic Images of Reservoir Rocks," presented at the $19964^{\text {th }}$ International Symposium on Evaluation of Reservoir Wettability and its Effect on Oil Recovery, Montpellier, France, Sept. 11-13.

26. Lindquist, W.B., et al.: "Pore and Throat Size Distributions Measured From Synchrotron XRay Tomography Images of Fountainebleau Sandstones," J. Geophys. Research, 105B, (2000) 21508-21528.

27. Chatzis, I., Morrow, N.R., and Lim, H.T.: "Magnitude and Detailed Structure of Residual Oil Saturation," SPEJ (April 1983) 311-326.

28. Chatzis, I., Kuntamukkula, M.S., and Morrow, N.R.: "Effect of Capillary Number on the Microstructure of Residual Oil in Strongly Water-Wet Sandstones," SPERE (Aug. 1988) 902-912.

29. Elmkies, P. et al.: "Further Investigations on Two-Phase Flow Property Modification by Polymers: Wettability Effects," paper SPE 64986 presented at the 2001 SPE International Symposium on Oilfield Chemistry, Houston, Feb. 13-16.

30. Wang, D. et al: "Study of the Mechanism of Polymer Solution with Visco-Elastic Behavior Increasing Microscopic Oil Displacement Efficiency and the Forming of Steady Oil Thread Flow Channels," paper SPE 68723 presented at the 2001 SPE Asia Pacific Oil and Gas Conference and Exhibition, Jakarta, April 17-19.

31. Seright, R.S. and Liang, J.: "A Survey of Field Applications of Gel Treatments for Water Shutoff," paper SPE 26991 presented at the 1994 SPE III Latin American \& Caribbean Petroleum Engineering Conference, Buenos Aires, Argentina, April 27-29.

32. Sydansk, R.D. and Moore, P.E.: "Gel Conformance Treatments Increase Oil Production in Wyoming," Oil \& Gas J. (Jan. 20, 1992) 40-45.

33. Borling, D.C.: "Injection Conformance Control Case Histories Using Gels at the Wertz Field $\mathrm{CO}_{2}$ Tertiary Flood in Wyoming, USA," paper SPE 27825 presented at the 1994 SPE/DOE Symposium on Improved Oil Recovery, Tulsa, April 17-20. 
34. Hild, G.P. and Wackowski, R.K.: "Reservoir Polymer Gel Treatments To Improve Miscible $\mathrm{CO}_{2}$ Flood," SPEREE (April. 1999) 196-204.

35. Lane, R.H. and Sanders, G.S.: "Water Shutoff Through Fullbore Placement of Polymer Gel in Faulted and in Hydraulically Fractured Producers of the Prudhoe Bay Field," paper SPE 29475 presented at the 1995 SPE Production Operations Symposium, Oklahoma City, April 2-4.

36. Lane, R.H., and Seright, R.S.: "Gel Water Shutoff in Fractured or Faulted Horizontal Wells," paper CIM/SPE 65527 presented at the 2000 SPE/Petroleum Society of CIM International Conference on Horizontal Well Technology held in Calgary, Alberta, Canada, Nov. 6-8.

37. Seright, R.S., Lane, R.H., and Sydansk, R.D.: “A Strategy for Attacking Excess Water Production," paper 70067 presented at the 2001 SPE Permian Basin Oil and Gas Recovery Conference, Midland, May 15-16.

38. Seright, R.S.: “Gel Placement in Fractured Systems," SPEPF (Nov. 1995), 241-248.

39. Seright, R.S.: "Use of Preformed Gels for Conformance Control in Fractured Systems," SPEPF (Feb. 1997) 59-65.

40. Seright, R.S: "Polymer Gel Dehydration During Extrusion Through Fractures," SPEPF (May 1999) 110-116.

41. Seright, R.S: "Mechanism for Gel Propagation Through Fractures," paper SPE 55628 presented at the 1999 SPE Rocky Mountain Regional Meeting, Gillette, May 15-19.

42. Seright, R.S.: "Improved Methods for Water Shutoff," Final Technical Progress Report (U.S. DOE Report DOE/PC/91008-14), U.S. DOE Contract DE-AC22-94PC91008, BDMOklahoma Subcontract G4S60330 (Oct. 1998) 21-54.

43. Seright, R.S.: "Gel Propagation Through Fractures," paper SPE/DOE 59316 presented at the 2000 SPE/DOE Symposium on Improved Oil Recovery, Tulsa, April 2-5.

44. Seright, R.S. and Lee, R.L.: "Gel Treatments for Reducing Channeling Through Naturally Fractured Reservoirs," SPEPF (Nov. 1999) 269-276.

45. Liu, Jin, and Seright, R.S.: "Rheology of Gels Used For Conformance Control in Fractures," SPE Journal (June 2001) 120-125. 


\section{APPENDIX A: Technology Transfer}

\section{Presentations}

On October 6, 2001, we presented the SPE Short Course, "Water Shutoff," in Kuala Lumpur, Malaysia.

On October 1, 2001, we presented the talk, "Characterizing Disproportionate Permeability Reduction Using Synchrotron X-Ray Computed Microtomography," at the 2001 SPE Annual Technical Conference and Exhibition in New Orleans, Louisiana.

On September 18, 2001, we presented the talk, "How Wide Are the Holes?" at the SPE Forum, "Downhole Water Management," in Sainte Maxime, France.

On September 17, 2001, we presented the poster, "Mechanism for Disproportionate Permeability Reduction" at the SPE Forum, "Downhole Water Management," in Sainte Maxime, France.

On August 20, 2001, we presented the talk, "A Strategy for Attacking Conformance Problems," at the Alaska Conformance Workshop in Anchorage, Alaska.

On June 4, 2001, we presented the talk, "Importance of the US DOE to Funding Academic Research for Oil and Gas Production," at the SPE Research and Development Conference in Houston, Texas.

On March 15, 2001, we presented the talk, "A Strategy for Attacking Excess Water Production," at the SPE Permian Basin Oil and Gas Recovery Conference in Midland, Texas.

On February 19, 2001, we held a project review in Socorro, NM.

On January 9, 2001, we presented the talk, "Advances in Water Shutoff," at the Amarillo SPE Section in Amarillo, Texas.

On December 6, 2000, we presented the talk, "A Strategy for Attacking Excess Water Production Problems," at the PTTC Workshop, Gelled Polymers and Their Applications in Wichita, Kansas.

On November 27, 2000, we presented the talk, "Squishing Goo into Fractures to Stop Water Production," at the SPE Roswell Section in Socorro, New Mexico.

On October 26, 2000, we presented the talk, "A Strategy for Attacking Excess Water Production Problems," at the SPE Permian Basin Section's Production Operations Study Group in Midland, Texas.

On September 21, 2000, we presented the talk, "Mechanism For Gel Propagation Through Fractures," at the 2000 International Energy Agency Meeting in Edinburgh, Scotland. 
On June 27, 2000, we presented the talk, "Using Chemicals to Optimize Conformance in Fractured Reservoirs," at the 2000 DOE Petroleum Technology Contract Review Meeting in Denver, Colorado.

On April 25, 2000, we presented the talk, "Conformance Issues Relating to Produced Water Reinjection in Layered Reservoirs," at Marathon Oil in Littleton, Colorado.

On April 5, 2000, we presented the talk, "Wall-Effect/Gel-Droplet Model of Disproportionate Permeability Reduction," at the 2000 SPE/DOE Improved Oil Recovery Symposium in Tulsa, OK.

On April 4, 2000, we presented the talk, "Gel Propagation Through Fractures," at the 2000 SPE/DOE Improved Oil Recovery Symposium in Tulsa, OK.

On April 4, 2000, we presented the talk, "Rheology of Gels Used For Conformance Control," at the 2000 SPE/DOE Improved Oil Recovery Symposium in Tulsa, OK.

On April 2, 2000, we presented the Short Course, "Water Shutoff," at the 2000 SPE/DOE Improved Oil Recovery Symposium in Tulsa, OK.

On March 30, 2000, we held a project review in Socorro, NM..

From November 16-20, 1999, we presented talks on "Improved Methods for Water Shutoff," at the Chinese Petroleum Corporation in Maioli, Taiwan.

On September 23, 1999, we presented the talk, "Disproportionate Permeability Reduction by Gels," at the 1999 IEA Meeting in Paris, France.

On September 13, 1999, we presented the talk, "Gel Propagation Through Fractures," at Marathon Oil in Littleton, Colorado.

On July 27 and 28, 1999, we held a project review in Socorro, NM..

On June 29, 1999, we presented the talk, "Sizing Gelant Treatments in Hydraulically Fractured Production Wells," at the 1999 DOE Oil and Gas Conference in Dallas, Texas.

On May 17, 1999, we presented SPE paper 55628, "Mechanism for Gel Propagation Through Fractures," at the 1999 Rocky Mountain Regional Meeting in Gillette, WY.

On April 23, 1999, we presented the talk, "Gel Dehydration During Extrusion Through Fractures," at Saga Petroleum in Stavanger, Norway.

On April 22, 1999, we presented the talk, "Gel Dehydration During Extrusion Through Fractures," at Stavanger College in Stavanger, Norway.

On April 22, 1999, we presented the talk, “A Strategy for Attacking Excess Water Production 
Problems," at Elf Norge in Stavanger, Norway.

On March 11, 1999, we presented the talk, "A Strategy for Attacking Excess Water Production Problems," for the Midcontinent SPE Section in Tulsa, OK.

From November 16-20, 1998, we presented talks on "Improved Methods for Water Shutoff," at the Chinese Petroleum Corporation in Maioli, Taiwan.

On October 6 and 7, 1998, we held a project review in Socorro, NM.

\section{Internet Postings on the Project and Software to Download}

A description of our research group can be found at the following New Mexico PRRC web site: http://baervan.nmt.edu/randy. This site was recently updated and expanded significantly.

This web site also allows downloading of software, Version 2.0 of "Gel Design," for sizing gelant treatments in hydraulically fractured production wells.

\section{Papers and Publications}

Seright, R.S, Liang J., Lindquist, B.W., and Dunsmuir, J.H.: "Characterizing Disproportionate Permeability Reduction Using Synchrotron X-Ray Computed Microtomography," paper 71508 presented at the 2001 SPE Annual Technical Conference and Exhibition, New Orleans, Sept. 30Oct. 3.

Liang, J., and Seright, R.S.: "Wall-Effect/Gel Droplet Model of Disproportionate Permeability Reduction," SPE Journal (Sept. 2001).

Liu, Jin, and Seright, R.S.: "Rheology of Gels Used For Conformance Control in Fractures," SPE Journal (June 2001) 120-125.

Seright, R.S., Lane, R.H., and Sydansk, R.D.: "A Strategy for Attacking Excess Water Production," paper 70067 presented at the 2001 SPE Permian Basin Oil and Gas Recovery Conference, Midland, May 15-16.

Lane, R.H., and Seright, R.S.: "Gel Water Shutoff in Fractured or Faulted Horizontal Wells," paper CIM/SPE 65527 presented at the $2000 \mathrm{SPE} /$ Petroleum Society of CIM International Conference on Horizontal Well Technology held in Calgary, Alberta, Canada, Nov. 6-8.

Seright, R.S.: "Using Chemicals to Optimize Conformance Control in Fractured Reservoirs," Annual Technical Progress Report (U.S. DOE Report DOE/BC/15110-4), U.S. DOE Contract DE-AC26-98BC15110 (Sept. 2000).

Seright, R.S.: "Mechanism For Gel Propagation Through Fractures," presented at the 2000 International Energy Agency Meeting in Edinburgh, Scotland, Sept. 20-22. 
Liang, J., and Seright, R.S.: "Wall-Effect/Gel Droplet Model of Disproportionate Permeability Reduction," paper SPE 59344 presented at the 2000 SPE/DOE Improved Oil Recovery Symposium, Tulsa, OK, April 3-5.

Liu, Jin, and Seright, R.S.: "Rheology of Gels Used For Conformance Control in Fractures," paper SPE 59318 presented at the 2000 SPE/DOE Improved Oil Recovery Symposium, Tulsa, OK, April 3-5.

Seright, R.S.: "Gel Propagation Through Fractures," paper SPE 59316 presented at the 2000 SPE/DOE Improved Oil Recovery Symposium, Tulsa, OK, April 3-5.

Seright, R.S. and Lee, Robert: "Gel Treatments for Reducing Channeling Through Naturally Fractured Reservoirs," SPE Production \& Facilities (Nov. 1999) 269-276.

Seright, R.S.: "Using Chemicals to Optimize Conformance Control in Fractured Reservoirs," Annual Technical Progress Report (U.S. DOE Report DOE/BC/15110-2), U.S. DOE Contract DE-AC26-98BC15110 (Sept. 1999).

Seright, R.S: "Mechanism for Gel Propagation Through Fractures," paper SPE 55628 presented at the 1999 Rocky Mountain Regional Meeting, Gillette, WY, May 15-18.

Seright, R.S: "Polymer Gel Dehydration During Extrusion Through Fractures," SPE Production \& Facilities (May 1999) 110-116.

Seright, R.S., Liang, J., and Seldal, M.: "Sizing Gelant Treatments in Hydraulically Fractured Production Wells,” SPE Production \& Facilities (Nov. 1998) 223-229.

Seright, R.S.: "Improved Methods for Water Shutoff," Final Technical Progress Report (U.S. DOE Report DOE/PC/91008-14), U.S. DOE Contract DE-AC22-94PC91008, BDM-Oklahoma Subcontract G4S60330 (Oct. 1998). 